\title{
The Nakahara Effect and Its Influence On Solution-Based 3D Printed Films
}

\author{
Daryl Kwakye-Ackah \\ West Virginia University, dkwakyea@mix.wvu.edu
}

Follow this and additional works at: https://researchrepository.wvu.edu/etd

Part of the Materials Science and Engineering Commons, and the Mechanical Engineering Commons

\section{Recommended Citation}

Kwakye-Ackah, Daryl, "The Nakahara Effect and Its Influence On Solution-Based 3D Printed Films" (2018). Graduate Theses, Dissertations, and Problem Reports. 3722.

https://researchrepository.wvu.edu/etd/3722

This Thesis is protected by copyright and/or related rights. It has been brought to you by the The Research Repository @ WVU with permission from the rights-holder(s). You are free to use this Thesis in any way that is permitted by the copyright and related rights legislation that applies to your use. For other uses you must obtain permission from the rights-holder(s) directly, unless additional rights are indicated by a Creative Commons license in the record and/ or on the work itself. This Thesis has been accepted for inclusion in WVU Graduate Theses, Dissertations, and Problem Reports collection by an authorized administrator of The Research Repository @ WVU. For more information, please contact researchrepository@mail.wvu.edu. 


\title{
The Nakahara Effect and Its Influence on Solution-Based 3D Printed Films
}

\author{
Daryl Kwakye-Ackah \\ Thesis submitted \\ to the Benjamin M. Statler College of \\ Engineering and Mineral Resources \\ at West Virginia University \\ in partial fulfilment of the requirements for the degree of \\ Master of Science \\ In \\ Mechanical Engineering \\ Konstantinos Sierros, Ph. D., Chair \\ Charter Stinespring, Ph. D. \\ Eduardo Sosa, Ph. D. \\ Samir Shoukry, Ph. D.
}

Department of Mechanical and Aerospace Engineering

Morgantown, West Virginia

December, 2018

Keywords: Cracking, Nakahara effect, Three-dimensional printing, $\mathrm{TiO}_{2}$

Copyright $₫$ Daryl Kwakye-Ackah 


\section{ABSTRACT}

\section{The Nakahara Effect and its Influence on Solution-Based 3D Printed Films}

\section{Daryl Kwakye-Ackah}

Motivated by the Nakahara Effect, the influence of altering printing parameters on fragmentation mechanism(s) of directly written titanium dioxide $\left(\mathrm{TiO}_{2}\right)$ films is investigated. The Nakahara effect states that a long lasting memory can be introduced into a colloidal system prior to drying, affecting the type of crack pattern formed due to externally applied forces. $\mathrm{TiO}_{2}$ has important applications due to its interesting semiconducting properties, tunable band gap, photocatalytic properties, biocompatibility, and relative abundance. This is the reason it is used in this project as a model printing ink system.

In this research, two deposition methods (i.e. direct-ink writing and doctor-blading) were compared in order to study the Nakahara Effect. In particular, the focus was to investigate the effects of film thickness, drying process used and the concentration of primary $\mathrm{TiO}_{2}$ particles in the aqueous ink on drying crack pattern formation. Crack patterns were observed during drying using an optical microscope, and crack lengths were measured using image analysis. Weibull statistics were used to study variability in crack patterns for the different deposition methods. The results suggest a distinction between the printed and doctor-bladed samples hence demonstrating the validity of the Nakahara Effect. They also provide new insights for the role of direct writing parameters for inducing distinct printing memory characteristics that may help to further understand and minimize crack formation during drying. 


\section{ACKNOWLEDGEMENTS}

I would like to thank my advisor Dr. Konstantinos Sierros for giving me such a wonderful opportunity to work with him on such an exciting topic. I would also like to thank my thesis committee members, Dr. Charter Stinespring, Dr. Eduardo Sosa and Dr. Samir Shoukry for their help and technical support.

I would also like to thank family, friends and the Benjamin M. Statler College of Engineering for their support during my tenure as a graduate student at West Virginia University. 


\section{Table of Contents}

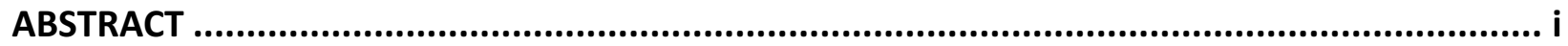

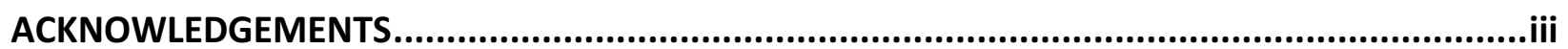

List Of Figures..................................................................................................................

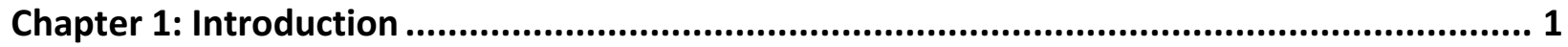

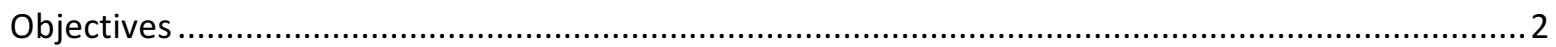

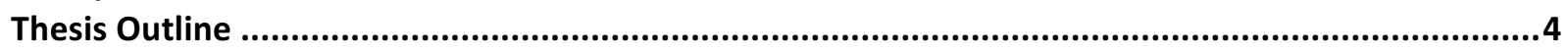

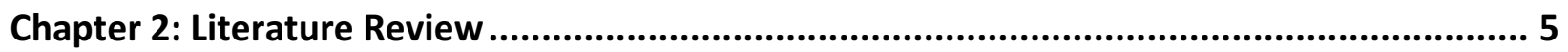

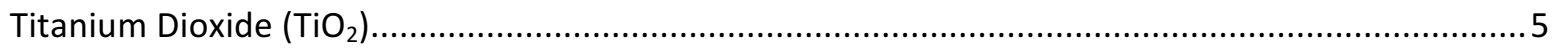

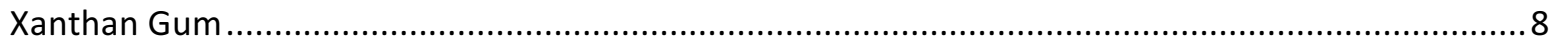

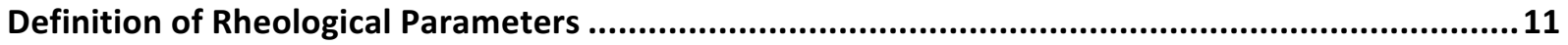

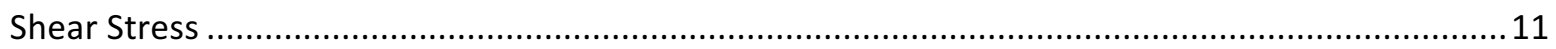

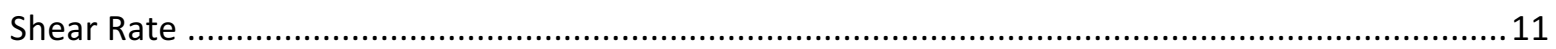

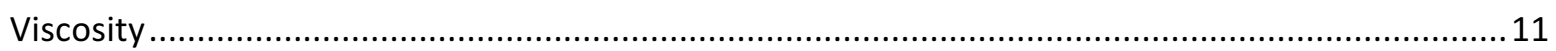

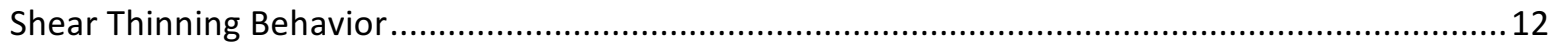

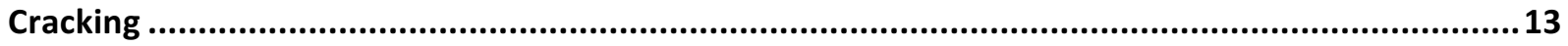

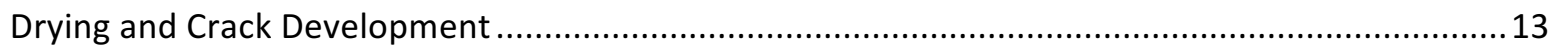

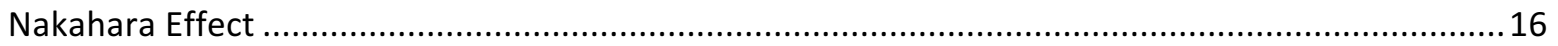

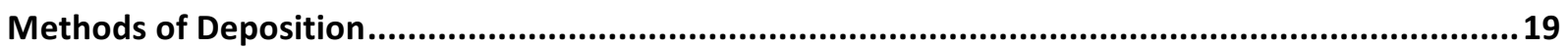

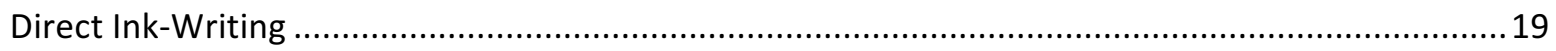

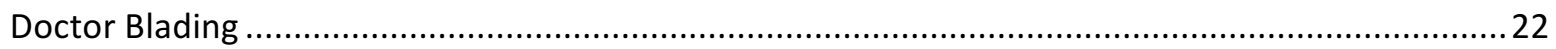

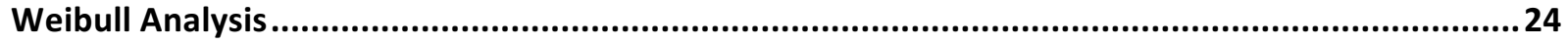

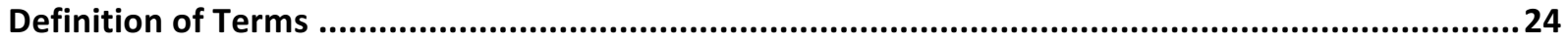

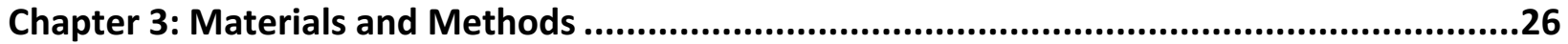

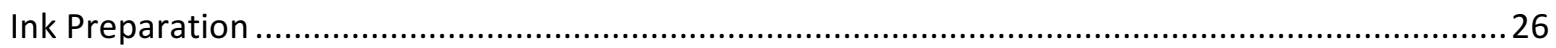

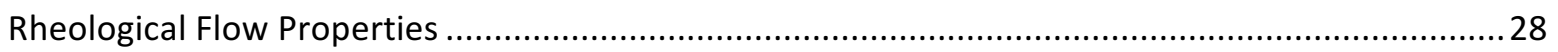

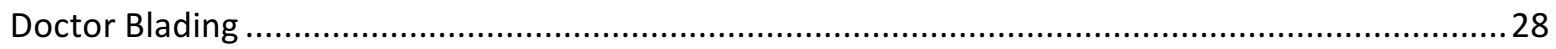

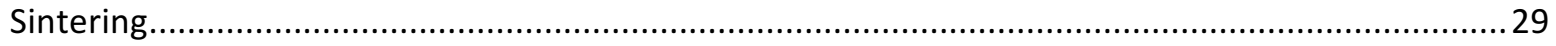

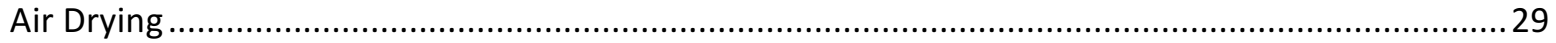

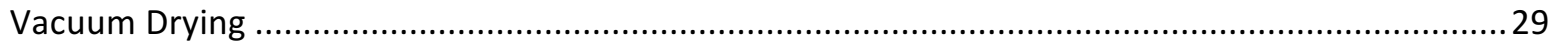

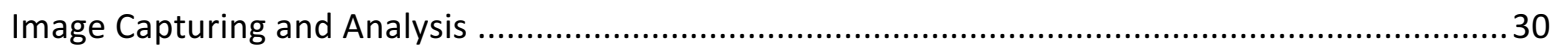

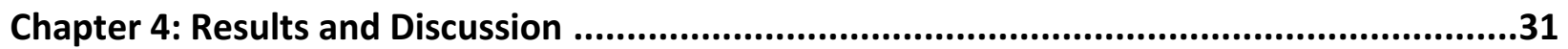

Viscosity Curves

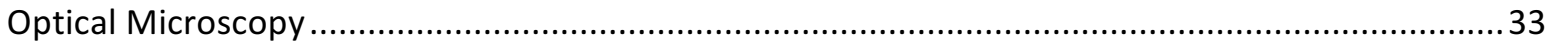

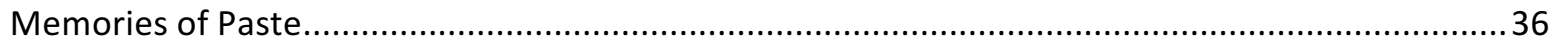

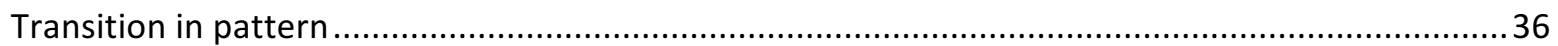

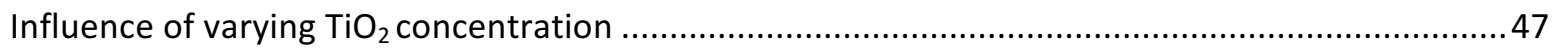

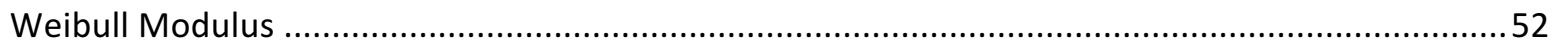

Chapter 5: Conclusions ......................................................................................................62

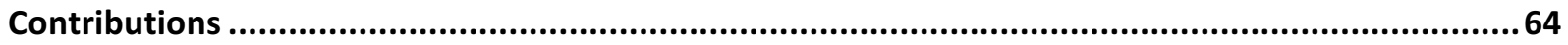

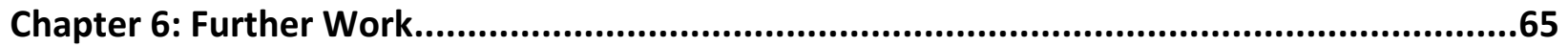

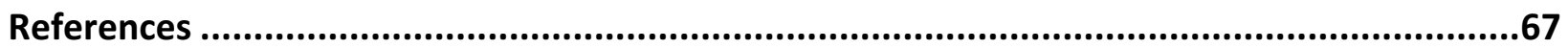




\section{List of Figures}

Figure 1:Mechanism of Photocatalysis.......................................................................... 6

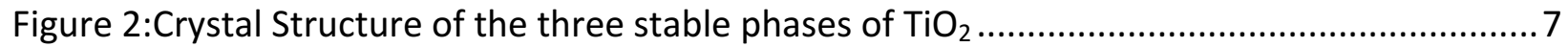

Figure 3 : Repeating Structure of Xanthan Gum ........................................................... 8

Figure 4: Shear rate dependence of steady shear viscosity for aqueous XG solutions of different

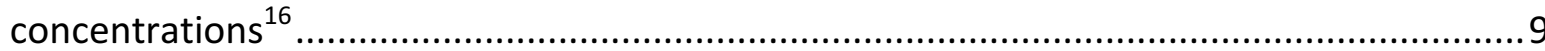

Figure 5: Flow curves of Newtonian and Non-Newtonian Fluids ....................................... 12

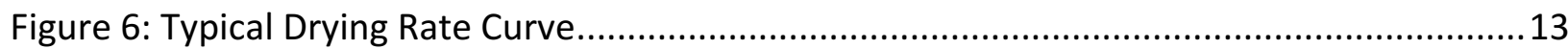

Figure 7: A schematic diagram of a film showing the a) clear film region, b) saturated solid region, and c) fluid region. ................................................................................. 15

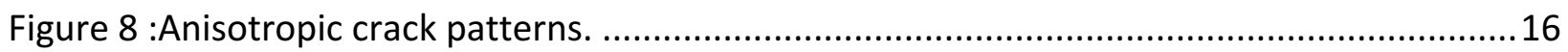

Figure 9: Transition in pattern as a result of difference in water content ...............................18 Figure 10:Nozzle based robotic deposition a) DIW stage setup b) Schematic of nozzle deposition

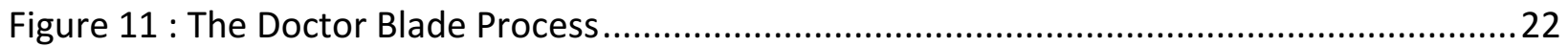

Figure 12: a. Selected Area of analysis in image $\mathrm{j} b$. fragment length measurement ..................30

Figure 13: Viscosity Curves for different $\mathrm{TiO}_{2}$ ink concentrations ........................................... 31

Figure 14: Shear Stress Dependence on Shear Rate for studied inks......................................... 32

Figure 15: Crack propagation sequence of a Doctor blading sample air dry (500 $\mathrm{mm}$ thickness,

$25 \%$ particle concentration) Crack progression a) +5 mins b. +10 mins c) 180 mins d)

+300 mins. Direction of Doctor blading is top to bottom

Figure 16: Crack Propagation sequence for a printed sample air dry (500 $\mu \mathrm{m}$ film thickness, $25 \%$ particle concentration) Crack Progression: a) +5 mins b) +10 mins c) +90 mins d) +200 mins. Direction of direct ink writing is a meander or snake pattern Printing Parameters: $500 \mu \mathrm{m}$

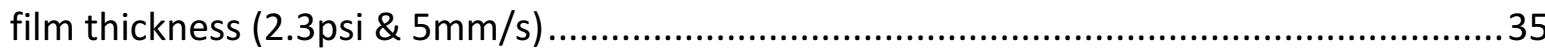

Figure 17 : Optical Microscope Images of $500 \mu \mathrm{m}$ film of $25 \% \mathrm{TiO}_{2}$ particle concentration..........38 Figure 18:Frequency of crack fragment in terms of bins of $25 \% \mathrm{TiO}_{2}$ particle concentration

$(500 \mu \mathrm{m})$ printed samples 39

Figure 19 : Frequency of crack fragment in terms of bins of $25 \%$ TiO2 particle concentration $(500 \mu \mathrm{m})$ doctor bladed samples

Figure 20: Comparison of different film thickness ( $250 \mu \mathrm{m}$ vs $500 \mu \mathrm{m}$ doctor bladed)................41 Figure 21:Thickness dependent fragment length for $250 \mu \mathrm{m}$ vs $500 \mu \mathrm{m}$ doctor bladed air dry ...42 Figure 22 : Thickness dependent fragment length for $250 \mu \mathrm{m}$ vs $500 \mu \mathrm{m}$ doctor bladed oven dry

Figure 23:Optical Image of a) 500 $\mathrm{m}$ DB vs b) $900 \mu \mathrm{m}$ doctor bladed air dried samples Direction of doctor blading is from top to bottom. ................................................................ 43

Figure 24:Thickness dependent fragment length for $500 \mu \mathrm{m}$ vs $900 \mu \mathrm{m}$ doctor bladed..............44 Figure 25:Optical Image of a) $250 \mu \mathrm{m}$ b) $500 \mu \mathrm{m}$ Print Air dried specimens ................................44 Figure 26:Thickness dependent fragment length for $250 \mu \mathrm{m}$ vs $500 \mu \mathrm{m}$ DB..............................45 Figure 27:Optical Image of a) $500 \mu \mathrm{m}$ b) $900 \mu \mathrm{m}$ Doctor Bladed Print Air dried specimens ........... 45 Figure 28:Thickness dependent fragment length for 500um vs 900um Air Dry Printed specimens 
Figure 29:Optical Microscope Images of XG $0.4 \%$ and $25 \% \mathrm{TiO}_{2}$ particles $(600 \mu \mathrm{m})$ thickness for doctor bladed and printed specimens a) Print Air Dry b) DB Air Dry c) Print Vacuum Oven dry d) DB Vacuum Oven Dry. Printing Parameters: $600 \mu \mathrm{m}(2.4 \mathrm{psi} \& 5 \mathrm{~mm} / \mathrm{s})$

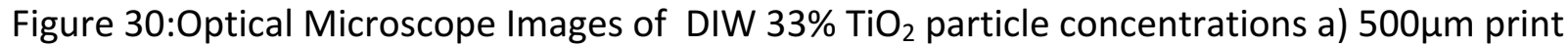
air dry b) $500 \mu \mathrm{m}$ print vacuum dry Print direction is in a snake or meander pattern. : $500 \mu \mathrm{m}(1.3 \mathrm{psi} \& 8 \mathrm{~mm} / \mathrm{s})$

Figure 31: Optical images for doctor bladed samples of 33\% particle concentration. a) air dry b) oven dry c) vacuum dry. Direction of doctor blading is from top to bottom 48

Figure 32:Optical Microscope Images of $18 \% \mathrm{TiO}_{2}$ particle concentration specimens a) $500 \mu \mathrm{m}$ print air dry b) $1000 \mu \mathrm{m}$ print air dry c) $500 \mu \mathrm{m}$ print vacuum dry d) $1000 \mu \mathrm{m}$ print vacuum dry e) $500 \mu \mathrm{m}$ DB vacuum dry f) $1000 \mu \mathrm{m}$ DB vacuum dry. Printing parameters: $500 \mu \mathrm{m}$ $(1.2 \mathrm{psi} \& 10 \mathrm{~mm} / \mathrm{s}) 1000 \mu \mathrm{m}(1.5 \mathrm{psi} \& 8 \mathrm{~mm} / \mathrm{s})$.

Figure 33:Optical Microscope Images of $12 \% \mathrm{TiO}_{2}$ particle concentration a) $500 \mu \mathrm{m}$ air dry print

b) $1000 \mu \mathrm{m}$ air dry print c) $500 \mu \mathrm{m}$ vacuum dry print d) $800 \mu \mathrm{m}$ vacuum dry print e) $500 \mu \mathrm{m}$ DB oven dry f) $1000 \mu \mathrm{m}$ DB oven dry. Print parameters: $500 \mu \mathrm{m}(1.1 \mathrm{psi} \& 10 \mathrm{~mm} / \mathrm{s})$

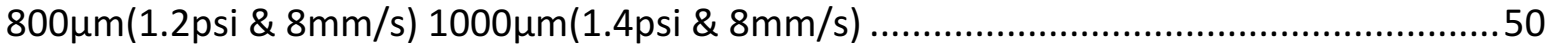

Figure 34 : Weibull Plot for $500 \mu \mathrm{m}$ DIW films with $25 \% \mathrm{TiO}_{2}$ concentration...............................52

Figure 35 :Weibull Plot for $500 \mu \mathrm{m}$ doctor bladed films with $25 \% \mathrm{TiO}_{2}$ concentration ................53

Figure 36:Weibull Plot for $250 \mu \mathrm{m}$ printed films with $25 \% \mathrm{TiO}_{2}$ concentration..........................54

Figure 37: Weibull Plot for $250 \mu \mathrm{m}$ doctor bladed films with $25 \% \mathrm{TiO}_{2}$ concentration ................55

Figure 38 Weibull Plot for DIW $600 \mu \mathrm{m}$ film thickness $25 \% \mathrm{TiO}_{2}$ particle concentration .............56 Figure 39:Weibull Plot for doctor bladed $600 \mu \mathrm{m}$ film thickness $25 \% \mathrm{TiO}_{2}$ particle concentration

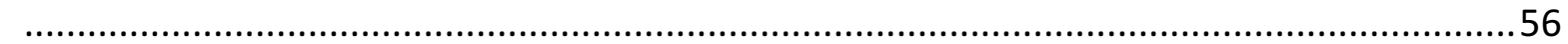

Figure 40:Weibull Plot for DIW 500 $\mu$ m thickness at $33 \% \mathrm{TiO}_{2}$ particle concentration ................57

Figure 41 : Weibull plot for doctor bladed $500 \mu \mathrm{m}$ thickness at $33 \% \mathrm{TiO}_{2}$ particle concentration

Figure 42:Weibull Plot for DIW 600 $\mu \mathrm{m}$ film thickness at $33 \% \mathrm{TiO}_{2}$ particle concentration .........58 Figure 43 : Weibull Plot for doctor bladed $600 \mu \mathrm{m}$ thickness at $33 \% \mathrm{TiO}_{2}$ particle concentration58 Figure 44 : Calculated Weibull Modulus for printed films...................................................59

Figure 45: Calculated Weibull Modulus for doctor bladed films ............................................60 


\section{Chapter 1: Introduction}

Direct ink writing of ceramic based inks has become very desirable in today's world. It allows for freedom of design, mass customization, waste minimization, manufacturing complex structures, and creating three dimensional parts directly from CAD designs resulting in fast

prototyping. ${ }^{1,2}$ It has already been established that ceramic based inks can be directly written into $\mathrm{TiO}_{2}$ films, specifically. ${ }^{3}$ One area of interest is to understand the most optimal and efficient way of depositing $\mathrm{TiO}_{2}$ films on a larger scale. In this research, the direct writing and mechanical behavior of multiphase $\mathrm{TiO}_{2}$-based inks were investigated, by controlling their printing parameters, such as pressure and speed. Observations were obtained regarding how these parameters affect mechanical behavior (i.e. cracking) in the drying process.

$\mathrm{TiO}_{2}$ is the preferred choice of metal oxide due to exhibiting several important properties. In particular, $\mathrm{TiO}_{2}$ has good semiconducting properties, a tunable band gap, photocatalytic properties and relative abundance. ${ }^{4}$ The approach ${ }^{5}$ used during the study represents clear progress in the fabrication of $\mathrm{TiO}_{2}$ inks, traditionally fabricated using multistep methods which is described in detail in the methods section. The approach used in ink fabrication is an environmentally friendly process: it uses abundant, water-compatible, nontoxic material precursors. ${ }^{3}$ The $\mathrm{TiO}_{2}$ inks consist of an aqueous phase consisting of $\mathrm{TiO}_{2}$, $\mathrm{Titanium}_{\text {(IV) }}$ bis ammonium lactato di-hydroxide (TALH) and deionized water. The $\mathrm{TiO}_{2}$ inks were mixed with Xanthan gum in order to enable advantageous printing. Xanthan gum is used as a replacement for the original oil phase, typically used to stabilize the $\mathrm{TiO}_{2}$ based emulsions. Xanthan gum serves as a stabilizer in these inks while adding viscosity hence allowing the printability of these inks. 


\section{Objectives}

The primary objective is to study the influence of 3D printing and its parameters on the mechanical behavior of drying printed inks. This is motivated by the interest in the Nakahara effect, which states that long lasting memory can be introduced into a colloidal paste as a result of specific external forces applied. The fragmentation pattern that develops during drying is determined by the direction of the external forces applied while processing. ${ }^{6}$ After understanding the mechanisms of drying and cracking, the ultimate goal of this research is to produce crack-free thin films.

The determined pattern was accomplished by capitalizing on previously developed processing maps and direct writing films using a range of parameters, such as pressure and speed. ${ }^{3}$ Films were dried using different processes to determine potential contributions of deposition method and drying. The primary objective was studied by comparing mechanical properties of films fabricated using methods of direct writing or doctor blading and dried using various drying techniques. The different drying techniques performed were air drying, vacuum drying, and sintering in order to attempt to control crack patterns. Another aspect worthy of study is the effect of particle weight percent of formulated ink on transition in crack pattern. The particle weight percent is a crucial characteristic during the formulation of ink due to the Nakahara Effect being sensitive to the particle concentration. The final objective of the study involves the variance of film thickness on crack behavior. Such knowledge is important to reducing drying-induced fragmentation and, also, for better understanding of anisotropyrelated flow phenomena caused by 3D printing. With understanding of mechanical behavior of 
drying inks, the large scale manufacturability of 3D printed structures may be achieved in the future. 


\section{Thesis Outline}

Chapter 1: Introduction. This chapter presents an outline of the background of this project, including relevant literature and research objectives. The thesis outline is also given in this chapter.

Chapter 2: Literature Review. This chapter studies and discusses previous research work carried out by other researchers. It also draws conclusions from other research to help achieve the goal of this project.

Chapter 3: Materials and Methods. This chapter describes the materials and experiments used in this project. It starts with the process of making inks and then proceeds to describe the methods of deposition and drying used. Finally, it discusses the method of analysis of collected experimental data.

Chapter 4: Results and Discussion. This chapter describes observations and evaluates the data collected from the experiments. Furthermore, the pattern of cracking for the two methods of deposition are discussed and compared. The patterns of cracking as drying occurs, are distinguished primarily based on the type of stress induced. Also, observations are made on how the different drying processes affect pattern cracking and drying.

Chapter 5: Conclusion. This chapter draws conclusions based on the experimental results and also summarizes the major contributions of this study.

Chapter 6: Future Work. This chapter offers projections on what this research could mean for the engineering industry in the future and further areas that can be explored to provide further understanding of cracking and drying mechanisms. 


\section{Titanium Dioxide $\left(\mathrm{TiO}_{2}\right)$}

\section{Chapter 2: Literature Review}

In recent years, research studies in $\mathrm{TiO}_{2}$ have increased tremendously. A quick survey over the span of 100 years shows that on the average, 910 papers are published each year on this material. ${ }^{4}$ Hence, it is considered one of the most studied oxide materials. $\mathrm{TiO}_{2}$ was discovered from ilmenite ore in 1791 . Titanium, the raw material of $\mathrm{TiO}_{2}$, is the ninth most abundant element in the earth's crust and the fourth most abundant metallic element; therefore, $\mathrm{TiO}_{2}$ can be used in many applications without the risk of scarcity. ${ }^{4}$

Commercial $\mathrm{TiO}_{2}$ is produced in two ways, either by the sulphate process or the thermochemical chloride process from ores and concentrates. ${ }^{4} \mathrm{TiO}_{2}$ has become a very useful material, and is used for several different applications. On a large scale, $\mathrm{TiO}_{2}$ has been predominantly used as pigment in paint over the years. It is also widely used for white pigment in paints, food coloring, toothpaste, polymers and other instances where colorization is required. ${ }^{7} \mathrm{TiO}_{2}$ is a good colorization agent in manufactured materials due to the high refractive indices of rutile and anatase which result in high reflectivity from the surfaces. Additionally, plastic and paper industries have also employed the use of this material. More recently, several applications have been developed such as $\mathrm{TiO}_{2}$ synthesized as nanoparticles and nanotubes. These new developments of $\mathrm{TiO}_{2}$ make it a good candidate for sustaining continual development in the area of renewable energy. ${ }^{8} \mathrm{TiO}_{2}$ is said to have important applications due to its interesting semiconducting properties, tunable band gap, photocatalytic properties, biocompatibility, and relative abundance. $\mathrm{TiO}_{2}$ has been applied in the industry of

food safety and quality control. $\mathrm{TiO}_{2}$ is also applied in self-cleaning glass, waste water treatment 
and hydrogen production as fuel. ${ }^{4}$ Based on the semiconducting properties of $\mathrm{TiO}_{2}$, it is gaining attention in applications for data storage and memory devices. Additional applications of $\mathrm{TiO}_{2}$ include its use as breathing cement and air purification which is due to its photocatalytic activity. ${ }^{4}$

\section{Mechanism of Photocatalysis}

Photocatalysis is a process where light and catalysts are concurrently used to support or speed up a chemical reaction. ${ }^{9}$ In photocatalysis, $\mathrm{TiO}_{2}$ absorbs ultraviolet radiation from sunlight or an illuminated light source such as fluorescent lamps and produces pairs of electrons and holes. The electron of the valence band of $\mathrm{TiO}_{2}$ becomes excited when illuminated by light. The excess energy of the excited electron promotes the electron to the conduction band of $\mathrm{TiO}_{2}$ and creates the negative-electron (e-) and positive-hole $(\mathrm{h}+)$ pair. This stage is referred to as the semiconductor's 'photo-excitation' state. The energy difference between the valence band and the conduction band is known as the 'Band Gap' ${ }^{10}$ and it is schematically presented in Figure 1.

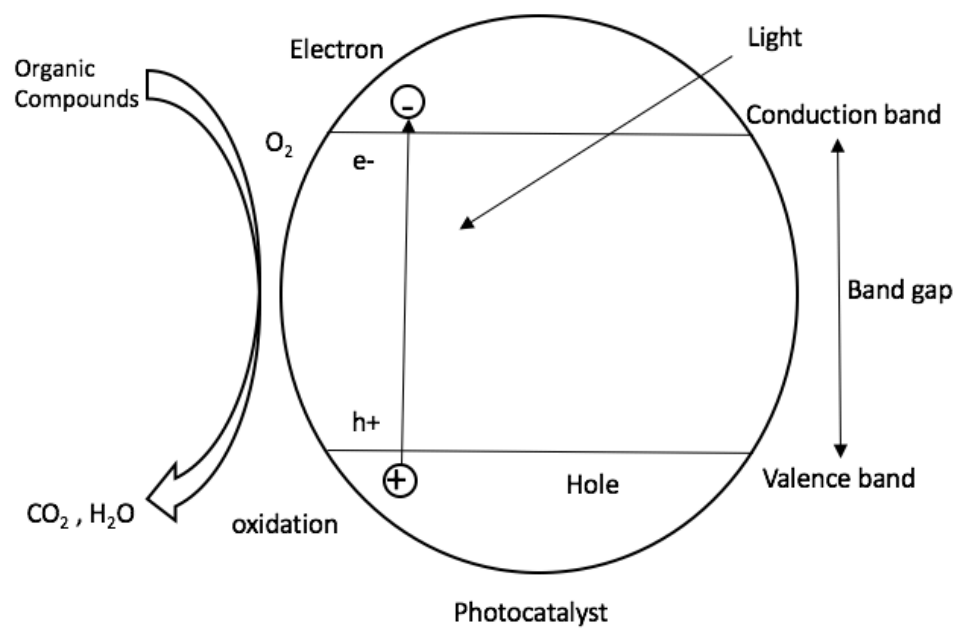

Figure 1:Mechanism of Photocatalysis 
The positive-hole of $\mathrm{TiO}_{2}$ breaks apart the water molecule to form hydrogen gas and hydroxyl radical while the negative-electron reacts with oxygen molecule to form super oxide anion. This cycle is continuous with the availability of light as shown in Figure 1.

\section{Structure of $\mathrm{TiO}_{2}$}

$\mathrm{TiO}_{2}$ minerals are found in three different crystallographic structures; rutile, anatase, and brookite as illustrated in Figure 2 . The rutile phase is stable, while both, the anatase and brookite, can be converted irreversibly through heat treatment. ${ }^{4,11}$ Rutile is the thermodynamically most stable phase, and the (110) face has the lowest surface energy, thereby making it the most intensely studied surface. Anatase and rutile have tetragonal unit cells while brookite has an orthorhombic structure. Anatase is three times longer than rutile along the c-axis. Brookite has the largest cell volume followed by anatase which is $9 \%$ higher in volume than rutile. Brookite transforms into rutile at relatively low temperatures of $300^{\circ} \mathrm{C}^{12}$ The anatase structure is metastable and is transformed into the rutile structure with heat treatments. $^{4,8,11}$

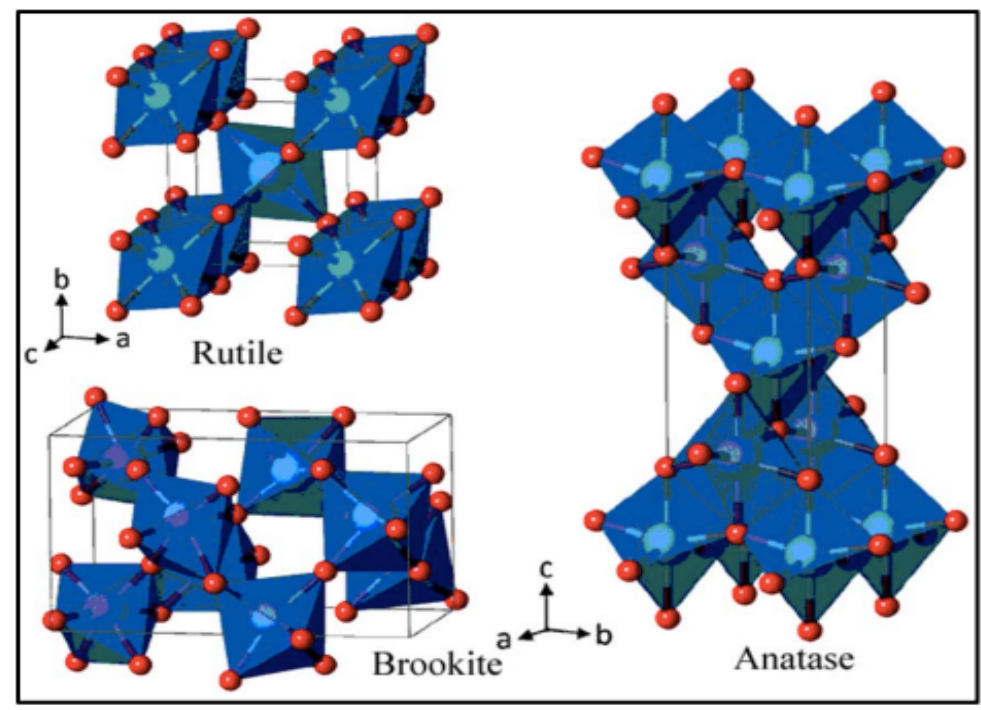

Figure 2:Crystal Structure of the three stable phases of $\mathrm{TiO}_{2}$ 


\section{Xanthan Gum}

Xanthan Gum(XG) is a microbial high molecular weight hydrocolloid that is a natural polysaccharide. It is produced by Xanthomonas campestris bacterium at cell wall surface by a complex enzymatic process during the normal lifecycle. ${ }^{13}$ Commercially produced xanthan gum is manufactured by an aerobic, submerged fermentation process. The process is carried out in several stages and when the final fermentation step is finished the $X G$ is recovered by precipitation. $^{14}$

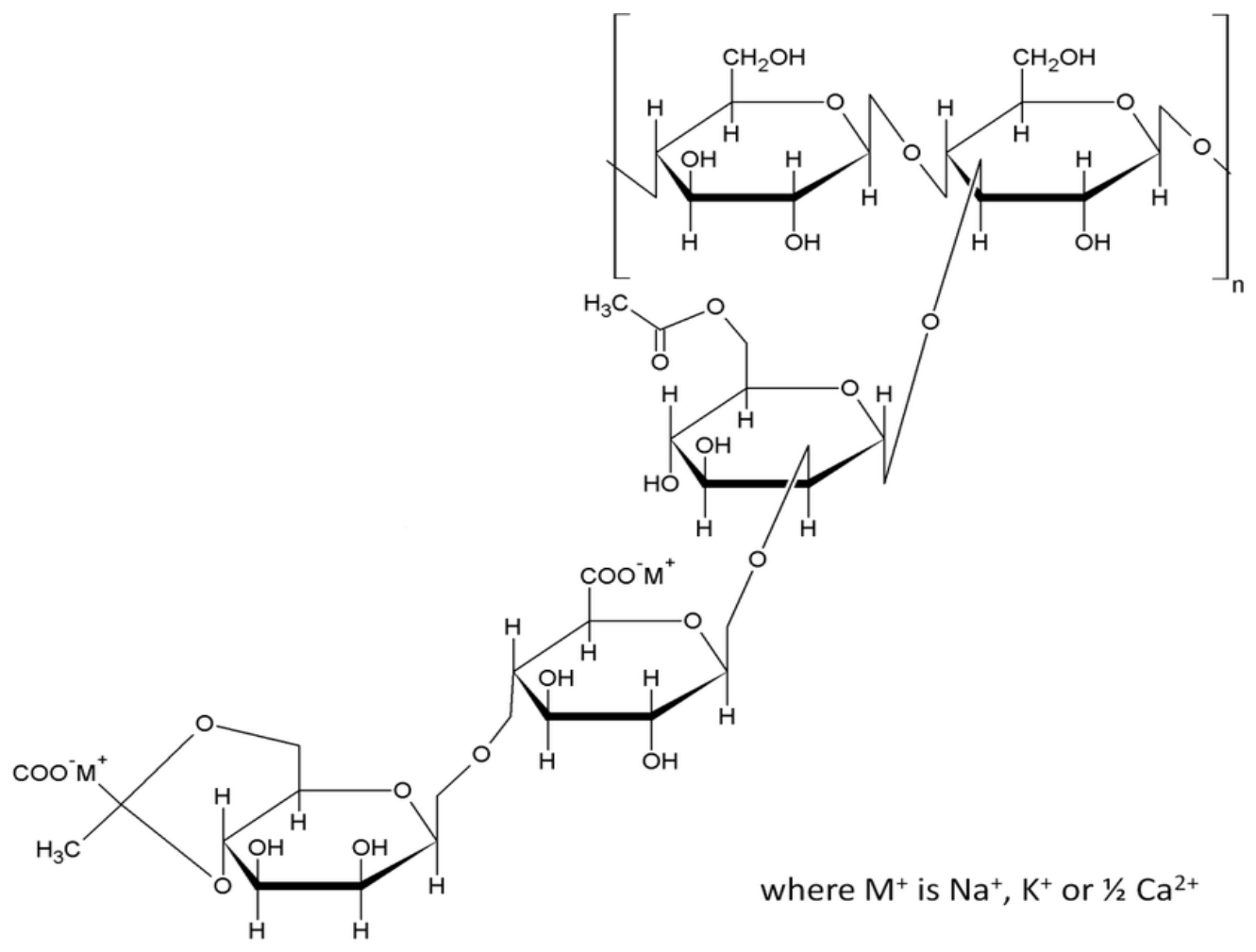

Figure 3 : Repeating Structure of Xanthan Gum

XG is a branched extracellular heteropolysaccharide which has a linear cellulosic backbone formed by (1->4)-linked $\beta$-D-glucose units (same as cellulose). The primary structure of xanthan gum, illustrated in Figure 3, consists of two glucose units, two mannose units and 
one glucuronic acid unit which together form repeated pentasaccharide units. Trisaccharide side chains are attached on every other glucose unit linked at C-3 position. The trisaccharide side chain contains a glucuronic acid residue between two D-mannose units. ${ }^{15}$

XG is used in the ink system studied in this work due to having many desirable properties. XG is soluble in both hot and cold water. At both low and high concentrations, XG exhibits pseudo-plastic flow thus confirming its highly viscous nature in solution. It displays shear thinning behavior that is saying that the high viscosity is amplified at lower shear rates. Figure 4 shows the shear rate $(\dot{\gamma})$ dependence of shear viscosity $(\eta)$ for aqueous xanthan gum solutions with different concentrations. ${ }^{16}$ The steady shear viscosity of all solutions is sharply decreased as an increase in shear rate, demonstrating that these systems exhibit shear thinning behavior.

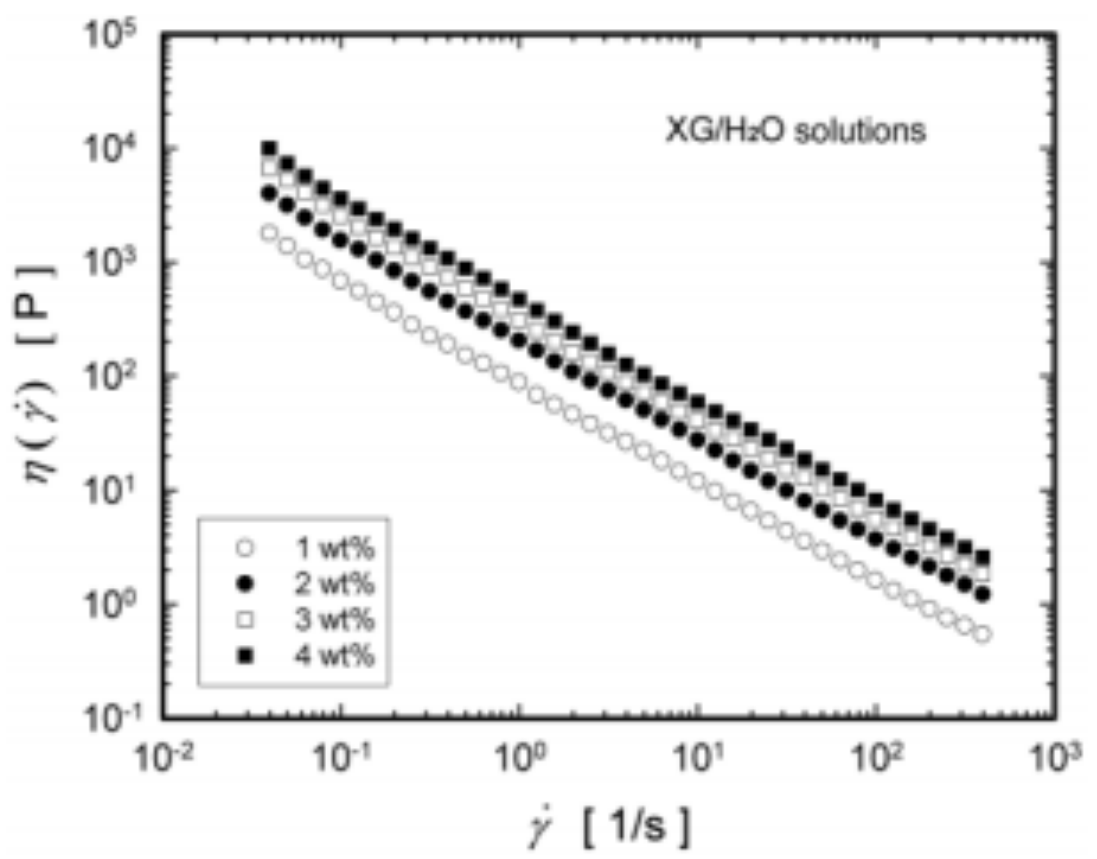

Figure 4: Shear rate dependence of steady shear viscosity for aqueous XG solutions of different concentrations $^{16}$ 
XG is also a stable colloidal material with a viscosity that is not vastly influenced by $\mathrm{pH}$ and temperature changes nor the presence of electrolytes. ${ }^{14}$ These unique functional properties make it very effective stabilizer and thickener in water based systems. Xanthan gum has a great commercial significance and it can be used widely at different industrial applications, however its manufacturing process renders it quite an expensive hydrocolloid on the market. ${ }^{14,15,17,18}$ Within this research, XG is used as a stabilizing and emulsifying agent for the aqueous $\mathrm{TiO}_{2}$ solutions. 


\section{Definition of Rheological Parameters}

Rheological features of materials define physical properties of liquids and solids.

Rheology is the study of flow and deformation of materials under applied forces and describes the deformation of a fluid under the influence of stress. ${ }^{19}$

\section{Shear Stress}

Shear stress describes the force divided by area over which it is applied. Shear stress $(\tau)$ is defined as the tangential or shear force per unit area. The shear stress is the component of force that is needed to achieve an angular or lateral deformation. It causes successive parallel layers of a material body to move relative to each other. ${ }^{19,20}$ In the SI system of units, the unit of Shear stress is Pascal(Pa).

$$
\operatorname{Shear} \operatorname{Stress}(\tau)=\frac{\text { Shear Force }(F)}{\operatorname{Area}(A)}
$$

Shear Rate

Shear rate is the rate of change of velocity at which a layer of fluid passes over an adjacent layer. The shear rate defines the change of shear strain, relative deformation in shear, per unit time. ${ }^{19,20}$

$$
\text { Shear Rate }(\dot{\gamma})=\frac{\operatorname{Velocity}(V)}{\text { Distance }(h)}
$$

where velocity is the rate of change of distance of a moving plate; $\mathrm{h}$ is the distance between two parallel plates.

\section{Viscosity}

Viscosity $(\eta)$ describes a material's resistance to flow which is defined as the ratio of shear stress and shear strain rate. In other words, viscosity describes the internal friction of a 
moving fluid. A fluid with large viscosity resists motion because its molecular makeup gives it a lot of internal friction. A fluid with low viscosity flows easily because its molecular makeup results in very little friction when it is in motion. The SI unit of viscosity is pascal-second (Pa .S).

$$
\operatorname{Viscosity}(\eta)=\frac{\text { Shear Stress }(\tau)}{\operatorname{Shear} \operatorname{Strain} \operatorname{rate}(\dot{\gamma})}
$$

\section{Shear Thinning Behavior}

In rheology, shear thinning is the Non-Newtonian behavior or characteristic of a fluid to decrease in viscosity under increasing shear strain. Shear thickening is the opposite phenomenon. By contrasting both, viscosity in Newtonian fluids is by definition independent of the forces exerted on the fluid, while fluids that exhibit shear thinning are sometimes called pseudo-plastics and are typically complex fluids such as blood, motor oil, ketchup, and even whipped cream, though simple fluids can also exhibit the behavior near their critical point. ${ }^{20}$

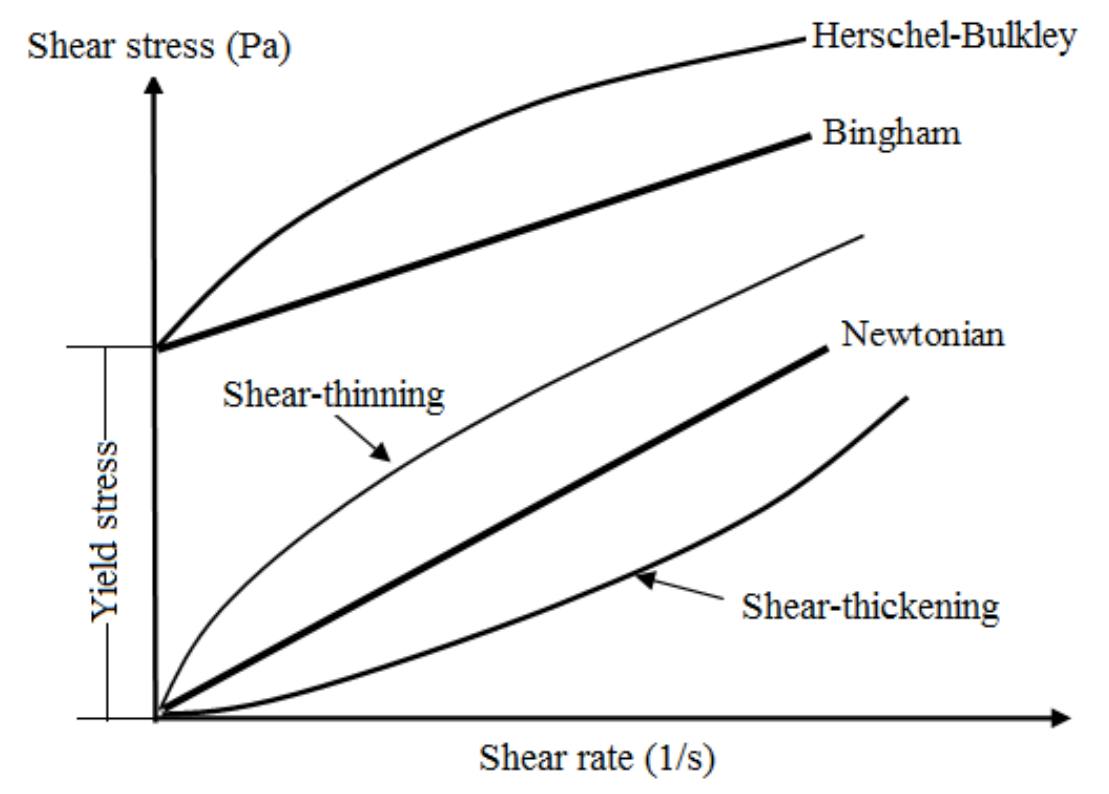

Figure 5: Flow curves of Newtonian and Non-Newtonian Fluids 


\section{Cracking}

Drying and Crack Development

In cracking, a strain is developed because the top layer retains its size. When this strain becomes large enough, channel cracks form in the dried-up surface to relieve the strain. Individual cracks spread and join up, forming a polygonal, interconnected network. Cracks usually initiate from the top of the coating to the bottom and for crack propagation to occur, a network is required. ${ }^{21}$ In this work, the focus of study is on the drying-induced cracks. Drying typically occurs in three stages as illustrated in Figure 6.

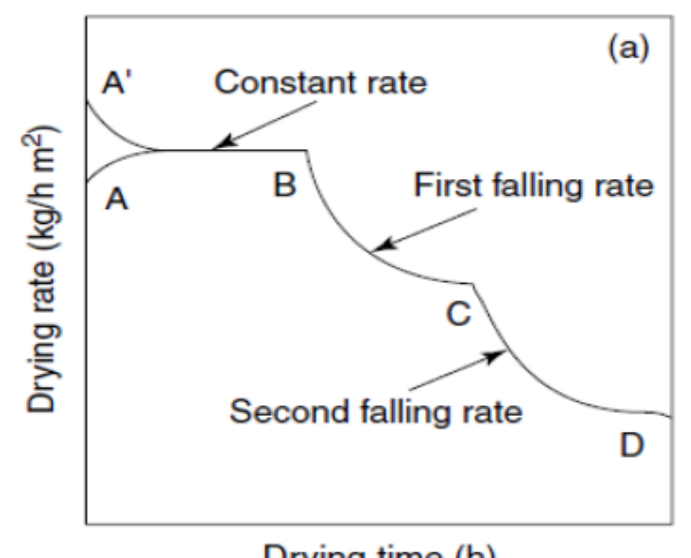

Drying time $(\mathrm{h})$

\section{Figure 6: Typical Drying Rate Curve}

As a colloidal film dries, the particle assembly develops a substantial elastic modulus that accompanies its low strength. The strain associated with slight non-uniformities in moisture on drying are thus sufficient to cause cracking. The first stage, also known as constant rate period of aqueous colloidal system drying, consists of volume decrease due to evaporation of the solvent. This stage is proportional to the rate of evaporation and there are usually no stresses involved in this stage. ${ }^{22}$ There is a low particle concentration hence a relatively open pore network that enables liquid to be transported to the air-liquid interface. The total time for 
occurrence of this stage is proportional to the initial volume fraction of liquid. The solid particle concentration increases as solvent evaporation proceeds and as this liquid evaporation occurs, the particle concentration stays uniform throughout the drying body. ${ }^{23,24}$

The second stage, also known as the first falling rate period is followed by capillary network formation due to the continual increase in particle volume fraction. This is referred to as the gel point where a three-dimensional particle network forms. There is a rearrangement of particles as granular density increases. This causes the development of a finite compressive yield stress in the film as drying continues due to the decrease in the liquid volume fraction in the film. As the liquid volume fraction decreases, the solid volume fraction increases. ${ }^{22}$ Therefore, there is a formation of a particle network that works against the compaction of the film. The extent to which compaction is resisted depends on the applied pressure and compressive yield stress where the former should be greater than the latter for compaction to occur. The local stresses resulting from the evaporation of liquid act in combination with local capillary forces due to the formation of a curved liquid-air interface, known as a meniscus. The meniscus causes a compressive pressure on the particle network due to surface tension as it forms between neighboring particles. The meniscus also produces a pressure gradient from the surface of the liquid to the liquid inside the drying body. In the case of slow drying, air drying for example, liquid rises to the surface as a result of the pressure gradient and continues to evaporate at a constant rate. ${ }^{22}$ The air-water interface remains attached to the surface layer of the particles and shrinks at the same rate as the particle network. Compaction of films occurs uniformly because the compressive stress of the particle network exceeds the compressive yield strength of the of the drying film. ${ }^{25-27}$ This continues until the developed compressive 
yield strength is large enough to withstand capillary pressure and compressive stress, thus signifying the point at which compaction stops.

When compaction is halted, the second falling rate is initiated. The liquid vapor interface begins to penetrate the particle compact and drying rate decreases. Further shrinking occurs due to negative hydrostatic pressure at the air-colloid interface. The area available for evaporation is reduced as a result of the receding of the liquid/vapor interface into the pores. Shrinkage of the film usually stops at this point. Cracking usually occurs at the point where shrinking stops and this is after the third stage. ${ }^{22,26}$ In past research, several studies have investigated the causes of stresses in drying powder compacts and how those stresses can lead to cracking. During this stage, there is an observed shrinkage in the top layer of the drying film as the bottom layer remains the same. This causes development of tensile stresses at the surface. These tensile stresses depend on the rate of drying. If drying is slow, shrinkage of drying body occurs uniformly across the film whereas if drying is fast shrinkage occurs nonuniformly. ${ }^{22,25}$ This is because in fast drying pressure and moisture gradients exist within the body whilst in slow drying the volume fraction of solids is uniform throughout the body. Cracking usually occurs at the end of the second constant rate drying period. ${ }^{26,28}$ evaporation

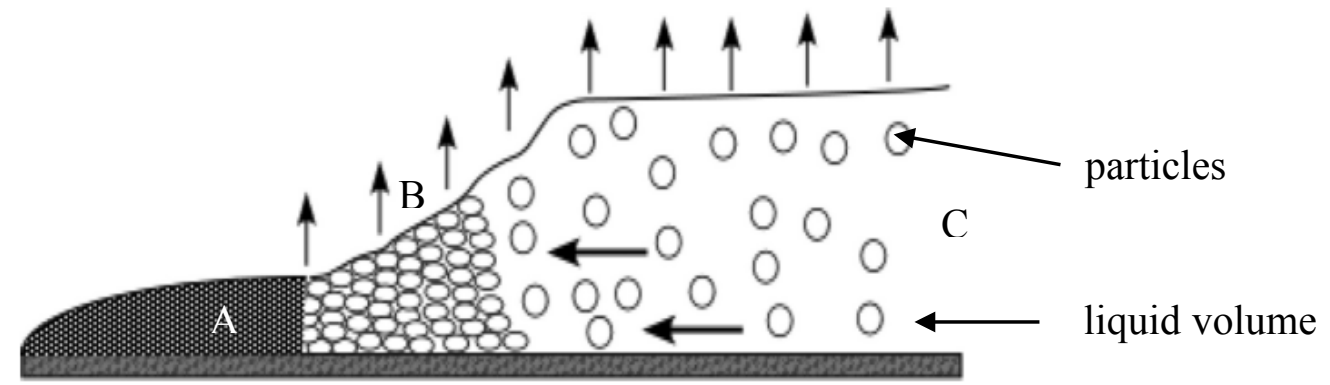

Figure 7: A schematic diagram of a film showing the a) clear film region, b) saturated solid region, and c) fluid region. 


\section{Nakahara Effect}

The Nakahara effect states that we can imprint a memory into the paste that determines how cracking may progress. That is, if we apply an external force to the paste before it is dried, it remembers the direction of the initial external forces, and the morphology of the resultant crack patterns is determined by the memory of this direction. ${ }^{6}$ Figure 8 shows results from experiments carried out by Nakahara and Matsuo to prove the Nakahara effect in colloidal pastes.

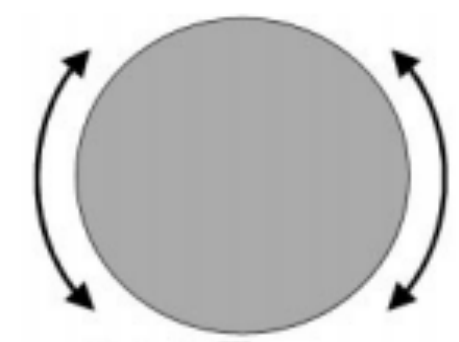

Dried

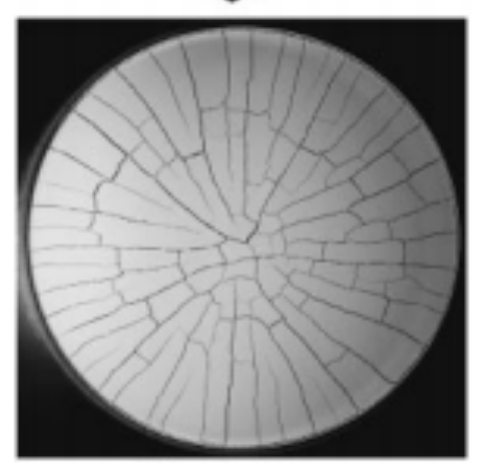

(a) Radial

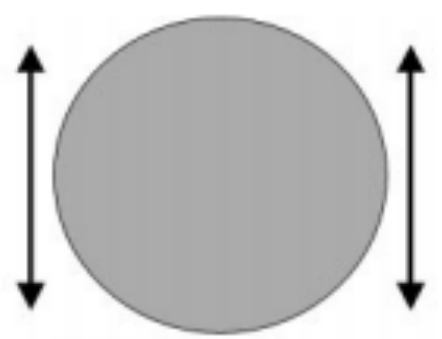

Dried

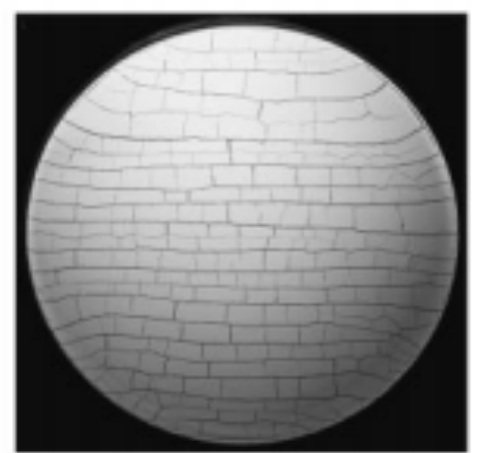

(b) Lamellar

Figure 8 :Anisotropic crack patterns. The diameter of each container is $500 \mathrm{~mm}$.

a) The radial crack pattern appears when the container is initially oscillated in an angular direction. $b$ ) The lamellar crack pattern appears when the container is initially vibrated in one direction.

Colloidal pastes have memories of external mechanical fields, such as flow and vibration. For example, a water poor colloidal paste has memory of vibration. A water-rich colloidal paste on the other hand, has memory of flow. When a water poor paste is dried after 
initial vibration, lamellar crack pattern appears with the directions all perpendicular to the direction of the initial vibration. This is known as a Type-I memory. When a water-poor paste is sheared horizontally, inelastic collisions between particles produce longitudinal density fluctuation, and the network of particles is weakened in that direction, leading to stripe crack pattern perpendicular to the direction of the initial shear. The pattern is of cellular structure, which means that the fragments are uniform in size and their arrangement is statistically homogeneous and isotropic. ${ }^{29}$ Comparatively water-rich colloidal paste has memory of flow as illustrated in Figure 9. When such paste is vibrated, it is easily fluidized and the resultant desiccation crack pattern has a structure similar to the flow pattern that is observed at the initial vibration. That is implying the direction of desiccation cracks becomes parallel to the flow direction( Type-II memory). ${ }^{30}$ However, in some cases, once the paste is fluidized, the paste cannot remember the direction of initial external shear and crack patterns formed are isotropic and cellular. A paste of Calcium Carbonate is a typical example of such pastes. ${ }^{31}$

From literature it is also suggested that, only when the mixture is a water-poor viscoplastic-like paste with a nonzero yield stress, can the mixture distinctively remember the direction of the initial external vibration and the anisotropic crack patterns appear. ${ }^{6}$

A paste generally consists of a powder mixed with water and is a concentrated colloidal suspension with plasticity. The Nakahara effect demonstrates that even after an external force is removed from a densely packed colloidal suspension, the memory of the external force still leaves a distinctive pattern. ${ }^{6,32}$ 
a) Water poor

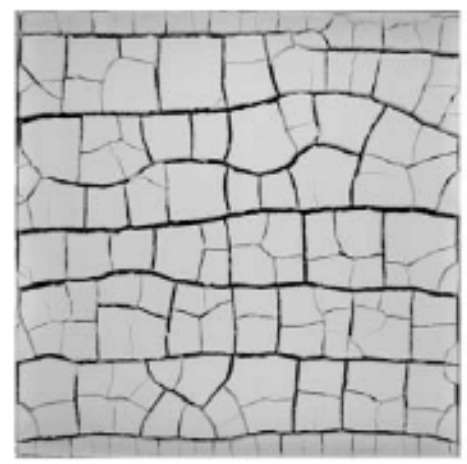

b) Water rich

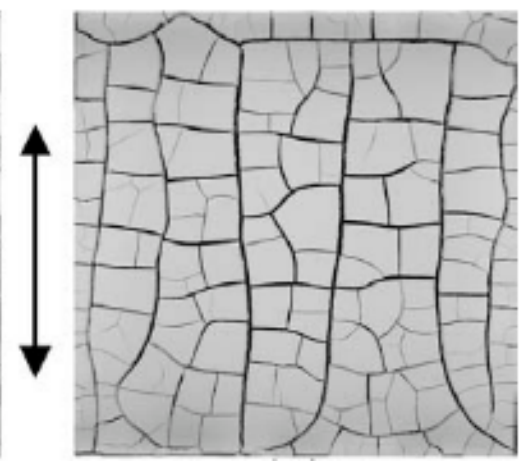

Direction

of vibration

Figure 9: Transition in pattern as a result of difference in water content

Figure 9 shows a transition in the direction of lamellar patterns 9(a)from perpendicular to a more parallel pattern 9(b) when compared to the direction of the initial vibration. A decrease in solid volume fraction of (water rich) paste results in a crack pattern parallel to the direction of external vibration 9(b). A water poor paste, on the other hand results in a crack pattern perpendicular to the direction of initial vibration 9(a). 


\section{Methods of Deposition}

\section{Direct Ink-Writing}

Direct ink-writing, also known as Robocasting, has received a lot of attention in academia and industry in the last decade. Direct ink-writing is used in the aerospace and biomedical industry as it provides a platform for manufacturing of complex shapes in short production periods. Direct ink-writing is an additive manufacturing technique that relies on the extruding of a line through a small diameter nozzle to write on a stage. ${ }^{33}$ Objects are built up in a layered fashion as ink is extruded. This ink extrusion is performed under controlled flow rates and controlled paths in order to fabricate structures. ${ }^{34}$ An ink with appropriate rheological properties for direct ink-writing must be able to ooze through the nozzle, therefore possess relatively low viscosity under stress also known as shear thinning behavior. The ink must also possess excellent shape retention capacity and therefore must have high elastic modulus and high yield stress upon deposition. ${ }^{34,35}$

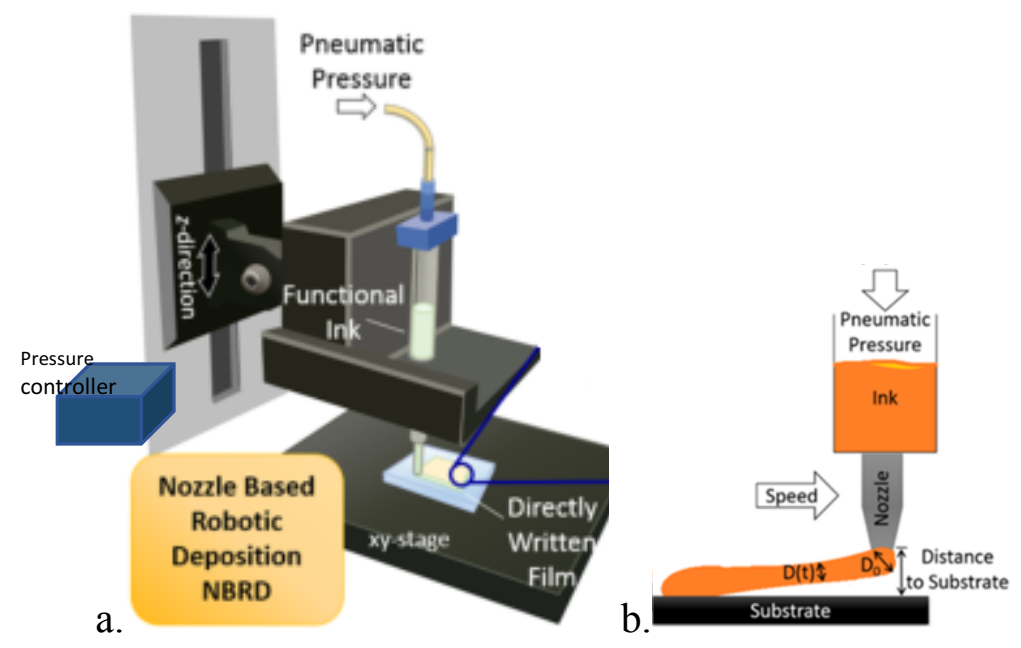

Figure 10:Nozzle based robotic deposition a) DIW stage setup b) Schematic of nozzle deposition It is essential to make sure the formulated ink exhibits the appropriate rheology desired for printing. After the desired rheological behavior is achieved, the ink is housed in a syringe/ink 
reservoir and extruded normally through a conical/cylindrical nozzle (inner diameter, $d$ typically $\geq 100 \mu \mathrm{m}$ ) by the computer-controlled robotic deposition system. In direct-ink writing, filaments are extruded by applying a uniform pressure and constant displacement to the ink reservoir as shown schematically shown in Figure $10(\mathrm{~b}) .{ }^{36}$ With the application of a pressure gradient (P) along the length (I) of the nozzle, the ink flows through the deposition nozzle and a radially varying shear stress $\left(\tau_{r}\right)$ is developed..$^{35}$

$$
\tau_{r}=\frac{r \Delta P}{2 l}
$$

Radial position within the nozzle is represented by $r$ (i.e. $r=0$ at the center axis and $r=R$ at the nozzle wall). Based on the velocity profile and the ink stability, the type of flow within the nozzle is laminar flow. Colloidal gel-based inks consist of a percolating network of attractive particles that are capable of transmitting stress above a critical volume fraction, $\phi_{g e l}$. When inks are stressed beyond their yield point $\left(\tau_{y}\right)$, they exhibit shear thinning flow behavior due to the attrition of particle-particle bonds within the gel, as described by Herschel Bulkley Model. $^{37,38}$

$$
\tau=\tau_{y}+K \dot{\gamma}^{n} \quad \text { (2) } \gg \text { Herschel Bulkley Model }
$$

Where the total shear stress is represented by $\tau, \tau_{y}$ is the shear yield stress $\mathrm{n}$ is the shear thinning exponent $(<1), \mathrm{K}$ is the viscosity parameter, and $\dot{\gamma}$ is the shear rate. ${ }^{35}$

The Herschel Bulkley model is applied on fluids with a non-linear behavior and yield stress. It is a more precise model since its equation has three adjustable parameters. The consistency index parameter (K) gives an idea of viscosity of the fluid. Fluids must possess similar flow behavior index $(n)$ to compare K-values of different fluids. ${ }^{19}$ When $\mathrm{n}$ is above 1 , the fluid acts as a shear 
thickening fluid and when $\mathrm{n}$ is below 1 , the fluid acts as a shear thinning fluid. ${ }^{39}$ From Eq. (2), some possible combinations include:

a) $\tau_{y}=0 \& n=1 \Rightarrow$ Fluid with Newtonian behavior

b) $\tau_{y}>0 \& n=1 \Rightarrow$ Fluid with Bingham plastic behavior

c) $\tau_{y}=0 \& n<1 \Rightarrow$ Fluid with pseudo plastic (shear thinning) behavior

d) $\tau_{y}=0 \& n>1 \Rightarrow$ Fluid with dilatant (shear thickening) behavior

Gel-based inks flow with a three-zone velocity profile (three region flow) within the cylindrical deposition nozzle that consists of an un-yielded (gel) core moving at a constant velocity surrounded by a yielded fluid experiencing laminar flow and a thin slip layer devoid of colloidal particles at the nozzle wall. The ink exits the nozzle as a continuous, rod-like filament with a rigid (gel) core-fluid shell architecture, which simultaneously promotes its shape retention while allowing the rods to fuse together at their contact points. The rod architecture is dynamic in nature, such that the fluid shell transforms to the gelled state as particle bonds reform. In contrast, inks that do not possess a yield stress exhibit laminar flow during extrusion. Upon deposition, the fluid shell quickly transforms into a gelled state as the attractive particle bonds reform. $^{32,35,37}$ 


\section{Doctor Blading}

Doctor blading, also referred to as tape casting, is known as one of the most commonly used techniques for producing thin films on large surface areas. Doctor blading was developed approximately in the 1940's as a method of forming thin sheets of piezoelectric materials and capacitors but has now become a typical method of achieving precise coatings. ${ }^{41}$ This process has several advantages thus making it an attractive manufacturing process. Doctor blading can produce thin single layers or can be stacked and laminated into multilayered structures. ${ }^{42}$ In the doctor blading process, a well-mixed slurry consisting of a suspension of ceramic particles along with other additives (such as binders, dispersants or plasticizers) is placed on a substrate beyond the doctor blade. When a constant relative movement is established between the blade and the substrate, the slurry spreads on the substrate to form a thin sheet which results in a gel-layer upon drying. The doctor blading devices can operate at speeds up to several meters (m) per minute ( $\mathrm{min}$ ) and they are suitable to coat substrate with a very wide range of wet film thicknesses ranging from tens to several hundred microns $(\mu \mathrm{m}){ }^{41}$

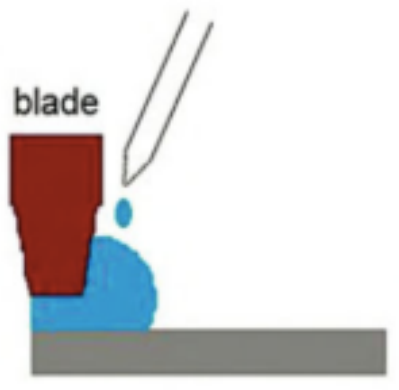

Solution deposition

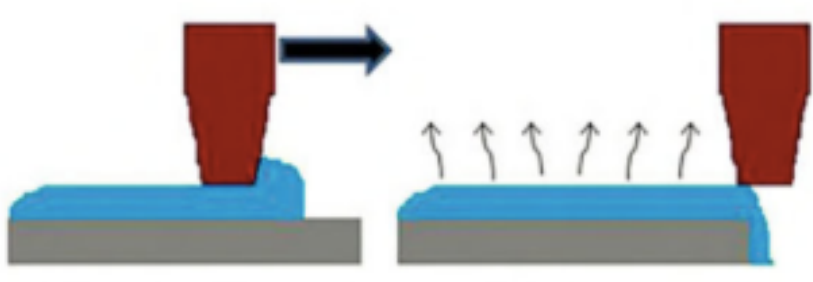

Spreading
Drying

Figure 11 : The Doctor Blade Process 
For simpler doctor blading, a portion of the colloidal paste or ink is applied near the top edge of the glass substrate right on the edge of the taped boundary. With a rigid doctor blade applicator or a squeegee, such as a microscope slide, a glass rod or blade, the paste is spread across the substrate with adhesive tapes bounding the desired doctor blade area as schematically shown in Figure 11. The gap between the strips of tape should be filled with a layer of colloidal paste during deposition. This operation is repeated until a homogenous layer is formed. ${ }^{43}$ Doctor blading is also a waste minimizing method, since ideally all ink can be fully utilized. 


\section{Weibull Analysis}

The Weibull distribution is widely used to describe the scatter of strength in brittle materials. ${ }^{44}$ The Weibull Modulus (k), which is the dimensionless parameter of the Weibull distribution which is used to describe variability in measured material strength for brittle materials. ${ }^{45}$ It is taken into account when describing the variability in strength of the material, so that strength is best represented as a distribution of values rather than as one specific value. If $k<1$, this implies that the weak and defective parts fail in the beginning, with the harder sections surviving. If $k=1$, this implies that there is random failure occurring. Thus, there should be some external factor strong enough to cause random failure irrespective of whether the section is strong or weak. If $k>1$, this points to a kind of ageing process, the weakening of the material with the passage of time. ${ }^{44}$

Weibull modulus would vary depending on the distribution of cracks, their distances, and the interaction with the geometry and stress field. If there is high variation in failure, Weibull modulus will be low and if there is low variation in failure, Weibull modulus will be high. $^{46}$

\section{Definition of Terms}

Crack Spacing

The average distance between cracks.

Crack Density

The number of cracks per unit length. Crack density is also defined as the inverse of crack spacing. 
Crack Number

Crack number is a randomly assigned number given to a measured crack.

Crack Fragment length

Average diameter of crack between two points measured diagonally at the final stage of drying.

Energy Release Rate (ERR)

Ratio of total internal energy to crack length. Total Internal Energy is assumed as potential energy which is derived by multiplying mass, gravity and height.

$$
G=\frac{\text { Total Internal Energy }(U)}{\text { Crack length }}
$$




\section{Ink Preparation}

\section{Chapter 3: Materials and Methods}

In this work, the different components of ink influence its printability and controllability.

The ink was composed of the crystalline $\mathrm{TiO}_{2}$ phase, the $\mathrm{Ti}(\mathrm{IV})$ bis-ammonium lactato dihydroxide (TALH) organic metal oxide precursor, an additive polymer poly acrylic acid (PAA), water as a solvent and Xanthan Gum (XG) as viscosity modifier and a stabilizer. The crystalline $\mathrm{TiO}_{2}$ phase was intended to serve as a photocatalytic wide band gap semi-conductor, and the Tiorganic complex TALH served as the bridging element to create a continuous structure. ${ }^{5}$ The addition of polymer has viscosity increasing effects, increases wettability and bridges flocculation.

The ink was prepared by mixing components of the aqueous phase together and then combined it with the desired weight of XG concentration. These two phases were mixed separately and then combined to create an emulsion. To prepare these inks, it is ideal to start with the aqueous phase and continuously stir for an hour, minimally, while mixing the XG in solution. Depending on the desired colloidal ink, preset formulations with the suitable amounts of materials have already been attained. For the aqueous phase, appropriate amounts of deionized (D.I) water was mixed, respectively, for 15 minutes in a closed beaker covered with parafilm with the following materials obtained from Sigma Aldrich: TALH (50 wt \% in $\mathrm{H} 2 \mathrm{O}$ ), $\mathrm{TiO}_{2}$ nanoparticles, and Aeroxide P25 (70\% anatase, 30\% rutile). After formulation of the aqueous phase mixture, the mixture was set to sonicate for 15 minutes in a sonication water/ice bath. During sonication, the mixture was stirred every five minutes to prevent sedimentation. The sonication step ensures complete dispersion of the $\mathrm{TiO}_{2}$ particles in the aqueous solution. 
Simultaneously, a PAA, product no.323667, Sigma-Aldrich, solution was made in DI water as a 5:1 ratio. The PAA solution was added to the aqueous phase mixture. The new mixture was stirred approximately 15 minutes on a stirring plate and then set for another 15 minutes of sonication. While sonicating, it was essential to make sure that water does not seep into the mixture so as not to compromise the amount of water in the system. The mixture was then set to stir for at least one hour before further mixing. The mole ratio for $\mathrm{TALH}$ to $\mathrm{TiO}_{2}$ was maintained at 1:12 for all four formulations used in experiments. The TALH to PAA ratio was also kept constant for all four systems.

The required amount of XG was mixed with water and was left to sit at room temperature for 6 hours to allow full homogenization of the xanthan gum particles in solution. Once this XG solution was homogeneous, the $X G$ is added to the aqueous phase dropwise with a spatula while stirring. This mixture was covered with para-film to prevent solvent evaporation. The mixture was stirred at $350 \mathrm{rpm}$ and allowed to homogenize.

The $\mathrm{TiO}_{2}$ solid particle concentrations in weight percent used in this study were $33 \%, 25 \%, 18 \%$ and $12 \%$, the other ink components used are also displayed in Table.

Table 1 : Ink composition by weight percent

\begin{tabular}{|c|c|c|c|c|}
\hline $\mathrm{TiO}_{\mathbf{2}} \%$ & $\mathbf{3 3 \%}$ & $\mathbf{2 5 \%}$ & $\mathbf{1 8 \%}$ & $\mathbf{1 2 \%}$ \\
\hline Di water & $58.24 \%$ & $64.4 \%$ & $71.11 \%$ & $74.78 \%$ \\
\hline TALH & $7.41 \%$ & $8.23 \%$ & $9.04 \%$ & $9.51 \%$ \\
\hline PAA & $1.81 \%$ & $2.02 \%$ & $2.21 \%$ & $2.33 \%$ \\
\hline XG & $0.36 \%$ & $0.403 \%$ & $0.44 \%$ & $0.466 \%$ \\
\hline
\end{tabular}




\section{Rheological Flow Properties}

Apparent viscosity measurements of the foams were then taken and recorded using a Brookfield DV-II + Pro rotational viscometer. Viscosity tests and flow behavior of the different formulations of colloidal pastes were studied.

\section{Direct Ink writing (Printing)}

To enable printing, the colloidal ink systems were loaded into syringe-type cartridges and printed on glass substrates using a Nordson JR2300N robotic arm, equipped with a Performus V pneumatic pressure ink dispenser system. Different codes for producing planar or three-dimensional (3D) paths can be used to fabricate films and spanning structures, and hollow column like structures. The printing speed and extrusion pressure were varied from 2 to $15 \mathrm{~mm} / \mathrm{s}$ and from $1 p s i$ to $5 \mathrm{psi}$, respectively to study the printing space for these ink systems. The fabricated films covered an area of $2 \mathrm{~cm}^{2}$ for both printed and doctor bladed samples. For all printed samples, Smooth Flow tapered plastic nozzles of $580 \mu \mathrm{m}$ inner diameter were used at approximately $500 \mu \mathrm{m}$ dispensing height. This was done for the four different formulations of ink. By the trial and error process, several samples were prepared by varying the speed and pressure to achieve desired thicknesses of film. The thickness of each film was approximately measured using the optical microscope and a duplicate sample was made by doctor blading while keeping thickness constant for the two processes.

\section{Doctor Blading}

This was carried out using a micrometer adjustable film applicator (50mm, EQ-Se-KTQ50) on borosilicate glass substrates. For each thickness achieved by a print, a doctor bladed sample was prepared on glass. To maintain sample consistency as much as possible, the doctor- 
bladed sample was limited to an area of $2 \mathrm{~cm}^{2}$. Once the desired thickness was achieved, samples were doctor bladed and drying behavior was compared to printed samples to observe for the different pattern of cracks that form in doctor-blading.

\section{Sintering}

The prepared films were sintered at $500^{\circ} \mathrm{C}$ for $30 \mathrm{~min}$ with a heating rate of $5^{\circ} \mathrm{C} / \mathrm{min}$ and a cooling rate of $5^{\circ} \mathrm{C} / \mathrm{min}$, in a muffle furnace equipped with a SMART-3 fuzzy logic temperature controller Temp, Inc. After sintering, images were captured with an optical (dinolite) microscope to observe further changes in the drying behavior of the printed films. For each film thickness, a sample was placed in the oven to be sintered to compare the difference between leaving the samples to air dry.

\section{Air Drying}

The prepared films were dried in air under laboratory atmospheric conditions. This was the least controlled drying process since it depends on the humidity of the room at any given point. To obtain a more controlled drying method, vacuum oven drying was employed.

\section{Vacuum Drying}

For a vacuum drying experiment, the films to be dried were placed in an enclosed container to vent air and reduce the pressure with a vacuum pump in order to increase the water vapor partial pressure. This was done to attain a controlled drying approach in relation to air drying. In summary, three samples were prepared for each thickness and the three different drying processes were employed to observe the effects of each drying method on these printed films. 


\section{Image Capturing and Analysis}

After samples were printed/ doctor bladed on the glass substrates, the drying behavior was observed with an optical microscope until no further cracking or drying was observed. A time lapse video was set such that it captures an image at 2 minute intervals for 8 hours for the air dried samples. Vacuum drying took approximately three times less the amount of time to dry and images were taken when final cracks were achieved. Image J software was then used to analyze the crack spacing, crack lengths, crack fragments as well as sample width. An example of the area selected for analysis is shown in Figure 12 (a) and fragment length is indicated in Figure $12(b)$.
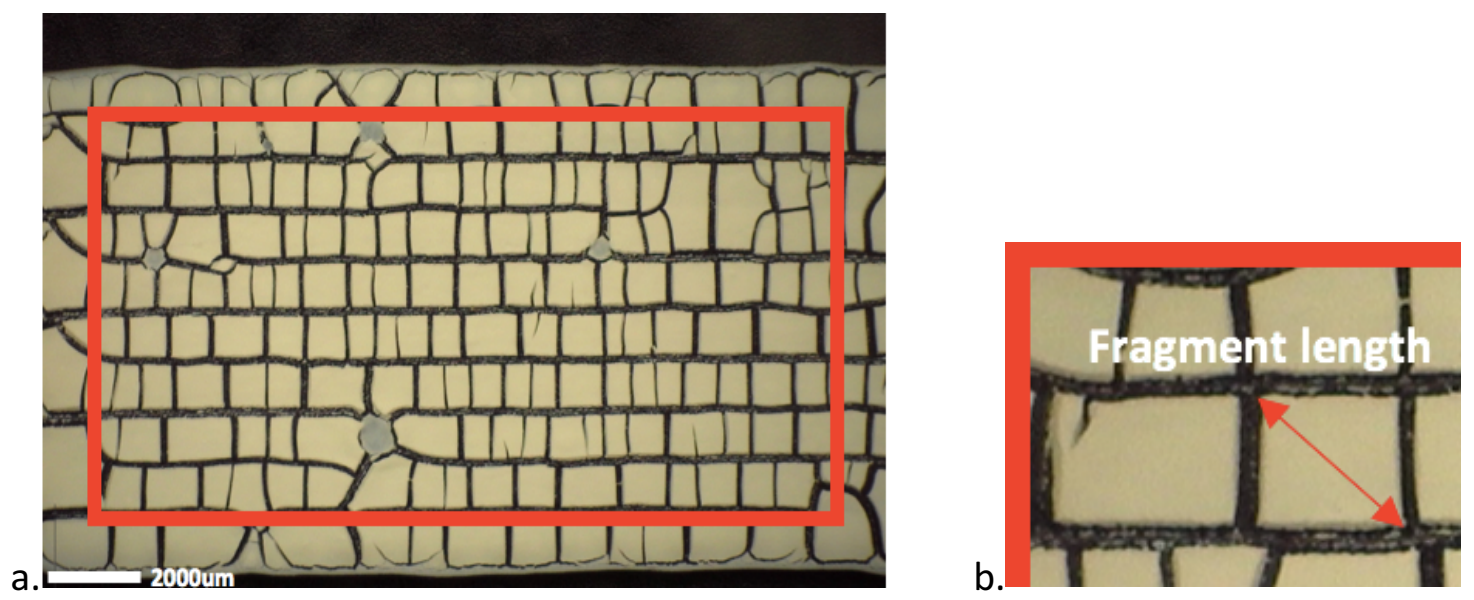

Figure 12: a. Selected Area of analysis in image j b. fragment length measurement

With the data achieved from Image J analysis Weibull plots were constructed to observe the different variations of crack patterns. 


\section{Chapter 4: Results and Discussion}

In this chapter the results of studies conducted in the experimental part are presented and discussed. Firstly, data from different analysis are reviewed. Then, the results of rheological characterization are explored and discussed. The effect of varying particle weight fraction in the mixture is studied. Also the effect of different drying processes on the crack pattern is observed. The differences in crack patterns for the two deposition processes are observed and compared.

\section{Viscosity Curves}

The results reveal that all the studied materials are showing shear-thinning behavior, which correlates with findings in the previous studies for $\mathrm{XG}$ and $\mathrm{TiO}_{2}$ solutions. ${ }^{3,16} \mathrm{XG}$ solutions are strongly pseudo-plastic materials where the viscosity drastically decreases as a function of increased shear rate. Viscosity curves were generated for the four different formulations of the colloidal ink used and are presented in Figure 13.

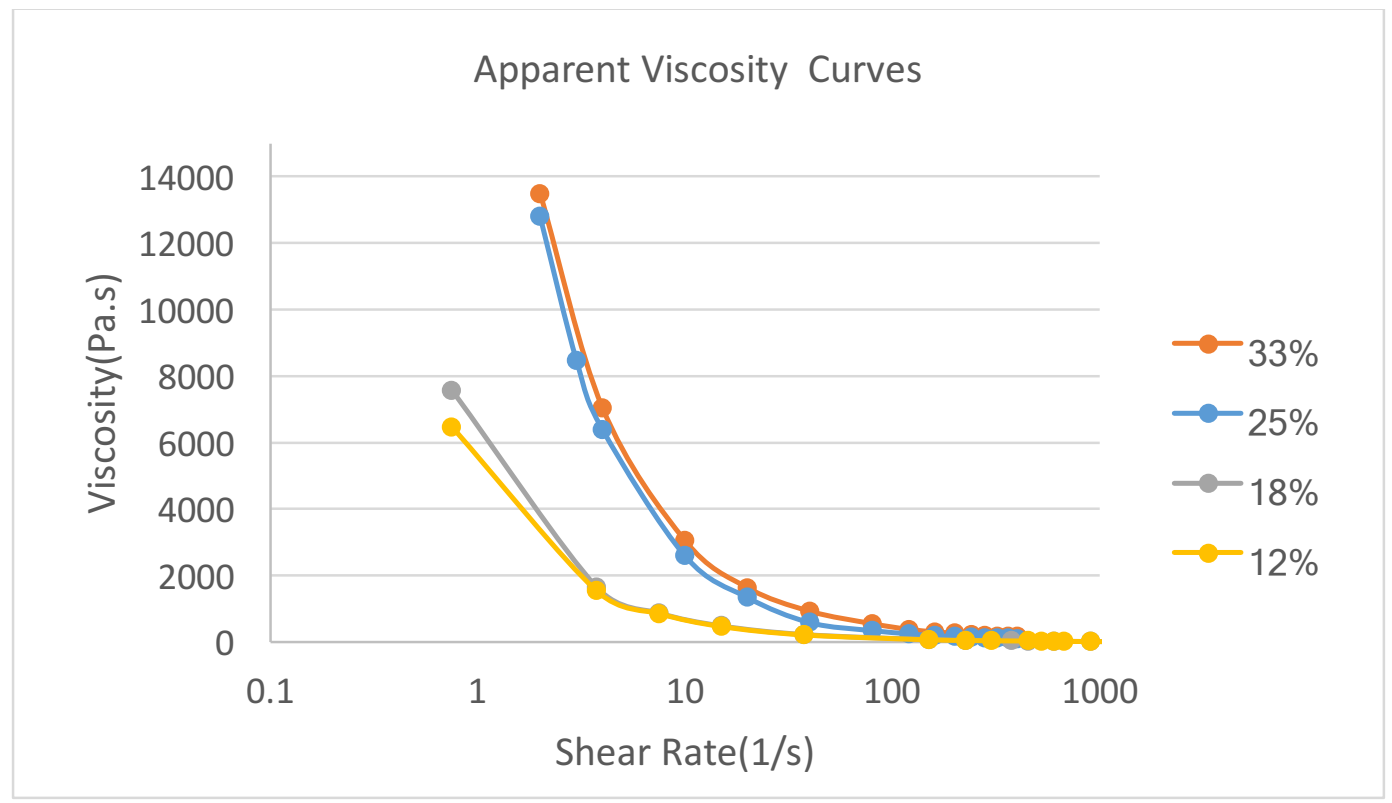

Figure 13: Viscosity Curves for different $\mathrm{TiO}_{2}$ ink concentrations 


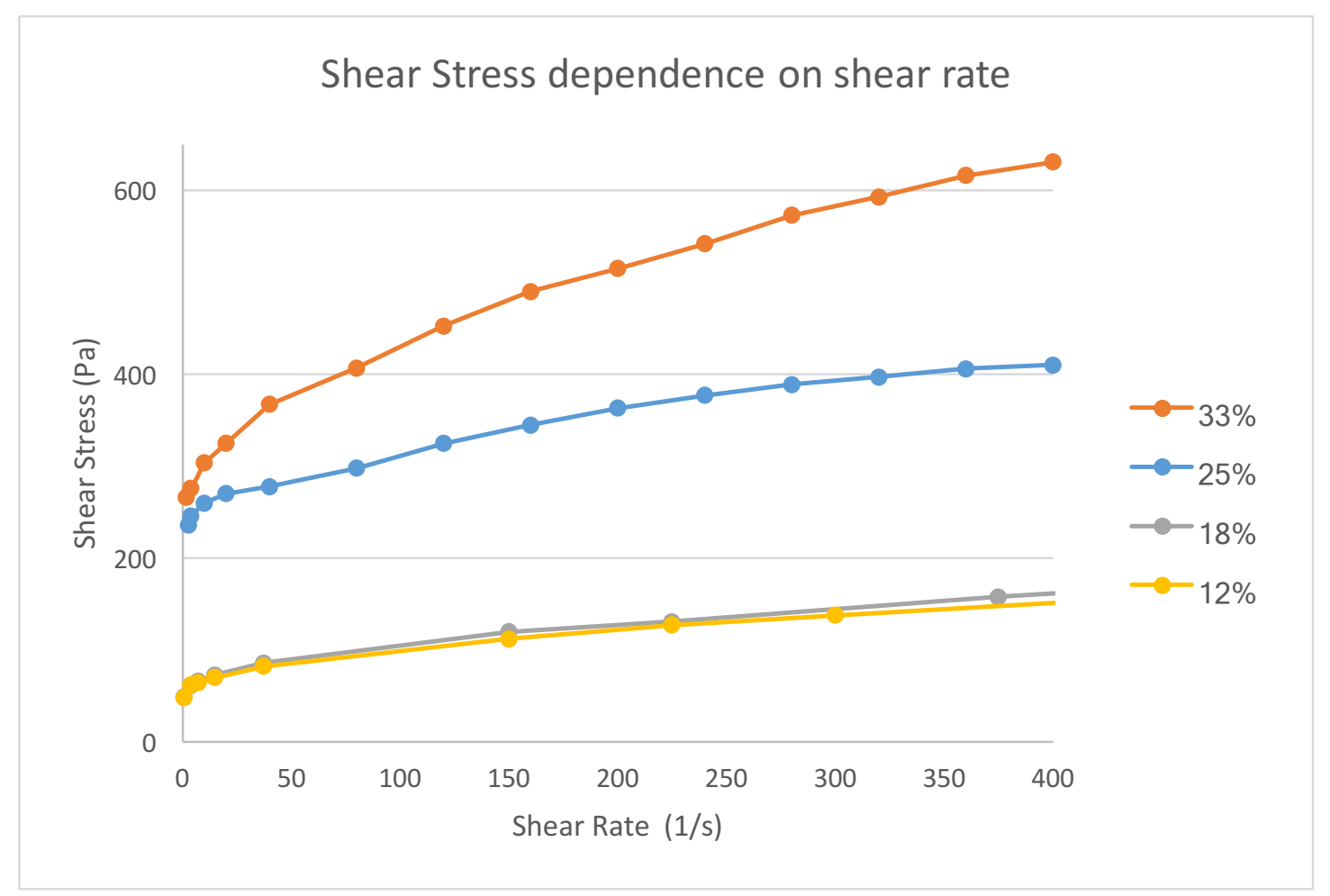

Figure 14: Shear Stress Dependence on Shear Rate for studied inks

The Herschel-Bulkley Model indicates shear thinning flow regimes. Analysis of the shear stress-shear rate curve of the different formulations of inks in Figure 14 results in the Herschel Bulkley coefficients summarized in Table 1 . The values of the flow indices ( $n$ ) are less than 1 hence confirming the inks demonstrate shear thinning behavior. $\tau$ is total shear stress and $\tau_{y}$ is the yield stress, $\mathrm{k}$ denotes fluid consistency. It can be noted that yield stress decreases as liquid volume fraction increases. From Figure 14, it is seen that the higher the particle concentration, the higher the shear stress. The increase in viscosity seen in Figure 13 and yield stress seen in Figure 14 for $33 \%$ and $25 \%$ particle concentration is attributed to the decreased distance between particles that occurs with an increase in particle content, leading to particle collisions and agglomeration. The ink with the highest solid loading concentration (33\%), had the highest yield point and viscosity observed, making it the most difficult suspension to extrude as the 
nozzle tip would dry and clog easily. On the other hand, the $12 \% \mathrm{TiO}_{2}$ concentration had the lowest yield point due to the decrease in frequency of particle collisions. The $18 \%$ and $12 \% \mathrm{TiO}_{2}$ concentrations extruded easily through the nozzle but were not viscous enough to support multiple layers and complex structures. The $25 \%$ concentration had intermediate viscosity and yield stress and was optimal for direct ink writing as it flowed easily from the nozzle and was viscous enough to support multiple layers and complex structures.

Table 2: Herschel Bulkley Coefficients of studied inks

\begin{tabular}{|c|c|c|c|}
\hline Ink & $\tau_{\mathbf{y}}(\mathbf{P a})$ & $\mathbf{K}$ & $\mathbf{n}$ \\
\hline $\mathbf{3 3} \%$ concentration & 303 & 234.37 & 0.149 \\
\hline $\mathbf{2 5 \%}$ concentration & 246 & 195.85 & 0.116 \\
\hline $\mathbf{1 8 \%}$ concentration & 73 & 44.22 & 0.220 \\
\hline $\mathbf{1 2 \%}$ concentration & 70.4 & 44.01 & 0.211 \\
\hline
\end{tabular}

\section{Optical Microscopy}

The films were analyzed with an optical microscope (Dino-lite Edge/DVI AM5218MZT) in order to visualize the cracking behavior of the films. The properties of interest are crack fragment size (average distance of a diagonal), crack spacing and time for crack initiation for different thicknesses. The difference in mode of cracking between doctor-bladed samples and printed samples was also observed. All data for parameters were obtained using the Image J software (Fiji for mac). Data obtained was analyzed and graphs were generated in Microsoft Excel. It was observed that in general for a given thickness, doctor bladed samples take a longer time to dry compared to printed samples. Doctor bladed samples generally covered a slightly 
larger area during the formation of a film compared to printed samples due to the uniformity in the doctor-blade deposition process. With this in mind, it can be suggested that the doctor bladed samples form a stronger particle network such that it has a higher compressive yield strength compared to printed samples hence taking a longer time for evaporation and subsequent cracking. It was also observed that larger thicknesses lead to larger crack fragments (i.e. Size of fragment increases with increasing thickness). Again, this can be explained by the increase in particle volume fraction that causes the formation of a strong and larger particle network. Also, a higher thickness results in a larger stress buildup hence, causing the formation of larger crack fragments. ${ }^{47}$ In doctor bladed samples we noted that sequential cracks propagate at constant speeds to form Y-shapes and near rectangular fragments thus demonstrating the three stage drying process as illustrated in Figure 15. The printed samples were also observed to produce more distinct rectangular crack fragments as shown in Figure 16 resulting from the printing direction.
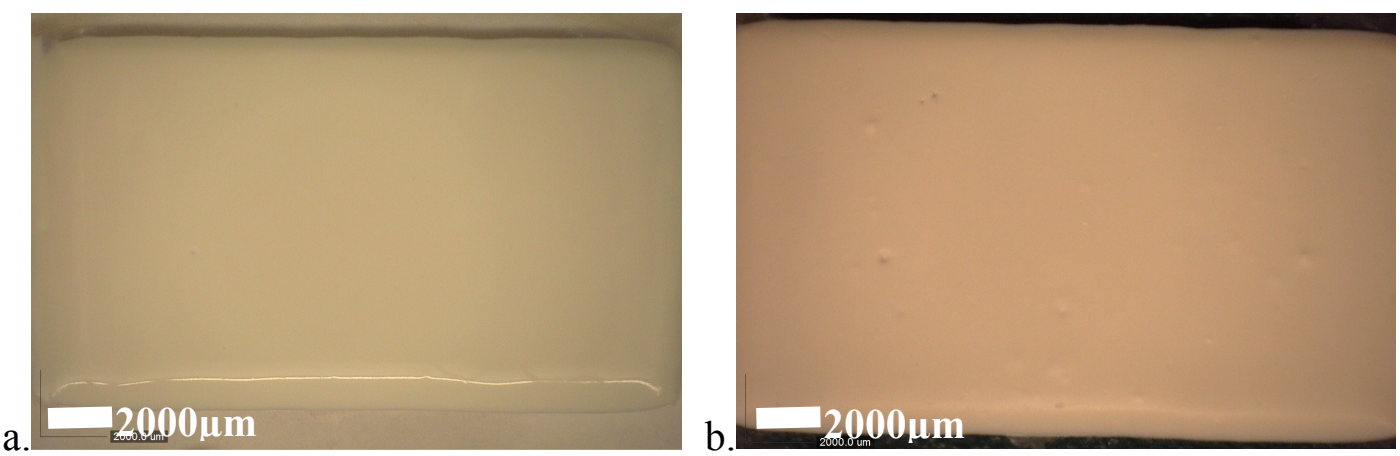

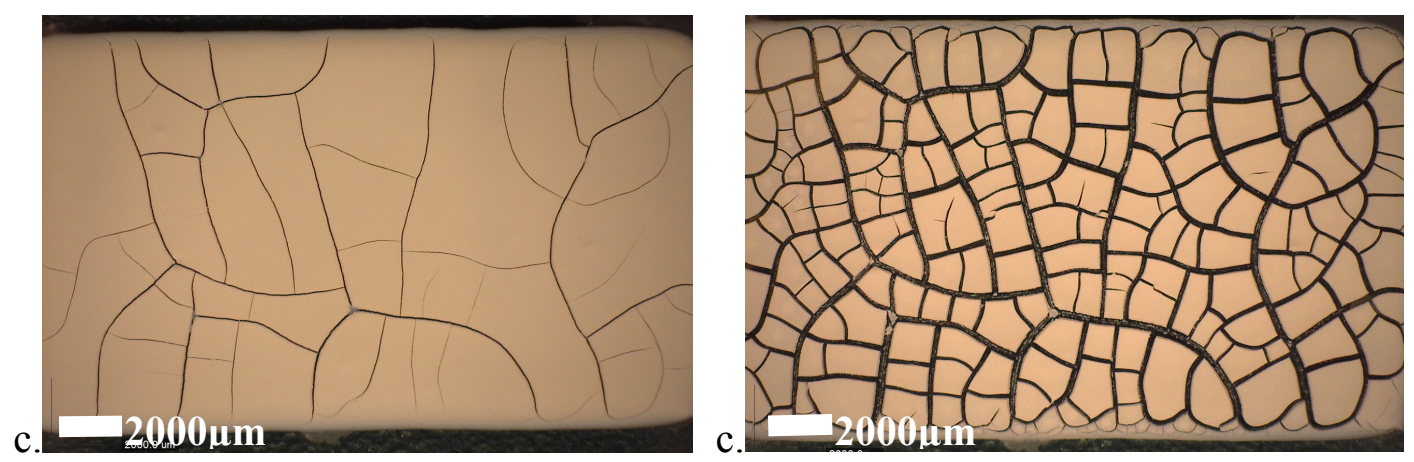

Figure 15: Crack propagation sequence of a Doctor blading sample air dry (500 $\mu$ m thickness, $25 \%$ particle concentration) Crack progression a) +5 mins b. +10 mins c) 180mins d) +300 mins. Direction of Doctor blading is top to bottom

a.

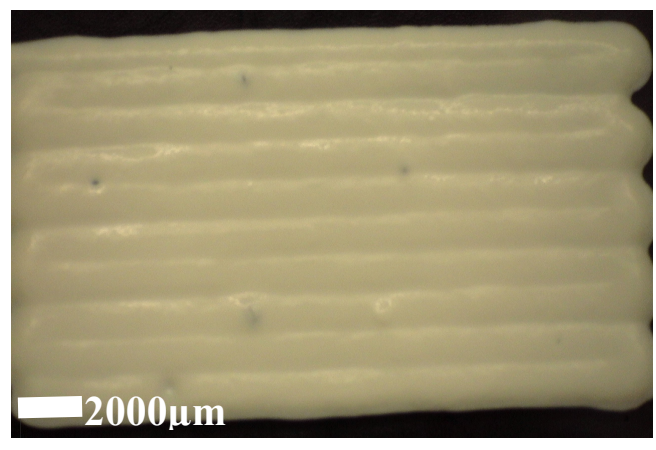

b.
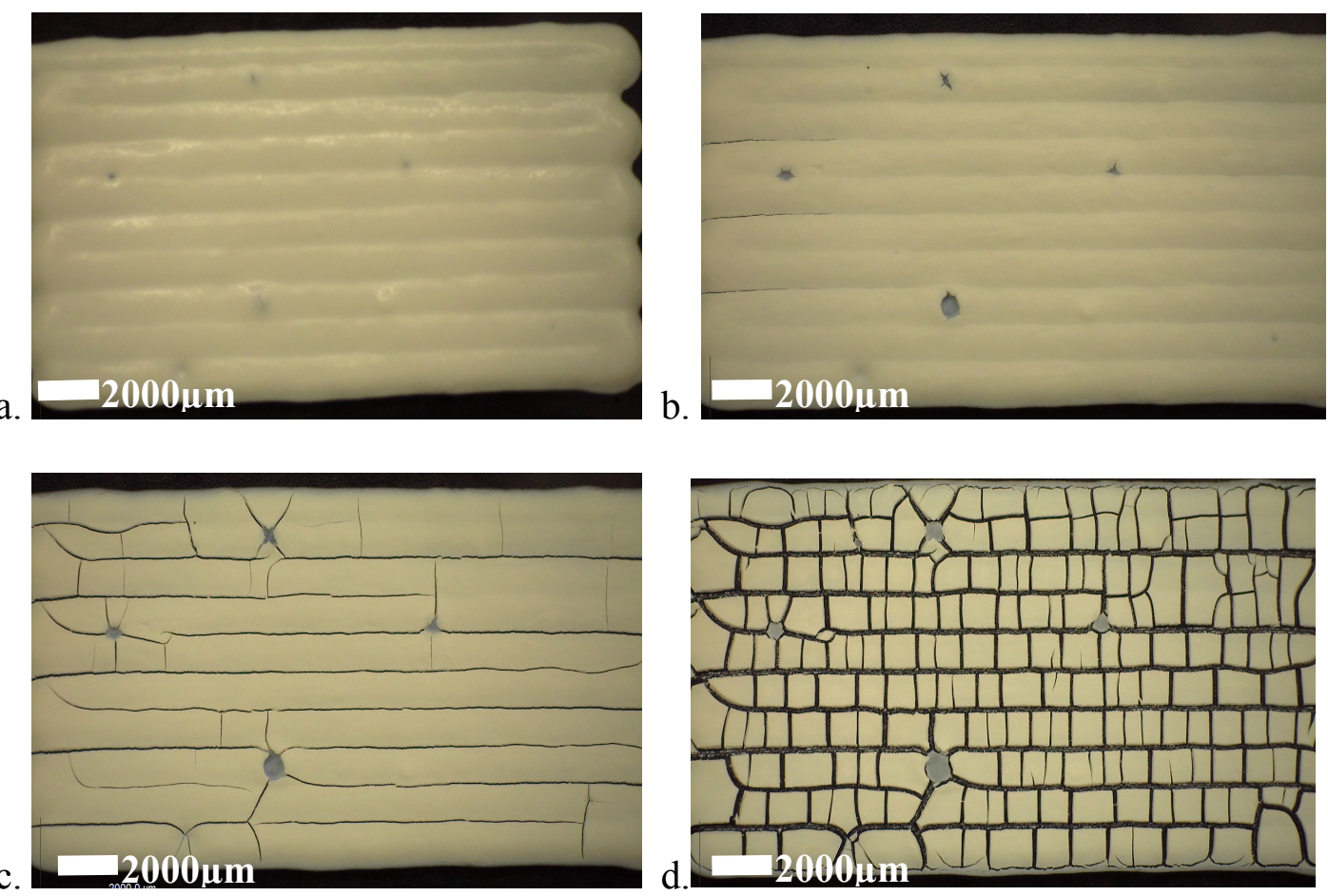

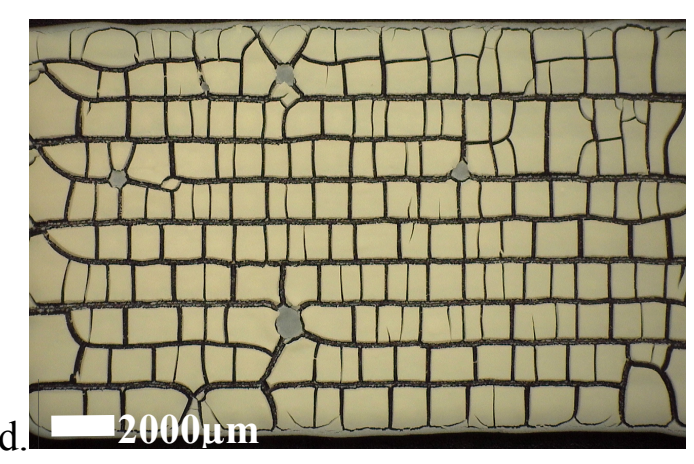

Figure 16: Crack Propagation sequence for a printed sample air dry (500 um film thickness, 25\% particle concentration) Crack Progression: a) +5mins b) +10 mins c) +90mins d) +200 mins. Direction of direct ink writing is a meander or snake pattern Printing Parameters: $500 \mu \mathrm{m}$ film thickness $(2.3 \mathrm{psi} \& 5 \mathrm{~mm} / \mathrm{s})$

Figures 15 and 16 demonstrate the formation of sequential cracks that progress into multiple cracks with increasing time. These images show the initiation and progression of cracks 
from when the film is first deposited onto the substrate, till final crack fragments have been formed.

\section{Memories of Paste}

It is established that colloidal pastes have memory of external mechanical fields such as flow and vibration. Therefore, we can compare the results from deposition of the colloidal ink using two different deposition methods, doctor-blading and printing. It was observed that both methods result in recognizable distinct memory that affect the crack pattern of the films. For printed samples, there is a clear uniaxial crack pattern that is formed and this crack pattern appears to be perpendicular to the direction of initial stress input seen in Figure 16 . The doctor bladed samples on the other hand produced random biaxial crack patterns seen in Figure 15. This observation is consistent with the theory of the Nakahara effect as the shear force from the broad surface of the doctor blade applicator leads to a large area of randomized cracks whereas the radially varying shear stress associated with the extrusion of the ink leaves a distinct pattern perpendicular to the direction of initial stress.

\section{Transition in pattern}

These experiments revealed a transition in the direction of lamellar(rectangular) cracks from perpendicular to more random or no cracks when compared with the direction of the initial stress input as the solid concentration of the paste is decreased. The water poor colloidal inks after printing and drying, a crack pattern appears to be perpendicular with the initial direction of shear. This is known as a Type-I memory. When the water-poor paste is sheared, inelastic collisions between particles produce longitudinal density fluctuation, and the network of particles is weakened in that direction, leading to stripe crack pattern perpendicular to the 
direction of the initial vibration. The pattern is of cellular structure, which means that the fragments are uniform in size and their arrangement is statistically homogeneous and isotropic. ${ }^{48}$ However, when the same experiments were carried out using the water rich colloidal inks, it was observed that the crack pattern does not follow a specific pattern and does not crack based on the memory of initial stress input. With this result, it is confirmed that only when the mixture is a water-poor visco-plastic paste with a nonzero yield stress, can the mixture remember the direction of the initial external stress input and the anisotropic crack patterns appear. ${ }^{49}$ Figure 17 compiles images obtained from the optical microscope for $500 \mu \mathrm{m}$ films. Films are deposited using the direct ink writing and doctor blading deposition methods and then dried using the three drying processes.

a.
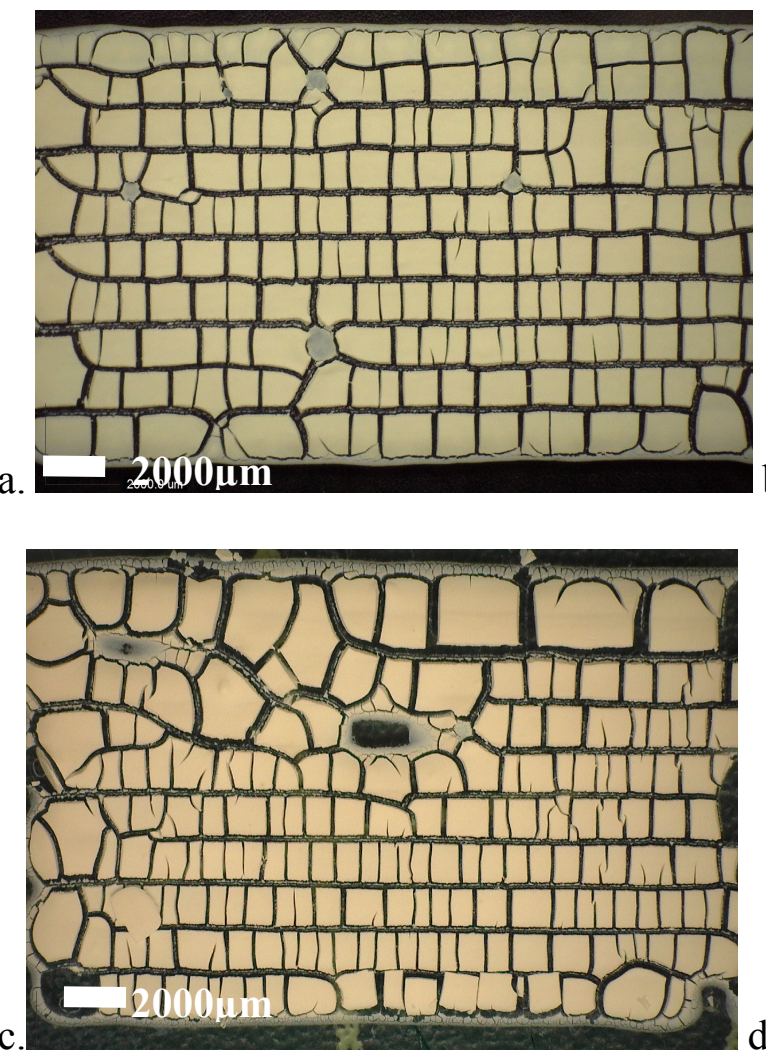
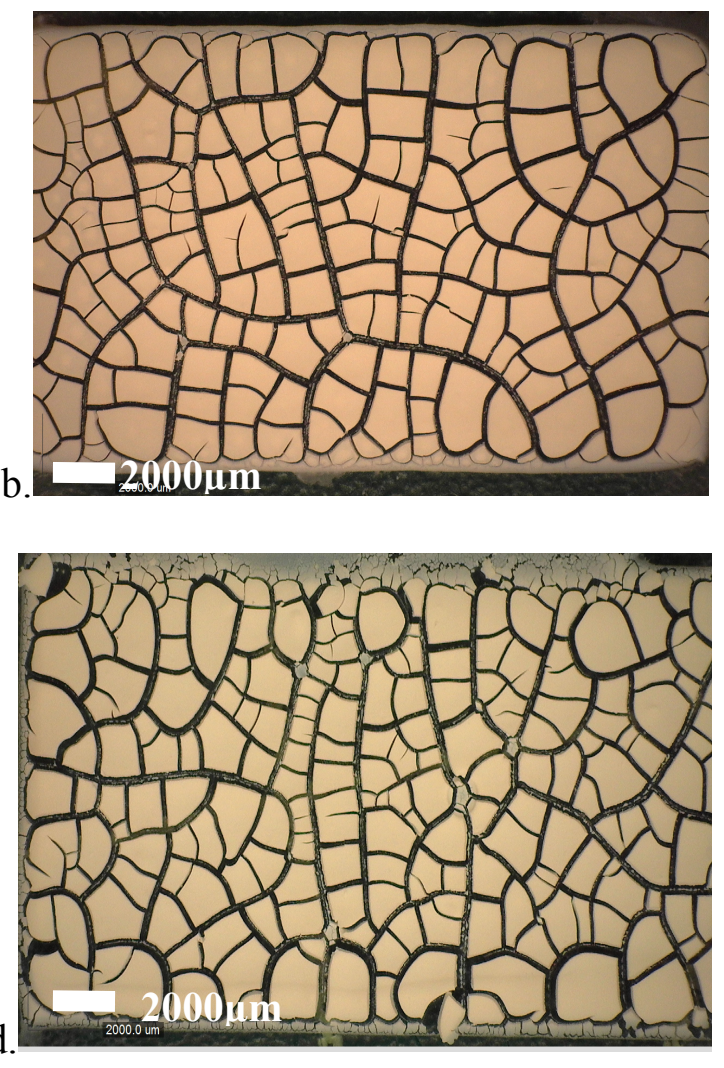

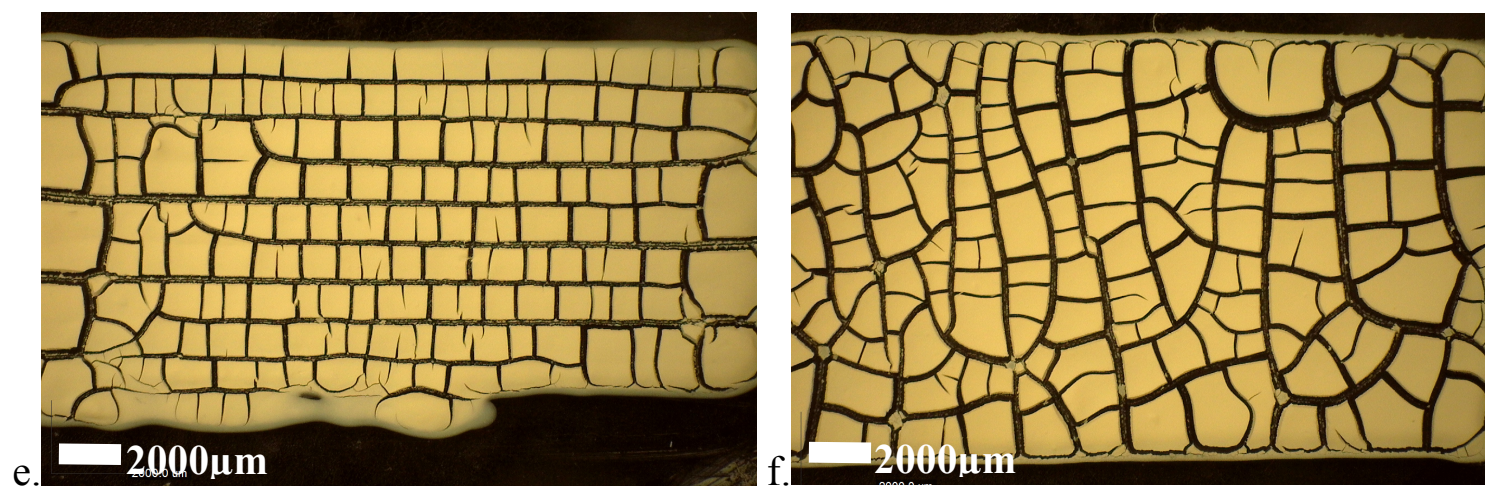

Figure 17 : Optical Microscope Images of $500 \mu \mathrm{m}$ film of 25\% $\mathrm{TiO}_{2}$ particle concentration

a) Print Air dry b) DB Air Dry c) Print oven dry d) DB oven dry e) Print vacuum dry f) DB vacuum dry. Doctor blading direction is from top to bottom. Direct ink writing direction is from left to right. Printing parameters: $500 \mu \mathrm{m}(2.3 \mathrm{psi} \& 5 \mathrm{~mm} / \mathrm{s})$

In figure 17, it can be observed the difference in pattern between the memory effect as the printed sample forms a uniaxial crack pattern perpendicular to the direction of extrusion. The cracks in the direction of extrusion is can be explained by the line by line deposition of the film. There tends to be less material in the regions of line spreading and as such it is observed first initial cracks in that direction. The doctor bladed films, on the other hand, form a biaxial crack pattern due the larger area of the applied shear. Since different drying processes are employed, it can also be observed that the method of drying does not have significant effect on the pattern of cracks. This suggest that thermal fluctuation does not destroy the network structure in the film due to strong particle particle interactions in a dense colloidal suspension hence memory effects are still present. It is also observed that the sintered films (oven dried) exhibit delamination (separation from the substrate) around the edges of the film as seen in Figures 17 (c) and 17 (d).

The histogram in Figure 18 describes the fragmentation behavior of the films for printed samples in terms of crack length for the three drying processes. Each fragment in the area of analysis is measured and displayed in terms of frequency. For the original data values which fall 
in a small interval, a bin (a central value representative of that interval) is used as a replacement in order to plot a histogram. The measured fragment length for printed air dried films range from $256 \mu \mathrm{m}$ to $2340 \mu \mathrm{m}$. The measured fragment length for printed oven dried films range from $583 \mu \mathrm{m}$ to 2816 um while the fragment size for the printed vacuum dried films range from $510 \mu \mathrm{m}$ to $2451 \mu \mathrm{m}$.

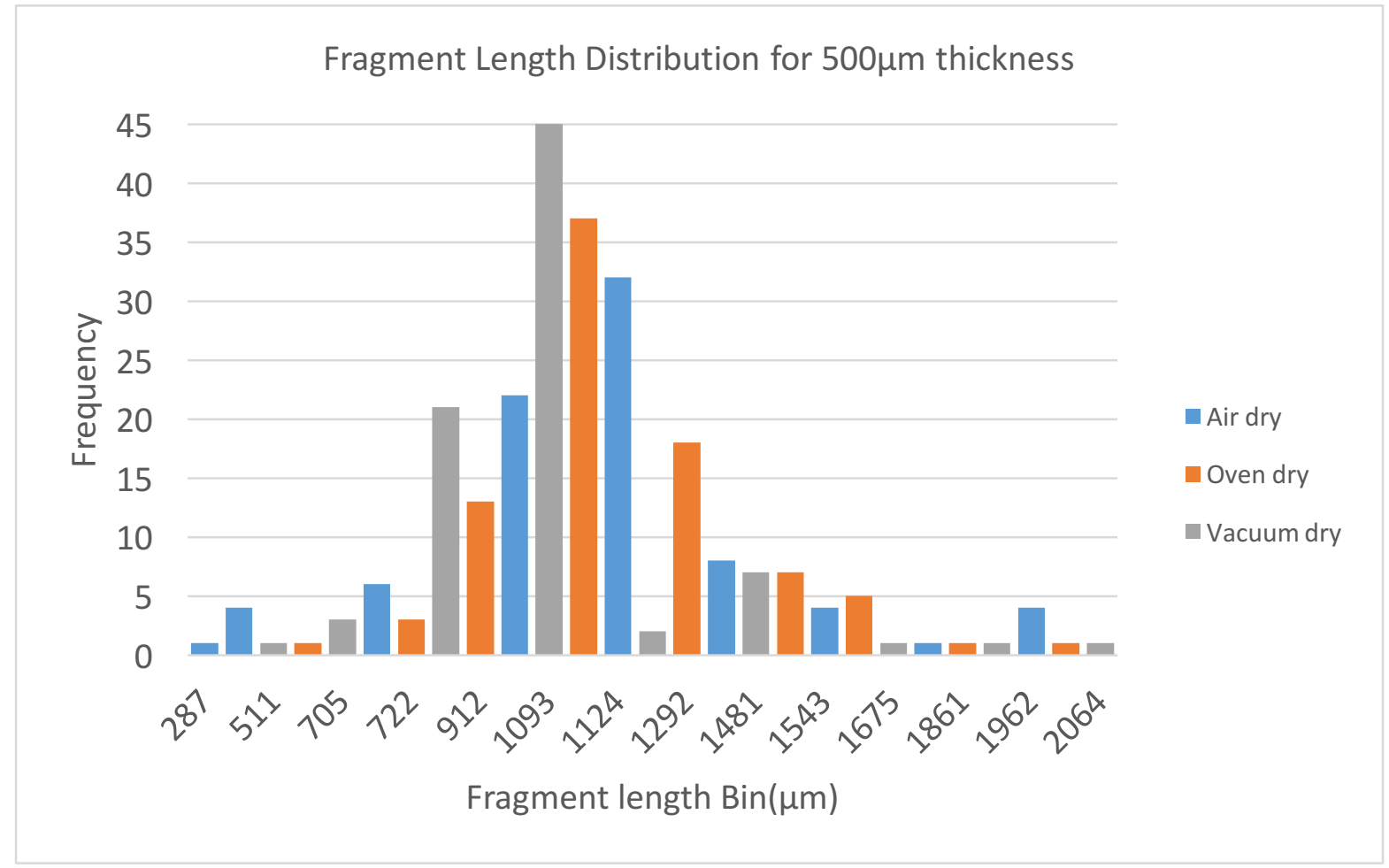

Figure 18:Frequency of crack fragment in terms of bins of $25 \% \mathrm{TiO}_{2}$ particle concentration $(500 \mu \mathrm{m})$ printed samples

The histogram in Figure 19 describes the fragmentation behavior of the films for doctor bladed samples in terms of crack length for the three drying processes. For the doctorbladed films, the measured fragment size range from $211 \mu \mathrm{m}$ to $2330 \mu \mathrm{m}, 298 \mu \mathrm{m}$ to $2400 \mu \mathrm{m}$ and $200 \mu \mathrm{m}$ to $2400 \mu \mathrm{m}$, respectively, for the air dried, oven dried and vacuum dried samples. In observing this histogram, it can be observed that the printed samples collectively in terms of bins show high frequencies between $912 \mu \mathrm{m}$ and $1292 \mu \mathrm{m}$, whereas the doctor bladed samples 
show an evenly distributed frequency between $532 \mu \mathrm{m}$ and $2051 \mu \mathrm{m}$. This demonstrates that the printed films crack in a more uniform manner than the doctor bladed samples as shown in Figure 17.

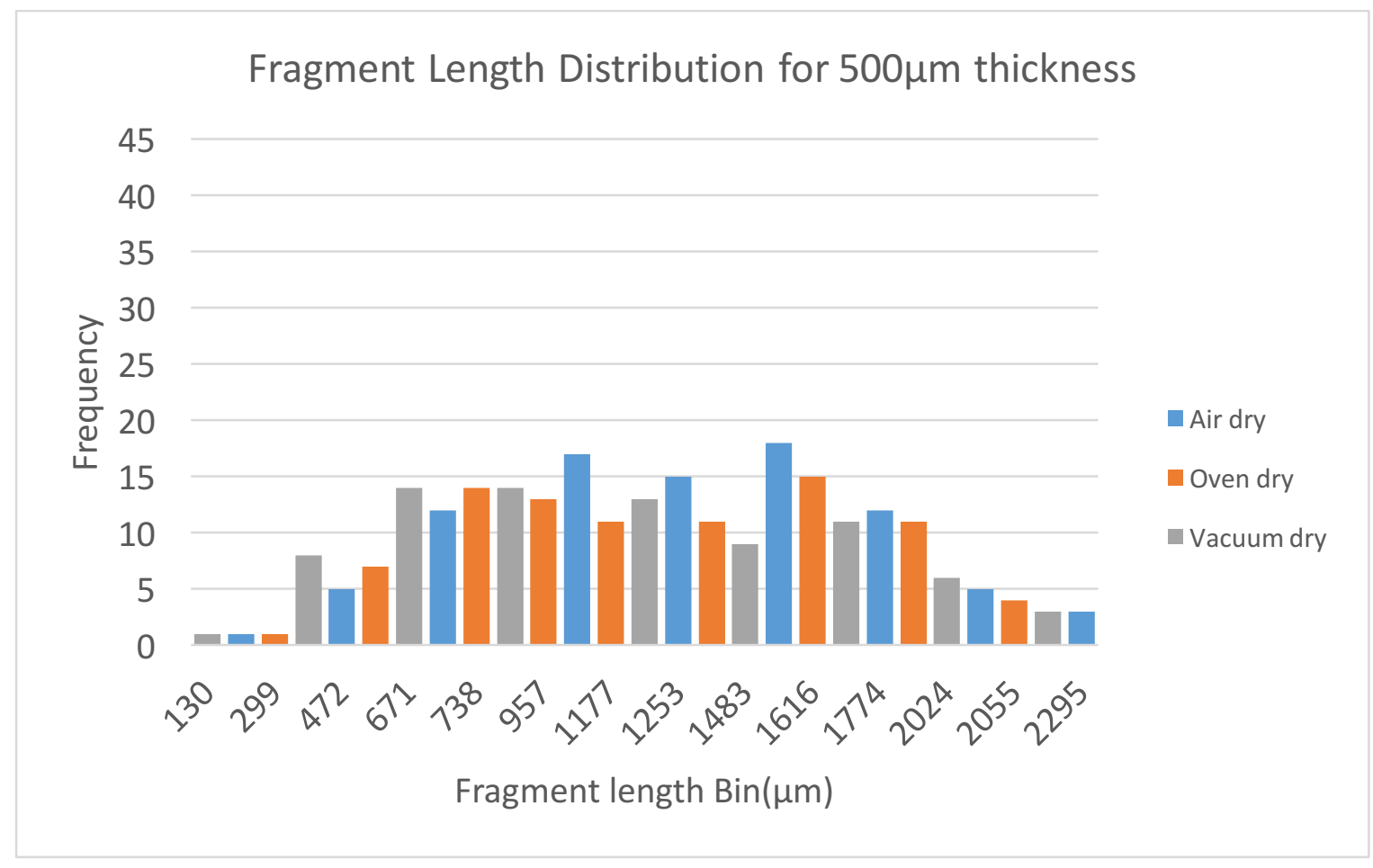

Figure 19 : Frequency of crack fragment in terms of bins of 25\% TiO2 particle concentration (500 $\mathrm{mm})$ doctor bladed samples

From Figure 20, It can be observed that fragment length is thickness dependent as fragment lengths are significantly reduced when compared to fragment lengths of $500 \mu \mathrm{m}$ thickness films. For the $250 \mu \mathrm{m}$ doctorbladed films, the measured fragment length ranges from $250 \mu \mathrm{m}$ to $1700 \mu \mathrm{m}, 250 \mu \mathrm{m}$ to $1780 \mu \mathrm{m}$ respectively for the air dried and oven dried films. For the $500 \mu \mathrm{m}$ films, the measured fragment length ranges from $220 \mu \mathrm{m}$ to $2330 \mu \mathrm{m}$ and $298 \mu \mathrm{m}$ to $2400 \mu \mathrm{m}$. 

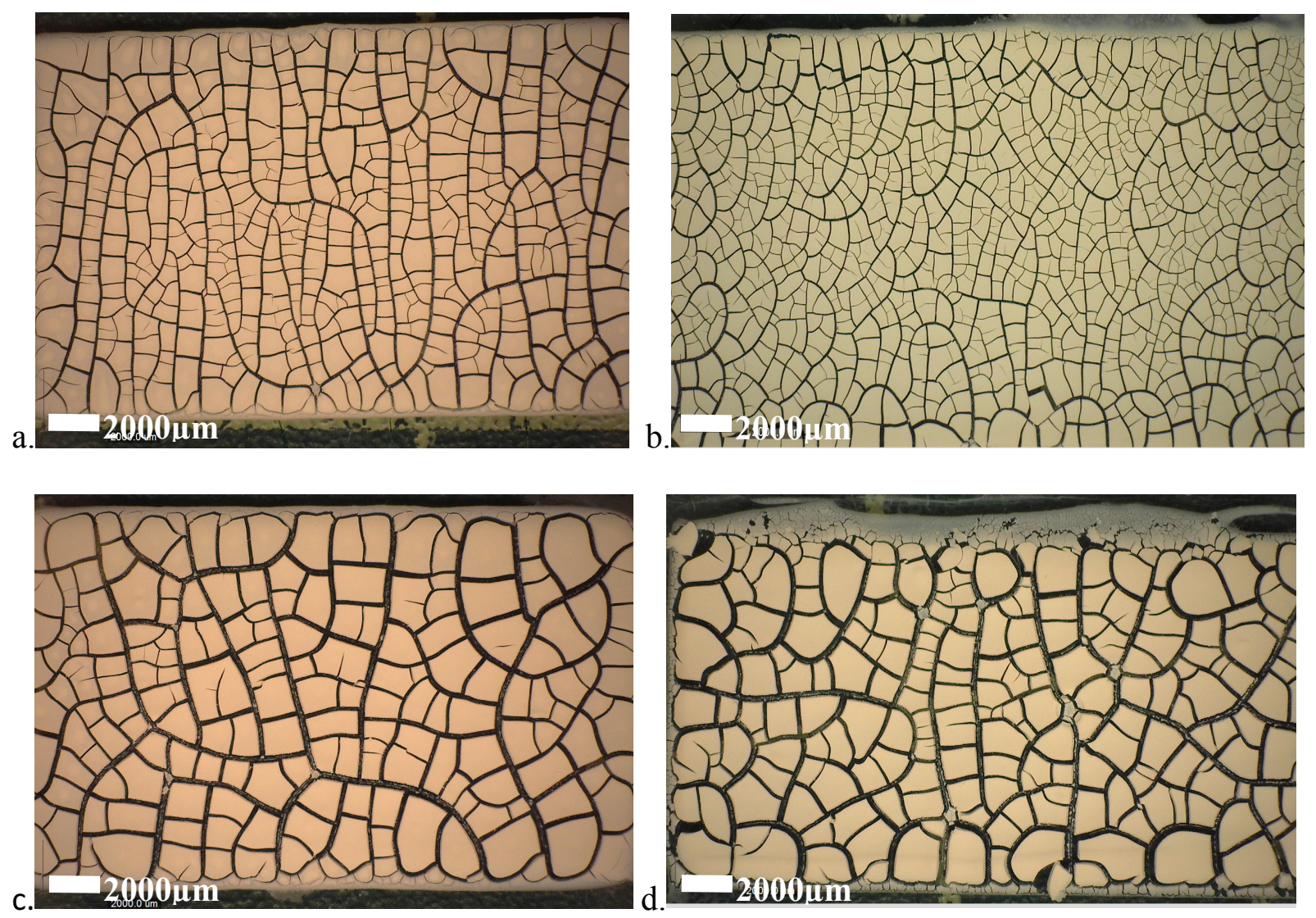

Figure 20: Comparison of different film thickness (250 $\mu \mathrm{m}$ vs $500 \mu \mathrm{m}$ doctor bladed)

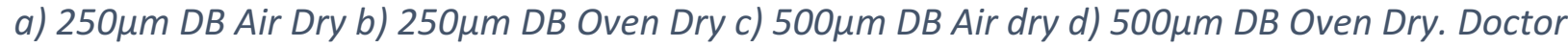
blading direction is from top to bottom

The frequency distribution of fragment lengths for the two thicknesses $(250 \mu \mathrm{m}$ and $500 \mu \mathrm{m})$ is shown in Figure 21. This is is illustrated for air dried samples. It is observed that the $500 \mu \mathrm{m}$ film thickness results in a generally higher fragment length compared to the $250 \mu \mathrm{m}$ thickness for the air dried process. 


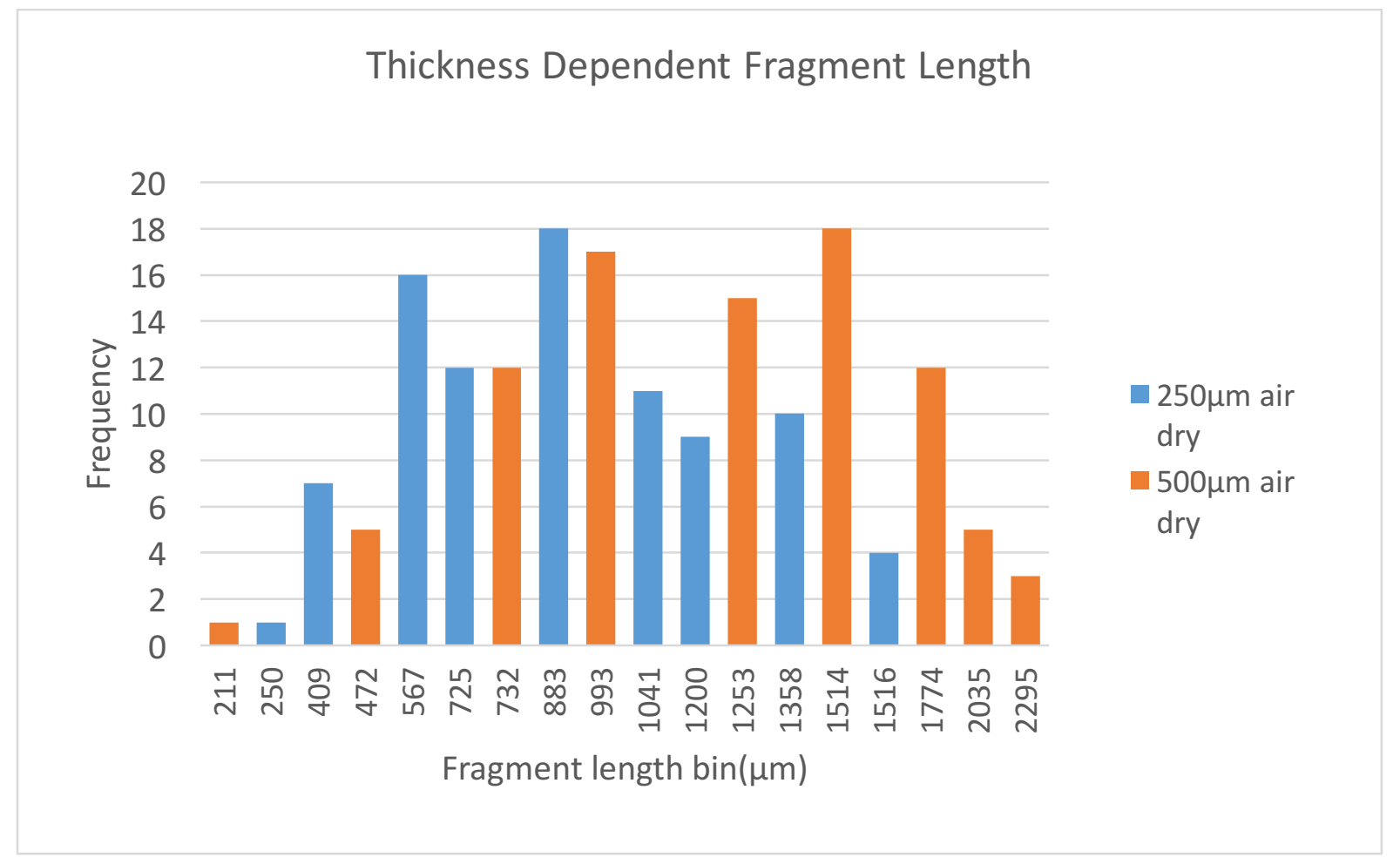

Figure 21:Thickness dependent fragment length for 250 um vs $500 \mu \mathrm{m}$ doctor bladed air dry

Figure 22 illustrates the fragment length frequency distribution for two oven dried doctor bladed samples at $250 \mu \mathrm{m}$ and $500 \mu \mathrm{m}$ thicknesses. It is observed that the $500 \mu \mathrm{m}$ film thickness results in a generally higher fragment length compared to the $250 \mu \mathrm{m}$ thickness for the oven dried process. The frequency distribution shown in Figure 23 indicates that the $500 \mu \mathrm{m}$ thick films, even though still spread across, fragment lengths are in the higher range of values compared to the $250 \mu \mathrm{m}$ thickness. From the statistical information it is confirmed that for $500 \mu \mathrm{m}$ thickness over $65 \%$ of the values are above $900 \mu \mathrm{m}$ whereas for the $250 \mu \mathrm{m}$ thickness over $65 \%$ are under $900 \mu \mathrm{m}$. 


\section{Thickness Dependent Fragment Length}

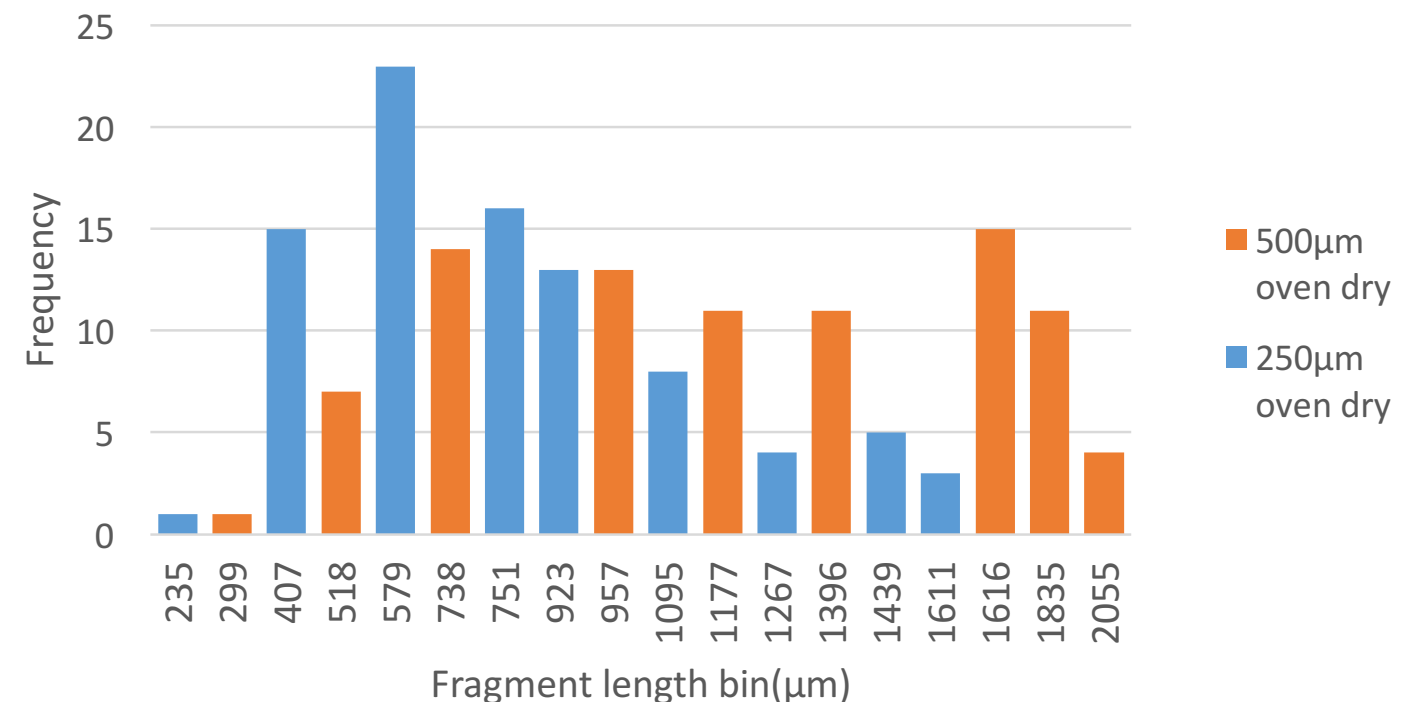

Figure 22: Thickness dependent fragment length for $250 \mu \mathrm{m}$ vs $500 \mu \mathrm{m}$ doctor bladed oven dry

The optical images in Figure 23 illustrate the difference in crack fragment length for the two different thicknesses $(500 \mu \mathrm{m}$ and $900 \mu \mathrm{m})$ of doctor bladed air dried specimens being compared.
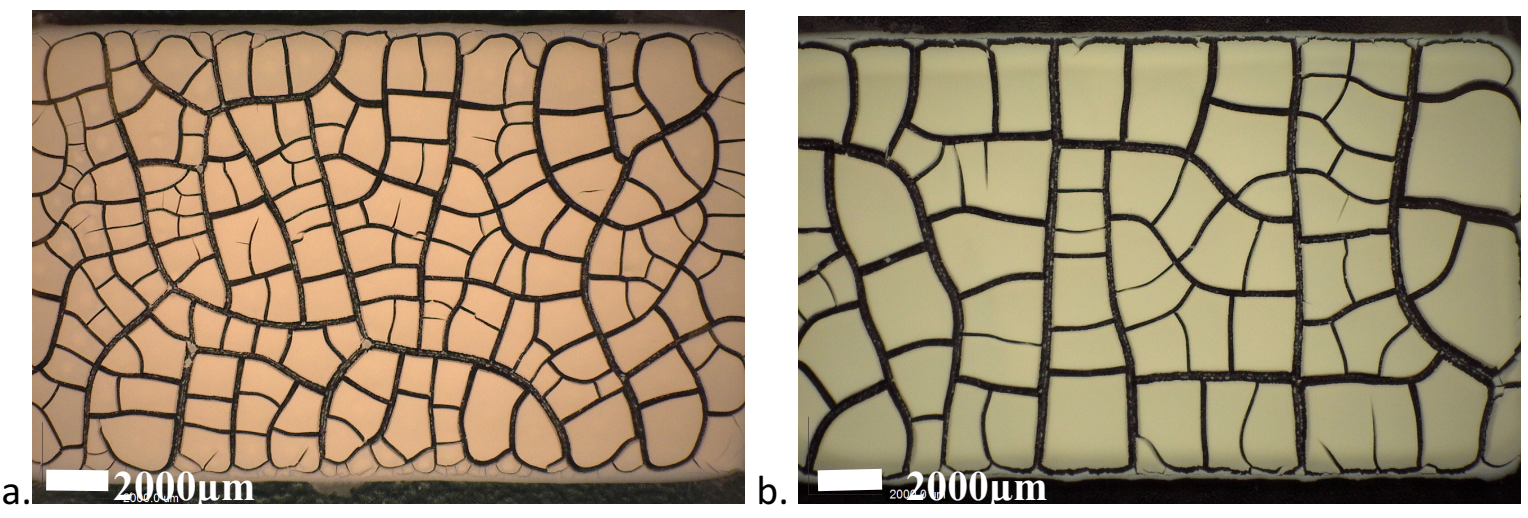

Figure 23:Optical Image of a) 500 $\mu \mathrm{m} D B$ vs b) $900 \mu \mathrm{m}$ doctor bladed air dried samples Direction of doctor blading is from top to bottom.

The histogram in Figure 24 illustrates that fragment length thickness for $900 \mu \mathrm{m}$ are more frequent above $1578 \mu \mathrm{m}$ while $500 \mu \mathrm{m}$ are more frequent under $1514 \mu \mathrm{m}$ thus further 
suggesting that crack fragment length increases with increasing thickness for doctor bladed samples. The scale on the left corresponds to the $250 \mu \mathrm{m}$ thickness while the scale on the right corresponds to $500 \mu \mathrm{m}$ thickness.

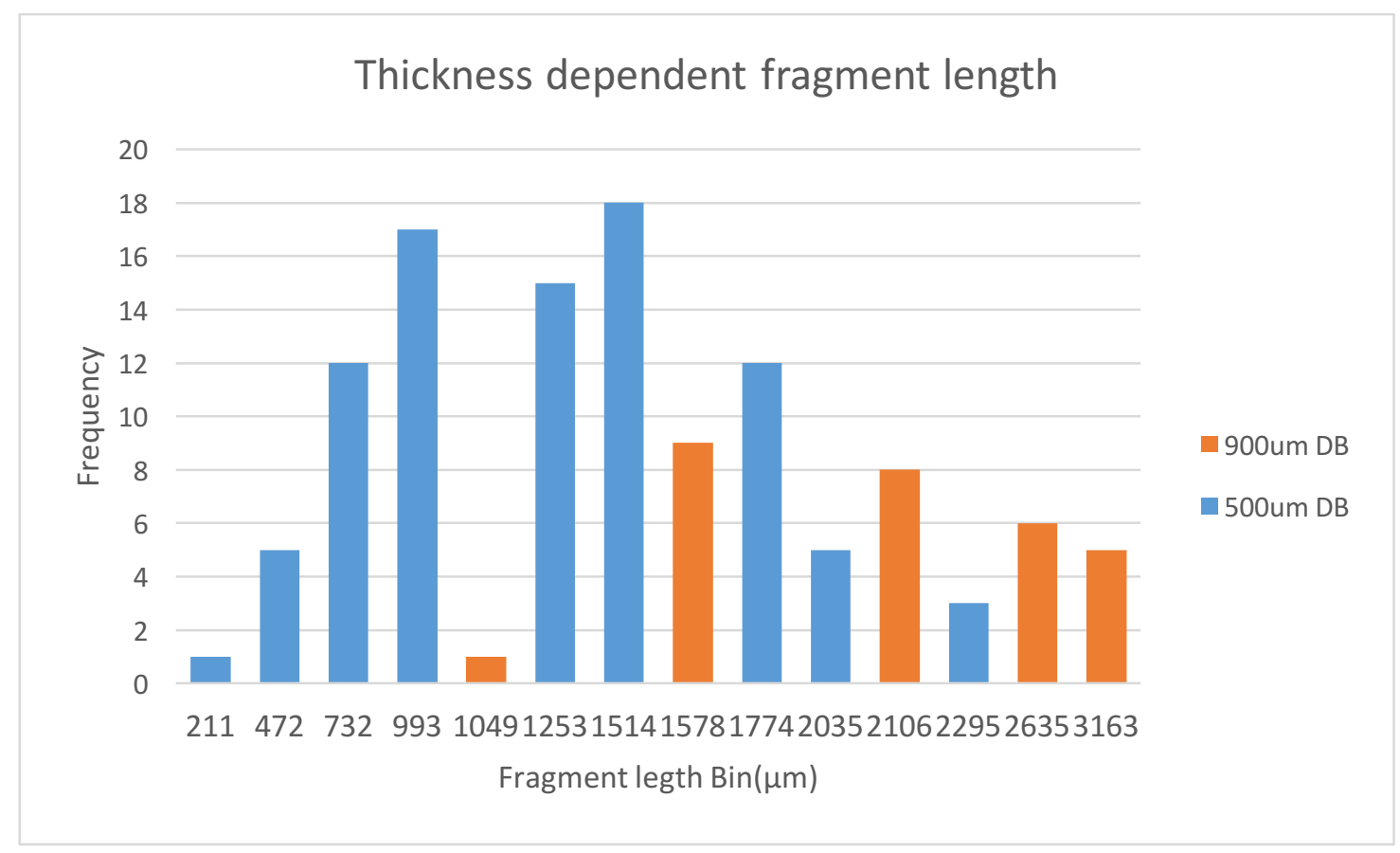

Figure 24:Thickness dependent fragment length for $500 \mu \mathrm{m}$ vs $900 \mu \mathrm{m}$ doctor bladed

The optical images in Figure 25 illustrate difference in measured fragment length for different thicknesses $(250 \mu \mathrm{m}$ vs $500 \mu \mathrm{m})$ for printed air dried specimens.

a.

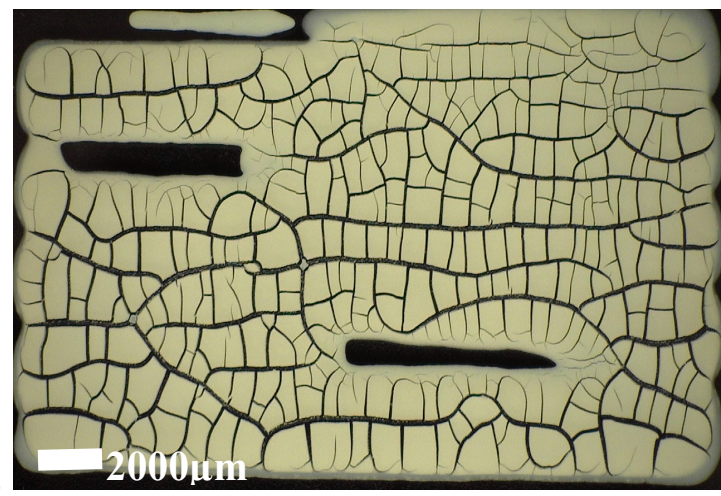

b.

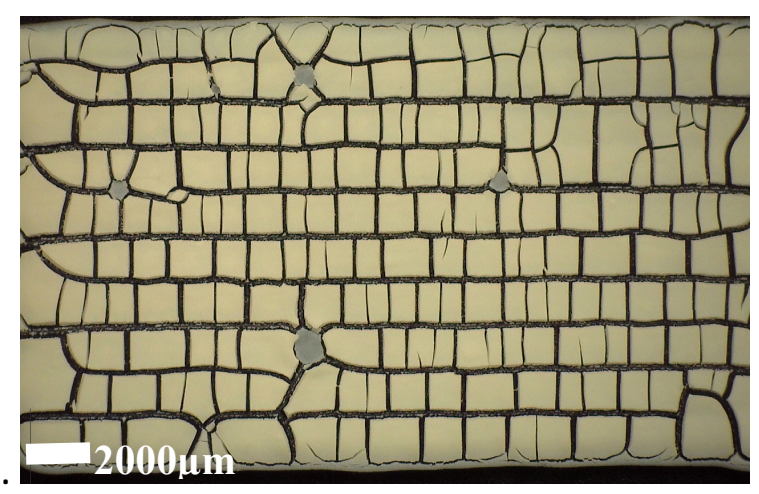

Figure 25:Optical Image of a)250 $\mathrm{mm}$ b) $500 \mu \mathrm{m}$ Print Air dried specimens Printing parameters: $250 \mu \mathrm{m}(2.1 \mathrm{psi} \& 8 \mathrm{~mm} / \mathrm{s}) 500 \mu \mathrm{m}(2.3 \mathrm{psi} \& 5 \mathrm{~mm} / \mathrm{s})$ 
The histogram in Figure 26 shows that $250 \mu \mathrm{m}$ compared to $500 \mu \mathrm{m}$ thickness results in smaller measured fragment lengths. Image analysis results show that fragment size ranges from $114 \mu \mathrm{m}$ to $854 \mu \mathrm{m}$ for $250 \mu \mathrm{m}$ thickness and ranges from $287 \mu \mathrm{m}$ to $1962 \mu \mathrm{m}$ for $500 \mu \mathrm{m}$ thickness.

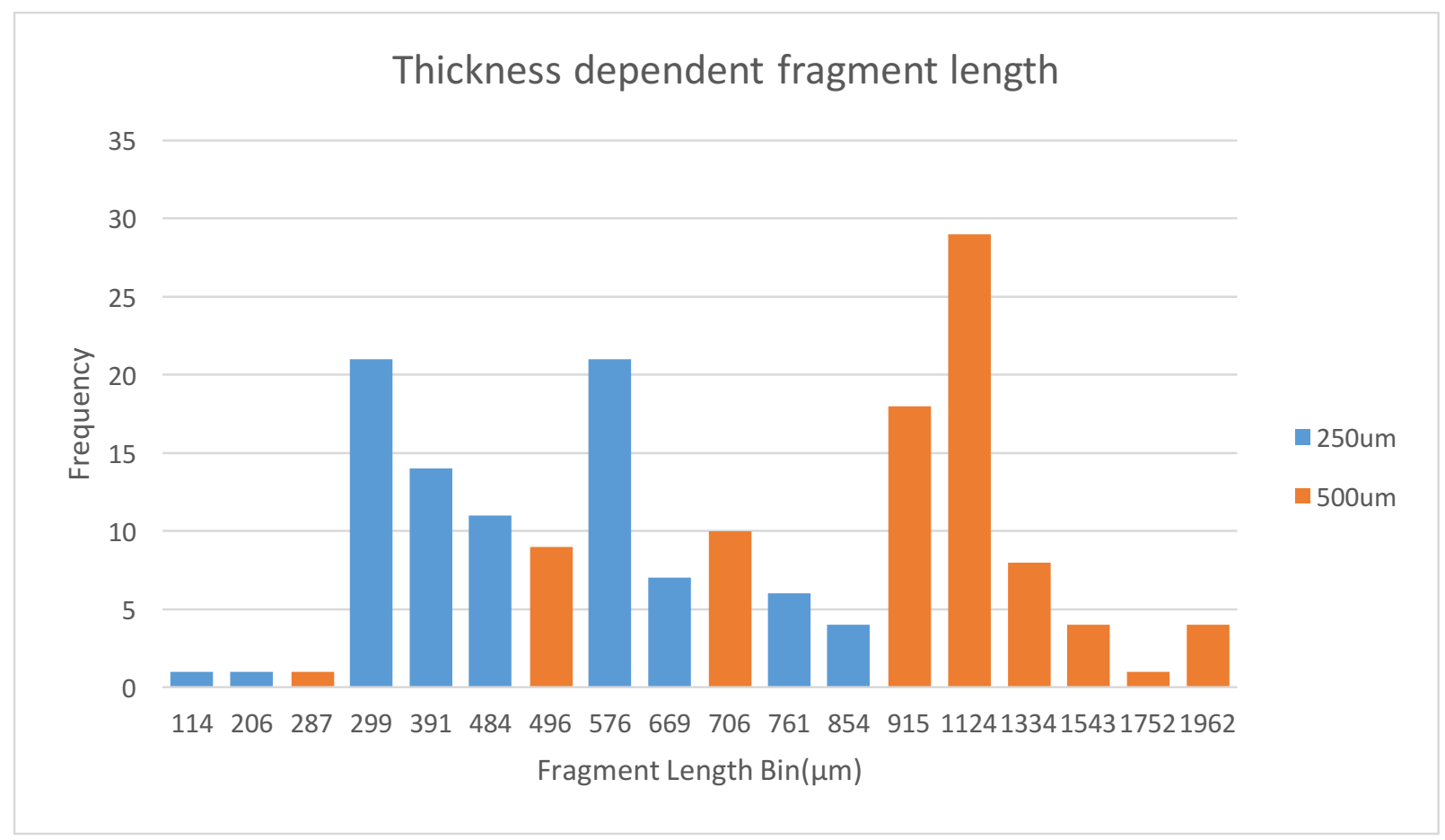

Figure 26:Thickness dependent fragment length for $250 \mu \mathrm{m}$ vs $500 \mu \mathrm{m} D B$

The optical images in Figure 27 illustrate difference in measured fragment length for different thicknesses $(500 \mu \mathrm{m}$ vs $900 \mu \mathrm{m})$ for printed air dried specimens.
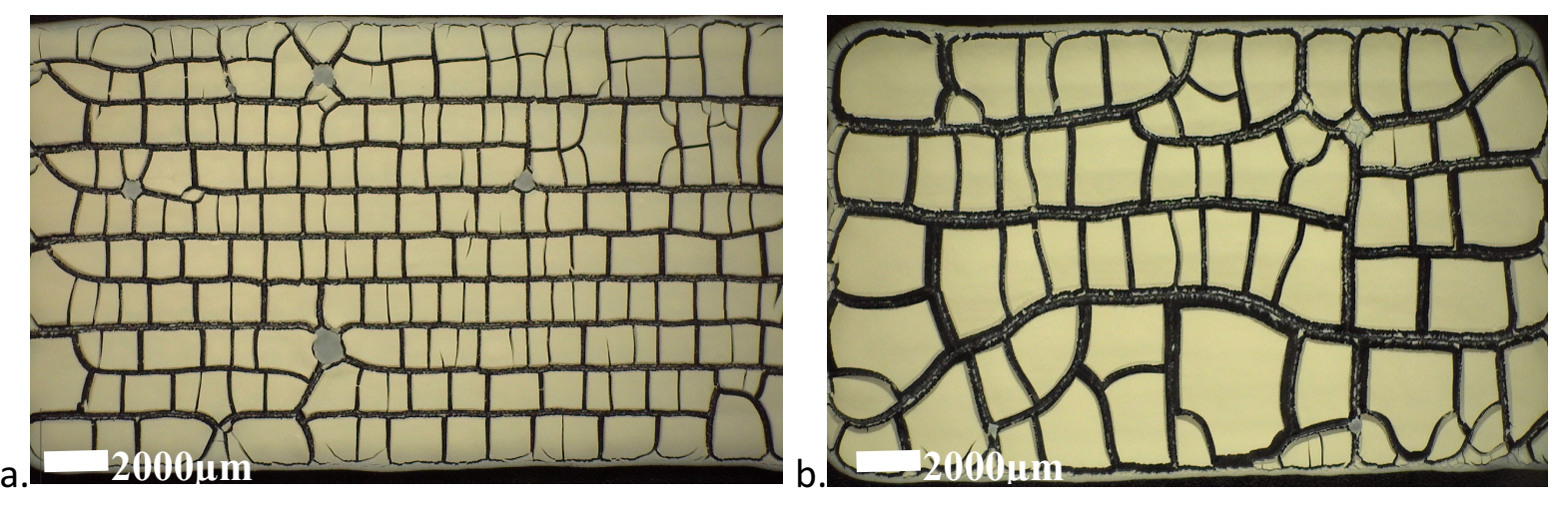

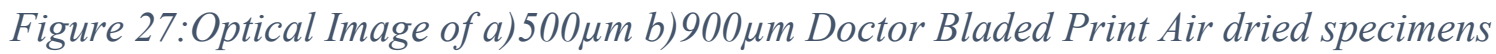
Printing parameters: $500 \mu \mathrm{m}(2.3 \mathrm{psi} \& 5 \mathrm{~mm} / \mathrm{s}) 900 \mu \mathrm{m}(2.6 \mathrm{psi} \& 3 \mathrm{~mm} / \mathrm{s})$ 
The histogram in Figure 28 illustrates that $500 \mu \mathrm{m}$ compared to $900 \mu \mathrm{m}$ thickness results in a smaller fragment length. Image analysis results show that fragment size ranges from $287 \mu \mathrm{m}$ to $1962 \mu \mathrm{m}$ for $500 \mu \mathrm{m}$ thickness and ranges from $923 \mu \mathrm{m}$ to $3132 \mu \mathrm{m}$ for $900 \mu \mathrm{m}$ thickness.

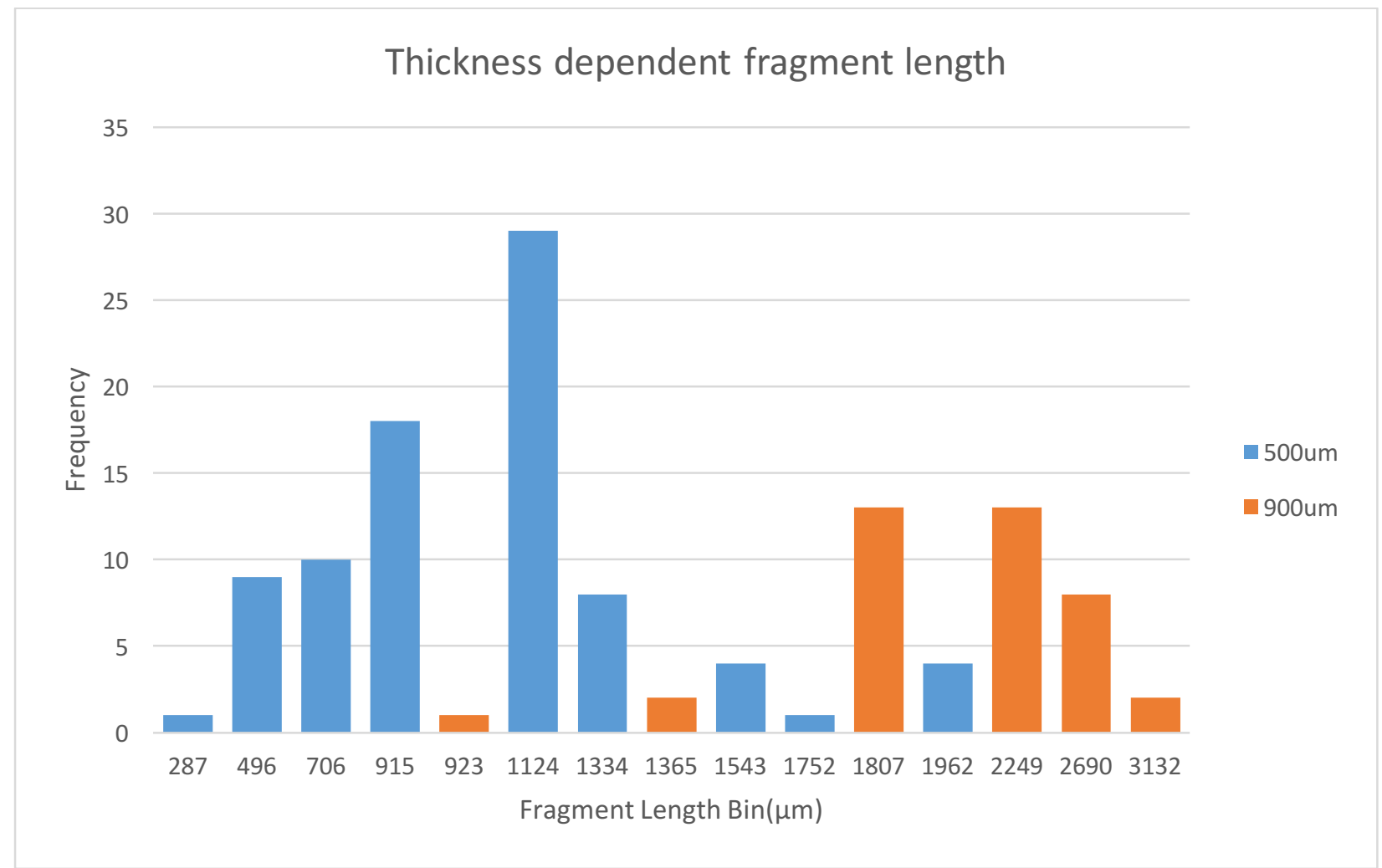

Figure 28:Thickness dependent fragment length for 500um vs 900um Air Dry Printed specimens

Figure 29 compares crack fragment lengths of doctorbladed and printed samples at $600 \mu \mathrm{m}$. The results from this reaffirm the suggestions made from the previous observations. A uniaxial crack pattern perpendicular to the direction of extrusion is present in the printed samples and a randomized crack pattern for the doctorbladed samples. 

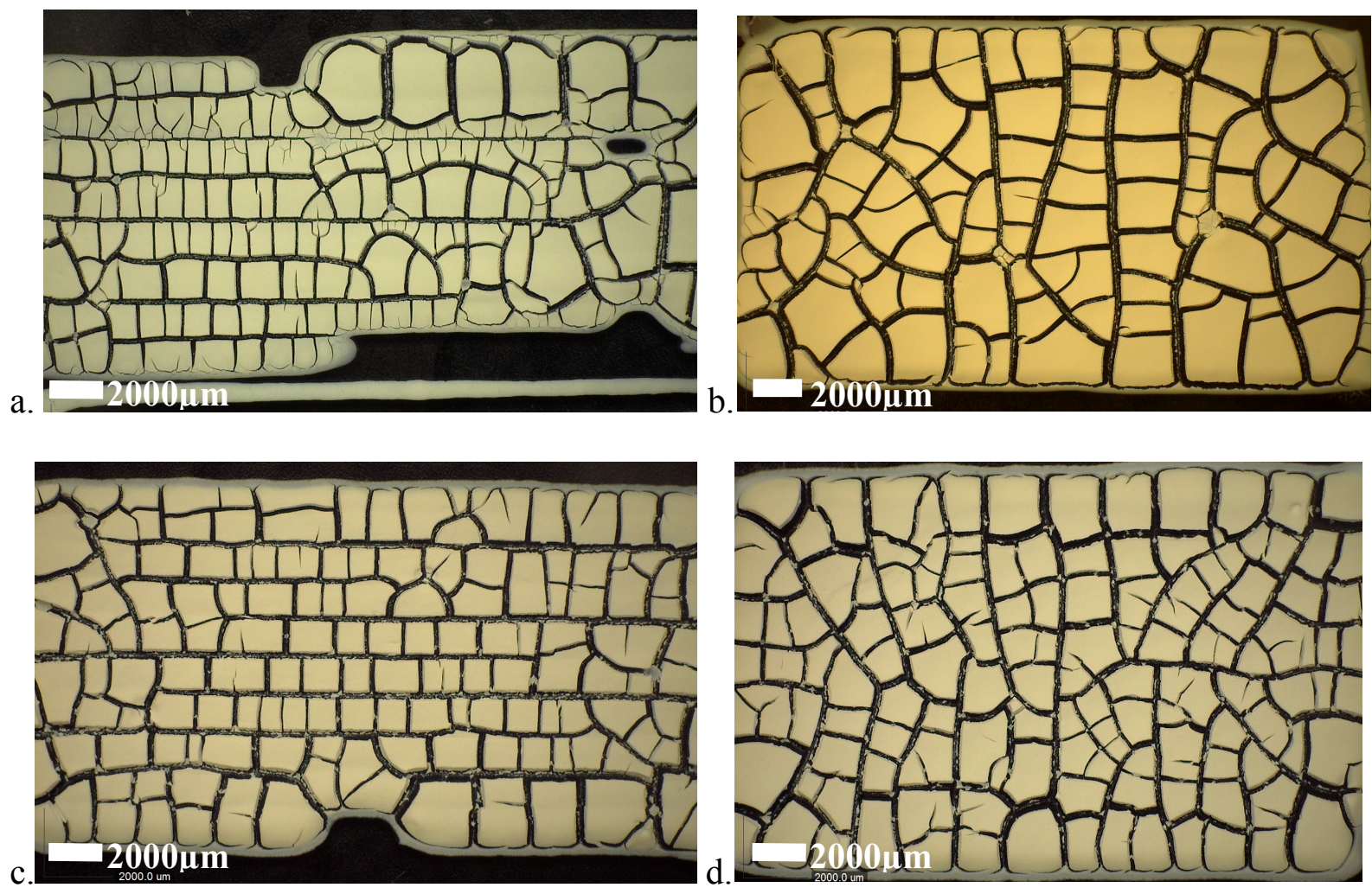

Figure 29:Optical Microscope Images of XG 0.4\% and 25\% $\mathrm{TiO}_{2}$ particles $(600 \mu \mathrm{m})$ thickness for doctor bladed and printed specimens

a) Print Air Dry b) DB Air Dry c) Print Vacuum Oven dry d) DB Vacuum Oven Dry. Printing Parameters: $600 \mu \mathrm{m}(2.4 \mathrm{psi} \& 5 \mathrm{~mm} / \mathrm{s})$

The fragment size for printed air dried films range from $400 \mu \mathrm{m}$ to $2000 \mu \mathrm{m}$. The

fragment size for printed vacuum oven dried films range from $400 \mu \mathrm{m}$ to $2100 \mu \mathrm{m}$. For the doctorbladed films, the fragment size range from $300 \mu \mathrm{m}$ to $2500 \mu \mathrm{m}, 350 \mu \mathrm{m}$ to $2200 \mu \mathrm{m}$ respectively for the air dried, oven dried films.

Influence of varying $\mathrm{TiO}_{2}$ concentration

\section{Increasing Particle Concentration}

In order to explore the effects, the particle concentration is first varied by increasing from $25 \%$ to $33 \%$ by weight. From further experiments, it can be concluded that it is ideal to keep particle volume concentration below $33 \%$ as this allows for printability of the ink. Another reason is that, above a concentration of $33 \%$, the particles are not able to mix homogenuously 
in solution. It is observed that the printed samples result in a crack pattern which is perpendicular to the direction of initial external vibration whiles the doctorbladed samples result in a biaxial crack pattern. The optical images in Figures 30 and 31 demonstrate similar crack pattern for films with $25 \%$ volume particle concentration as such it can be suggested that the Nakahara effect is still seen in films with a higher concentration of primary $\mathrm{TiO}_{2}$ particles.

a.
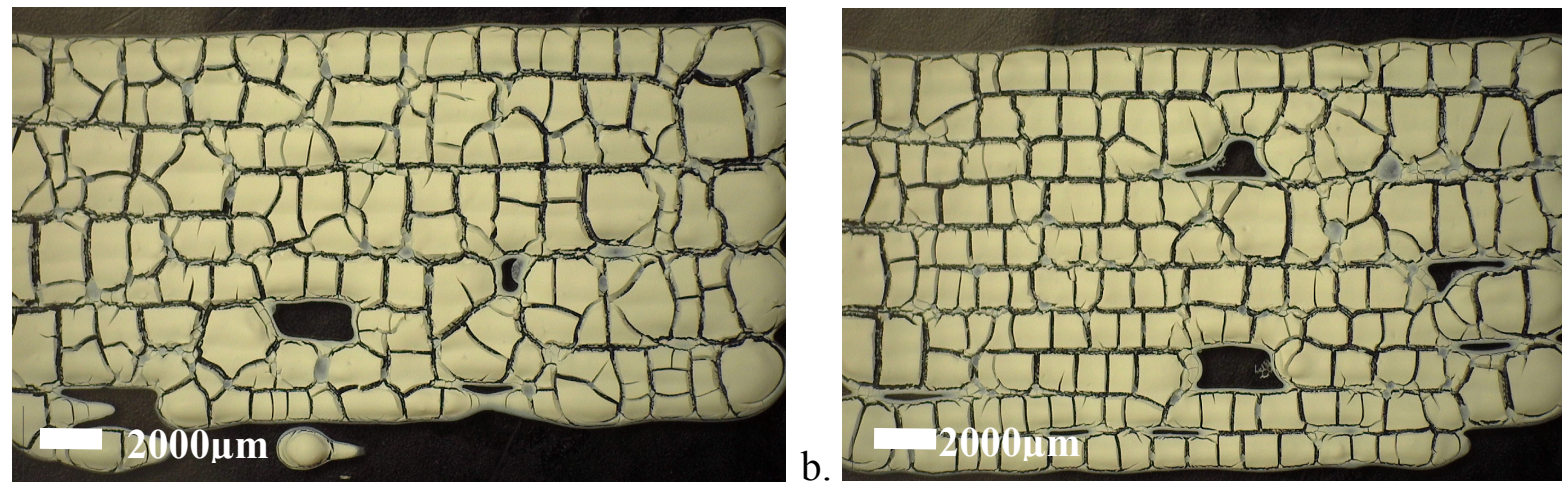

Figure 30:Optical Microscope Images of $\mathrm{DIW} 33 \% \mathrm{TiO}_{2}$ particle concentrations

a) $500 \mu \mathrm{m}$ print air dry b) $500 \mu \mathrm{m}$ print vacuum dry Print direction is in a snake or meander pattern. Print paramters: $500 \mu \mathrm{m}(1.3 \mathrm{psi} \& 8 \mathrm{~mm} / \mathrm{s})$
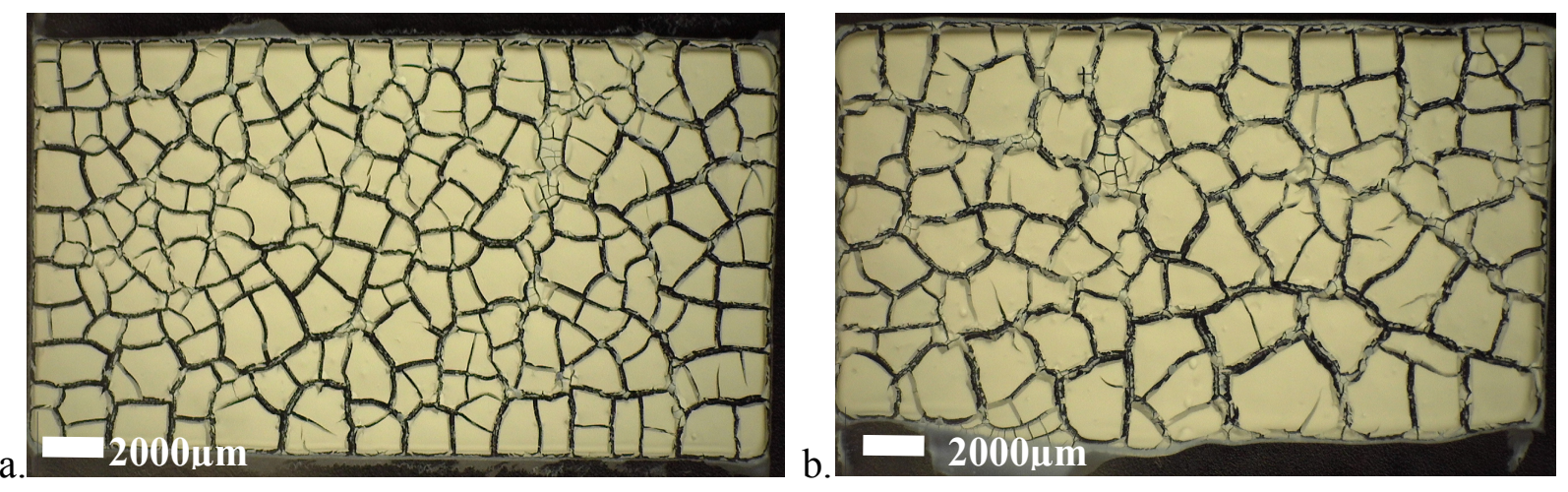

Figure 31: Optical images for doctor bladed samples of 33\% particle concentration a) air dry b) oven dry c) vacuum dry. Direction of doctor blading is from top to bottom

\section{Decreasing Particle Concentration}

After the effects of increasing particle concetration have been observed, particle concentration is now decreased to also observe the effects on the fragmentation behavior of 
the films. From the optical images in Figure 32 illustrates the results of crack patterns in films for $18 \%$ primary particle concentration. It is observed that no specific crack pattern is formed and memory effects are eliminated due to the high water content in the inks.

a.
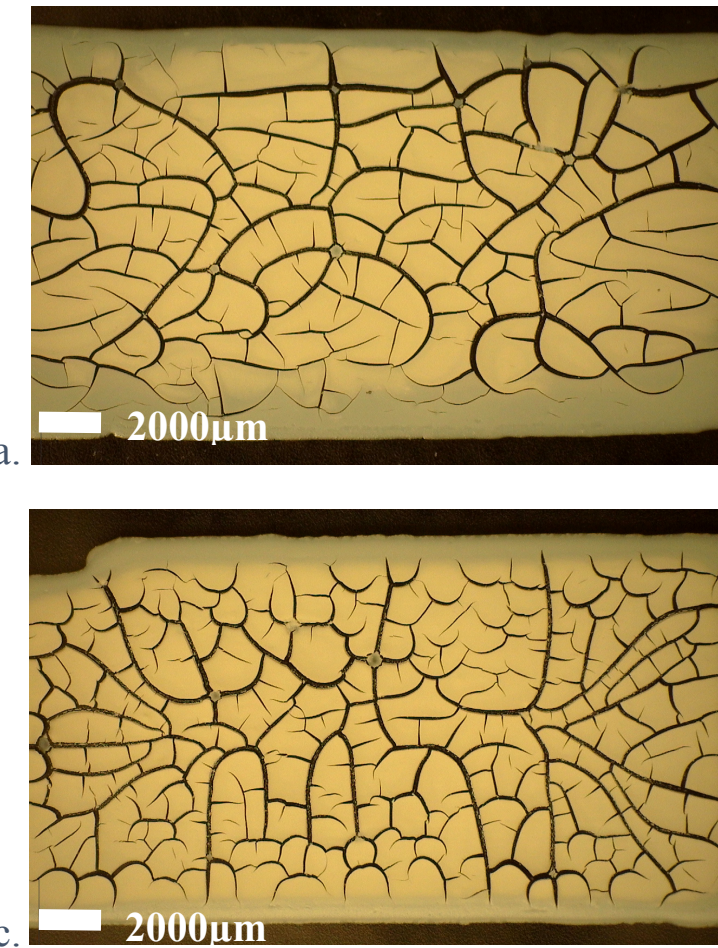

c. $2000 \mathrm{um}$

e.

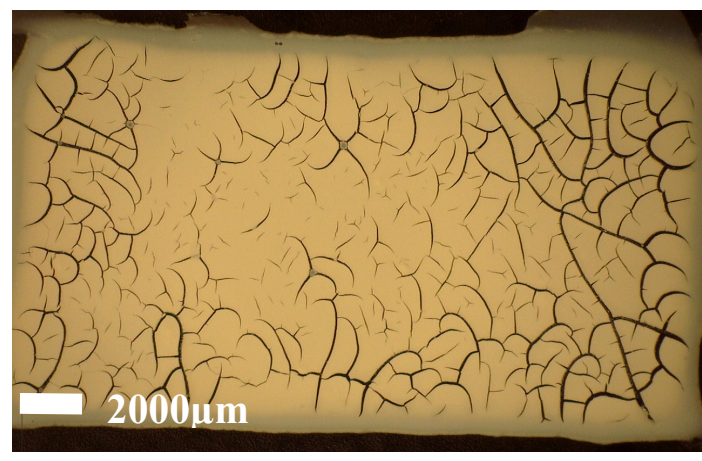

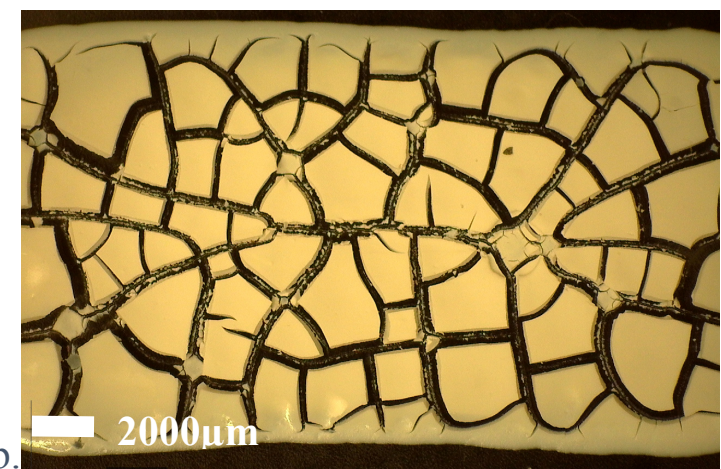

b.

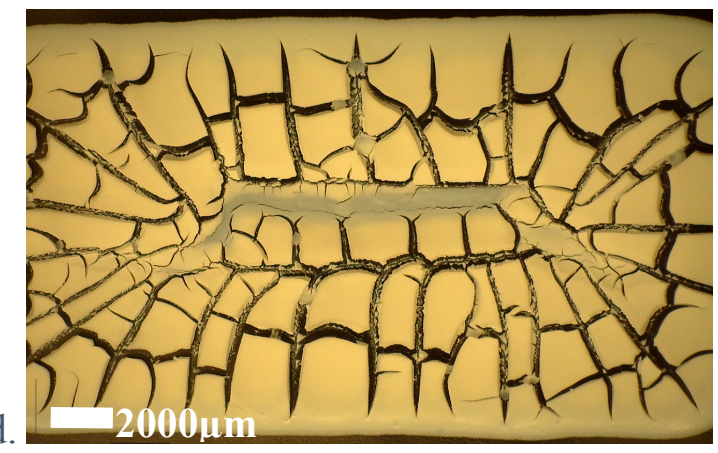

f.

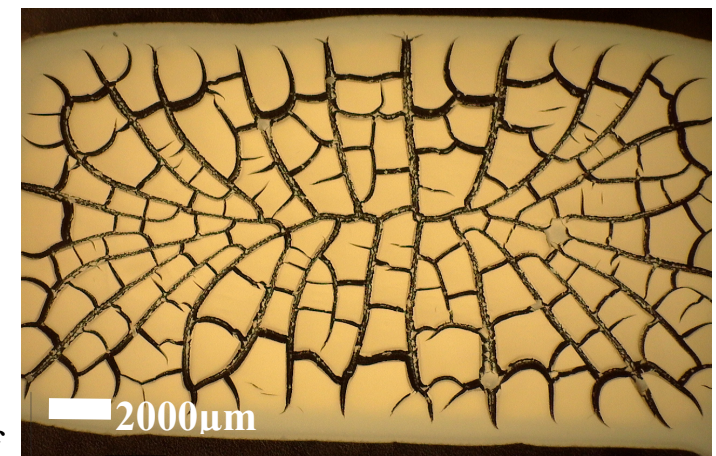

Figure 32:Optical Microscope Images of 18\% $\mathrm{TiO}_{2}$ particle concentration specimens a) $500 \mu \mathrm{m}$ print air dry b) $1000 \mu \mathrm{m}$ print air dry c) $500 \mu \mathrm{m}$ print vacuum dry d) $1000 \mu \mathrm{m}$ print vacuum dry e) $500 \mu \mathrm{m}$ DB vacuum dry f) $1000 \mu \mathrm{m}$ DB vacuum dry. Printing parameters: $500 \mu \mathrm{m}(1.2 \mathrm{psi} \& 10 \mathrm{~mm} / \mathrm{s}) 1000 \mu \mathrm{m}(1.5 \mathrm{psi} \& 8 \mathrm{~mm} / \mathrm{s})$

$\mathrm{TiO}_{2}$ concentration is further reduced to $12 \%$ particle concentration and optical images for the film specimens are illustrated in Figure 33. It is observed that a further reduction in 
primary particle concentration also results in films with no specific crack pattern as memory effects are eliminated due to high water content in the inks.

a.
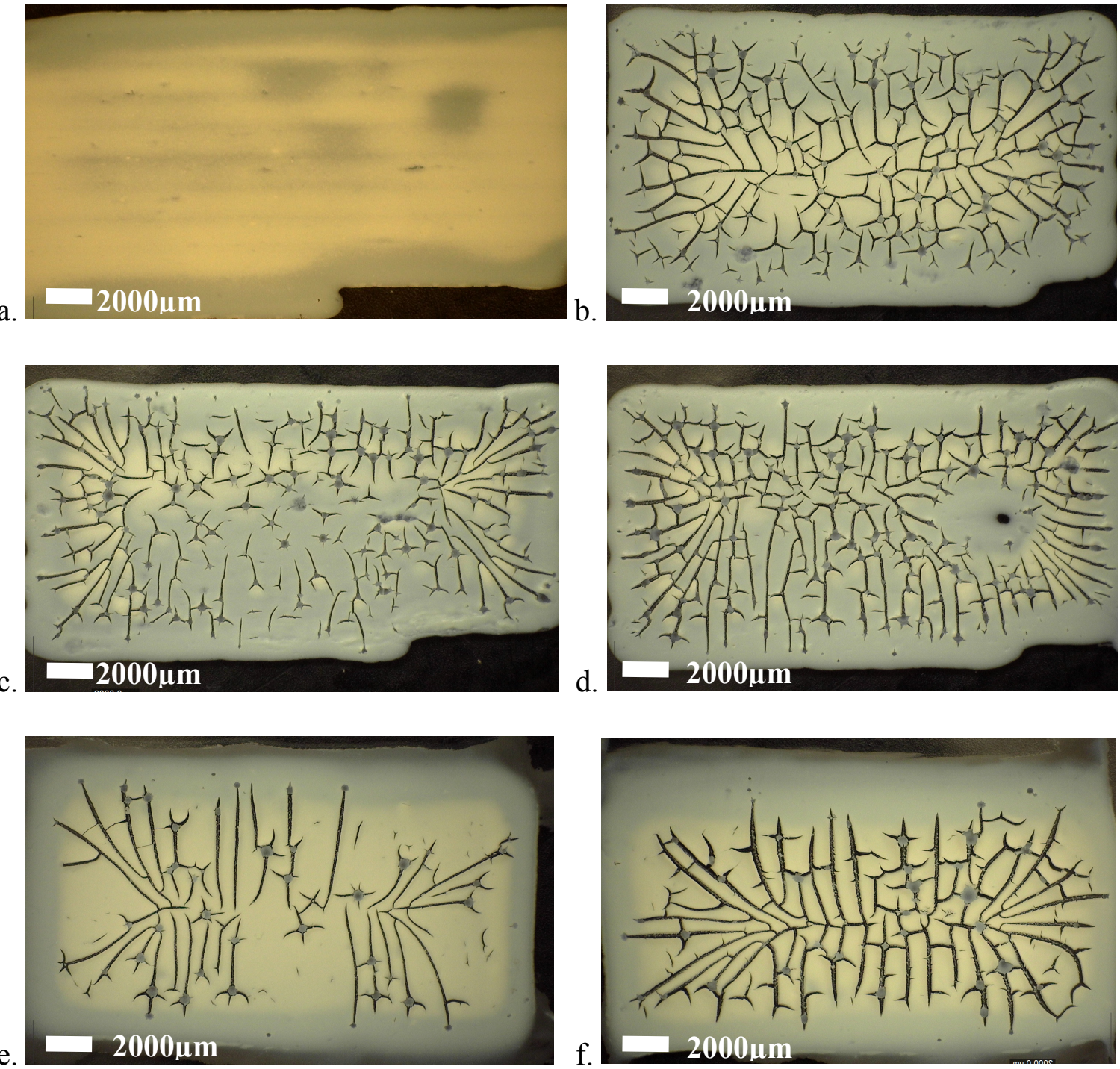

Figure 33:Optical Microscope Images of 12\% $\mathrm{TiO}_{2}$ particle concentration

a) $500 \mu \mathrm{m}$ air dry print b) $1000 \mu \mathrm{m}$ air dry print c) $500 \mu \mathrm{m}$ vacuum dry print d) $800 \mu \mathrm{m}$ vacuum dry print e) $500 \mu \mathrm{m} \mathrm{DB}$ oven dry f) $1000 \mu \mathrm{m}$ DB oven dry. Print parameters: $500 \mu \mathrm{m}$ (1.1psi \& $10 \mathrm{~mm} / \mathrm{s}) 800 \mu \mathrm{m}(1.2 \mathrm{psi} \& 8 \mathrm{~mm} / \mathrm{s}) 1000 \mu \mathrm{m}(1.4 \mathrm{psi} \& 8 \mathrm{~mm} / \mathrm{s})$

Based on the results from decreasing particle concentration, it is confirmed that there is a less likelihood for the film to form a crack pattern based on memory effect which suggest that memory effect is only remembered in water poor pastes with higher primary particle 
concentrations. Distinct fragments are not able to be formed as the cracking is more randomized. It is suggested that the ink contains too much water which induce waves and global forces thus eliminating the memory effect and us such no distinct trend can be noted from the pattern of the cracks. This suggests that indeed the crack pattern that we see formed for the $25 \%$ and $33 \%$ particle concentrations is as a result of the Nakahara effect. 


\section{Weibull Modulus}

In attempts to acquire further insights on fragment mechanisms, fragment length data is modeled using the Weibull distribution. This distribution gives the Weibull Modulus $(k)$ which is the parameter of the distribution used to describe variability in measured material strength of brittle materials. In this case, the Weibull modulus is used the differentiate primarily the fragment length distribution (FLD) in printed vs. doctor bladed specimens. As stated earlier, if there is high variation in FLD, the calculated Weibull modulus is relatively low and if there is low FLD, the calculated Weibull modulus is relatively high.

Figure 34 illustrates the Weibull plots for printed specimens of $25 \%$ particle concentration for the air, vacuum and oven drying processes at $500 \mu \mathrm{m}$ film thickness. It is observed that the vacuum dried results in the highest Weibull modulus of 5.01, followed by the oven dried of 4.74 and then the air dried of 3.18 .

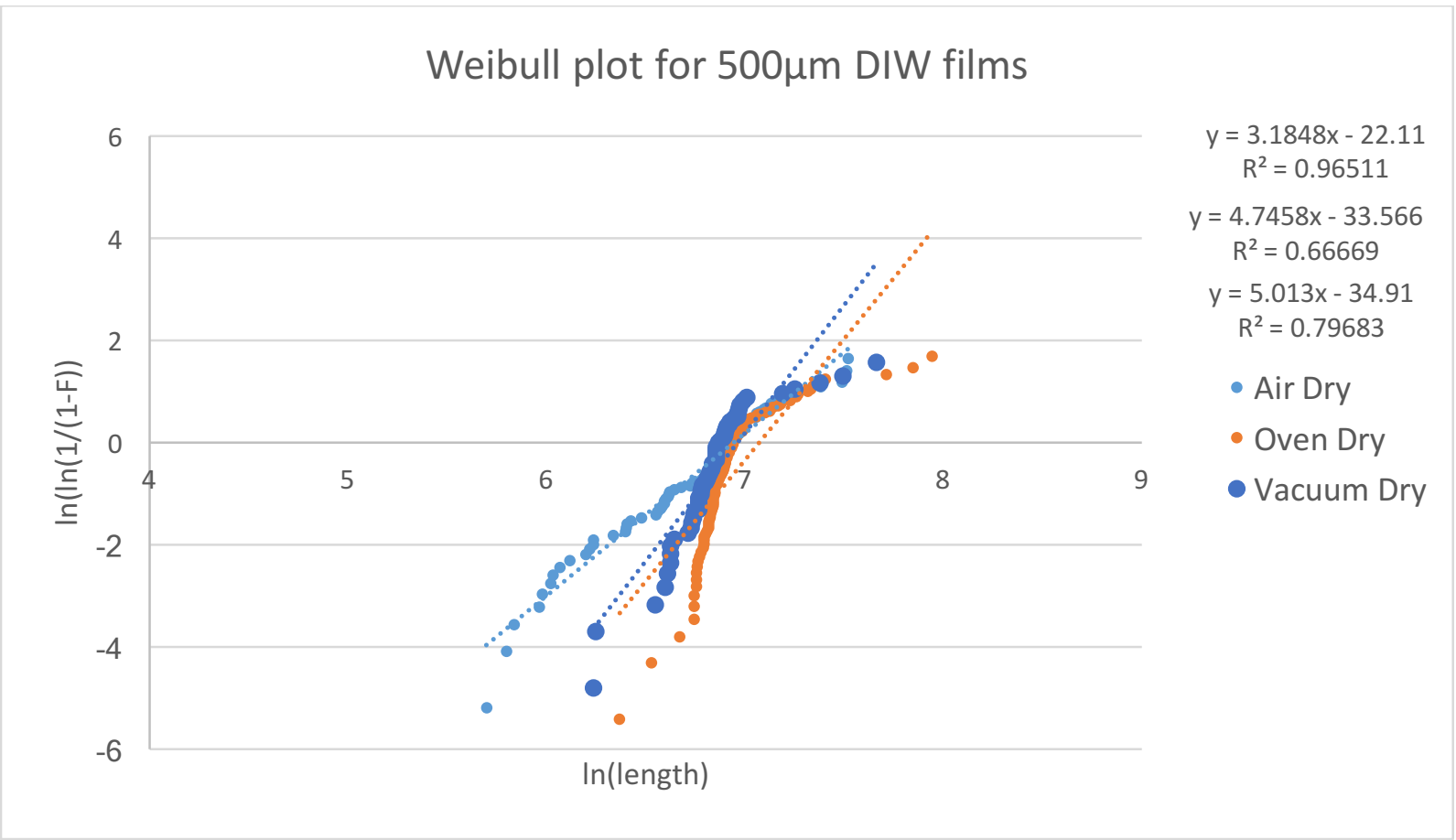

Figure 34 : Weibull Plot for $500 \mu \mathrm{m}$ DIW films with 25\% $\mathrm{TiO}_{2}$ concentration 
Figure 35 illustrates the Weibull plots for doctor bladed specimens of 25\% particle concentration for the air, vacuum and oven drying processes at $500 \mu \mathrm{m}$ film thickness. It is observed that the vacuum dried results in the highest Weibull modulus of 2.6 , followed by the oven dried of 2.3 and then the air dried of 2.2.

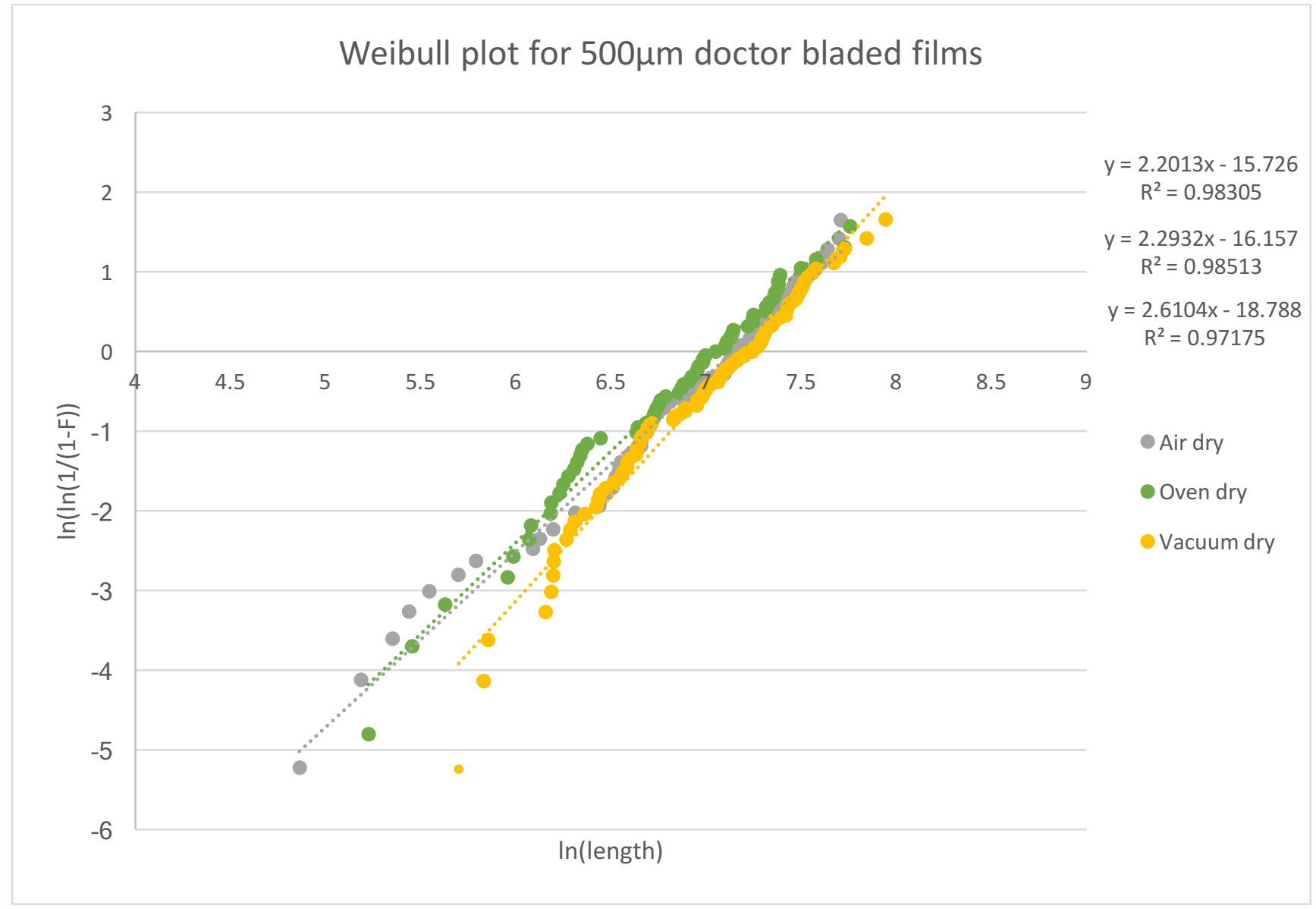

Figure 35 : Weibull Plot for $500 \mu \mathrm{m}$ doctor bladed films with 25\% $\mathrm{TiO}_{2}$ concentration

Figure 36 illustrates the Weibull plots for printed specimens of $25 \%$ particle concentration for the air and oven drying processes at $250 \mu \mathrm{m}$ film thickness. It is observed that the oven dried results in the higher Weibull modulus of 5.89 , followed by the air dried of 5.73. 


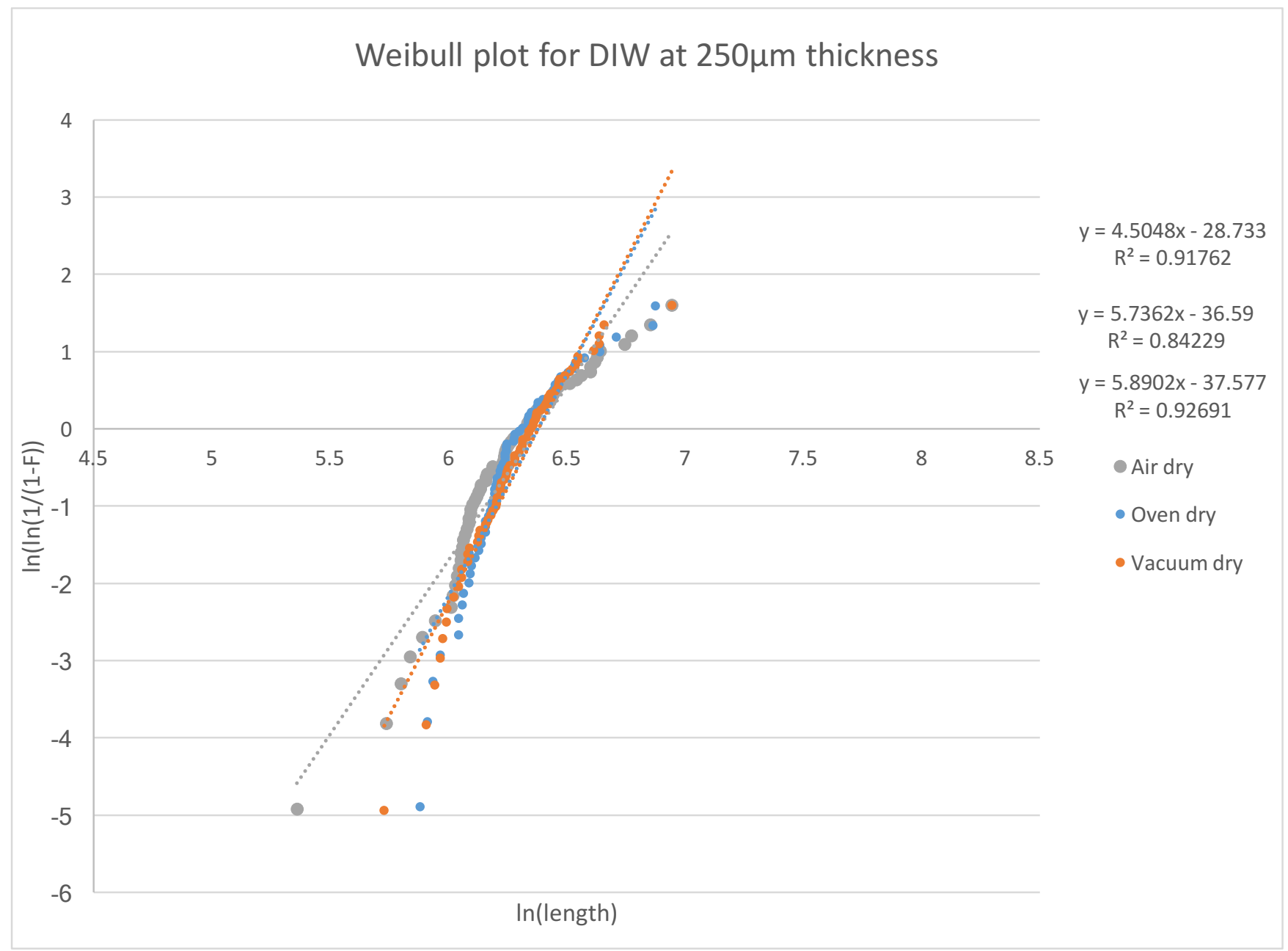

Figure 36: Weibull Plot for $250 \mu \mathrm{m}$ printed films with 25\% $\mathrm{TiO}_{2}$ concentration

Figure 37 illustrates the Weibull plots for doctor bladed specimens of $25 \%$ particle concentration for the air and oven drying processes at $250 \mu \mathrm{m}$ film thickness. It is observed that the oven dried results in the higher Weibull modulus of 2.64 , followed by the air dried of 2.12 .

These results indicate a generally lower modulus for the doctor bladed samples thus indicating there is more variability in the fragment length distribution for doctor bladed specimens. 


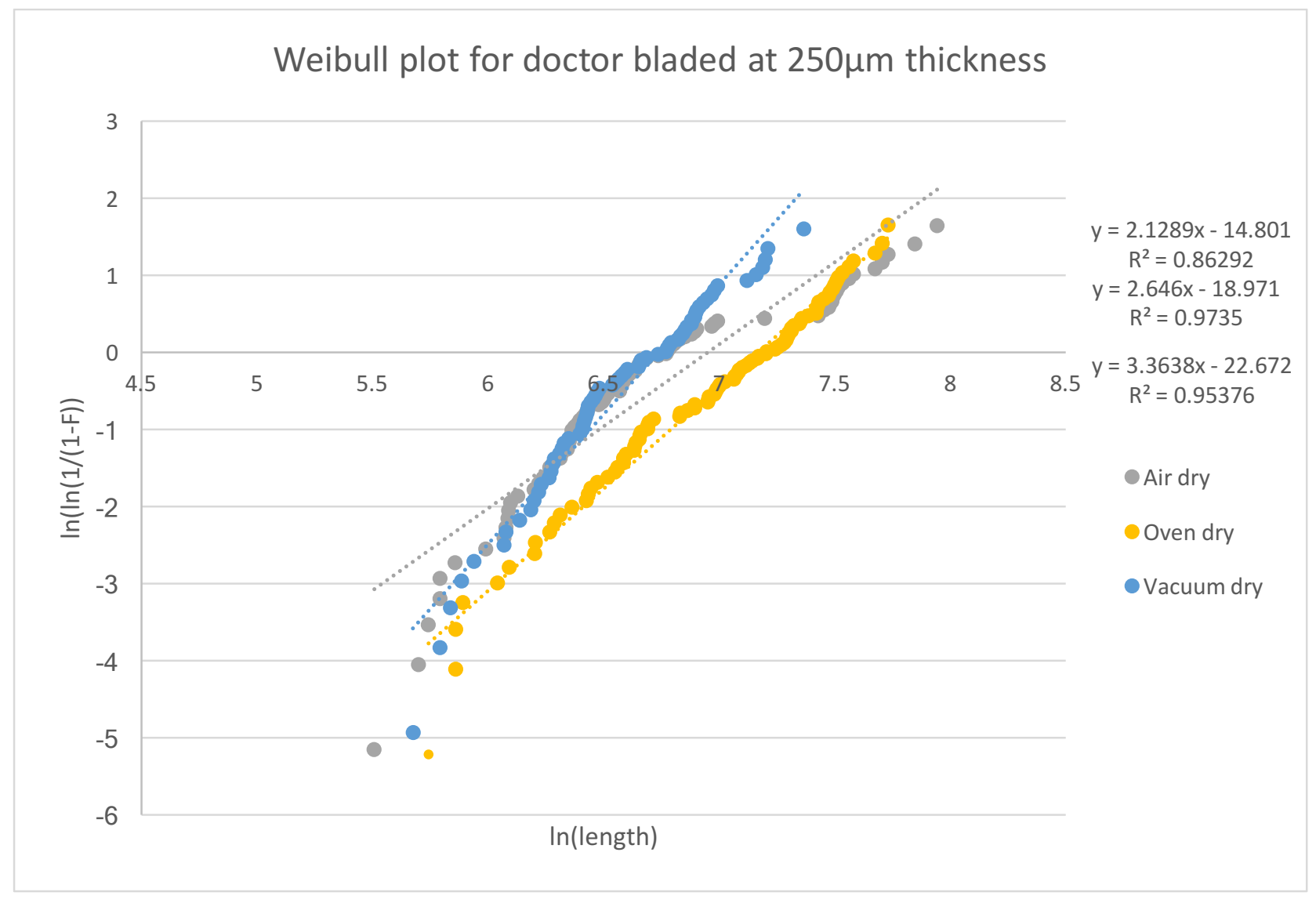

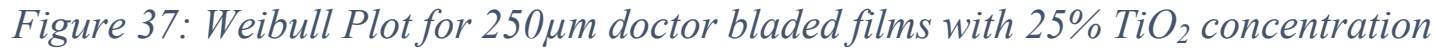

Figures 38 and 39 illustrate the Weibull plots for doctor bladed specimens of $25 \%$ particle concentration for the air and vacuum drying processes at $600 \mu \mathrm{m}$ film thickness. It is observed that the printed samples had a higher modulus compared to the doctor bladed samples.

Figures 40, 41, 42 and 43 also illustrate the same trend where the calculated Weibull Modulus is higher for printed samples than doctor bladed samples for $33 \%$ primary particle concentration. The vacuum drying process is also seen to have the highest Weibull Modulus, followed by the intermediate oven drying process and then finally the air drying process. 


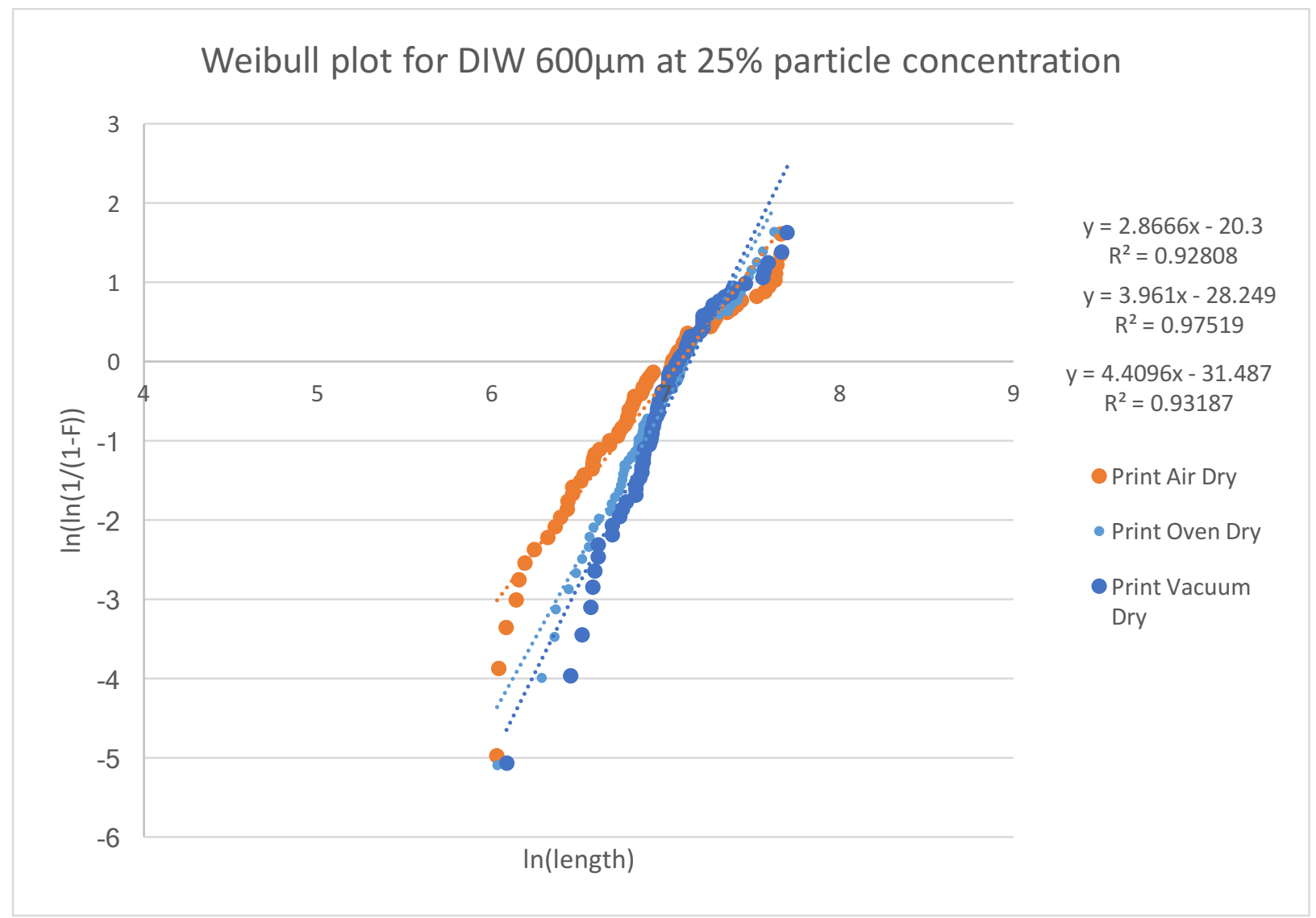

Figure 38 Weibull Plot for DIW $600 \mu$ m film thickness 25\% TiO 2 particle concentration

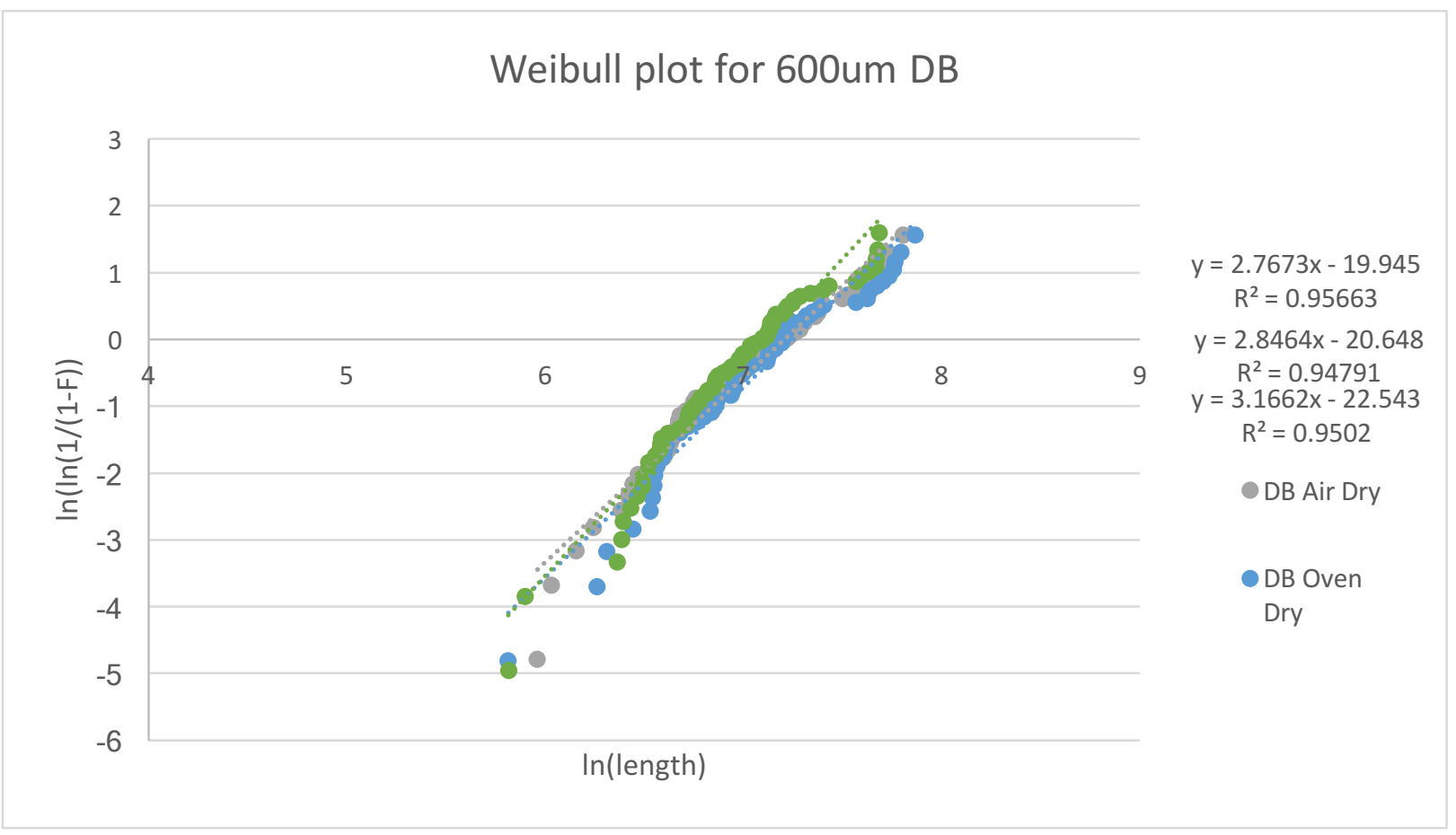

Figure 39:Weibull Plot for doctor bladed 600 4 m film thickness 25\% $\mathrm{TiO}_{2}$ particle concentration 


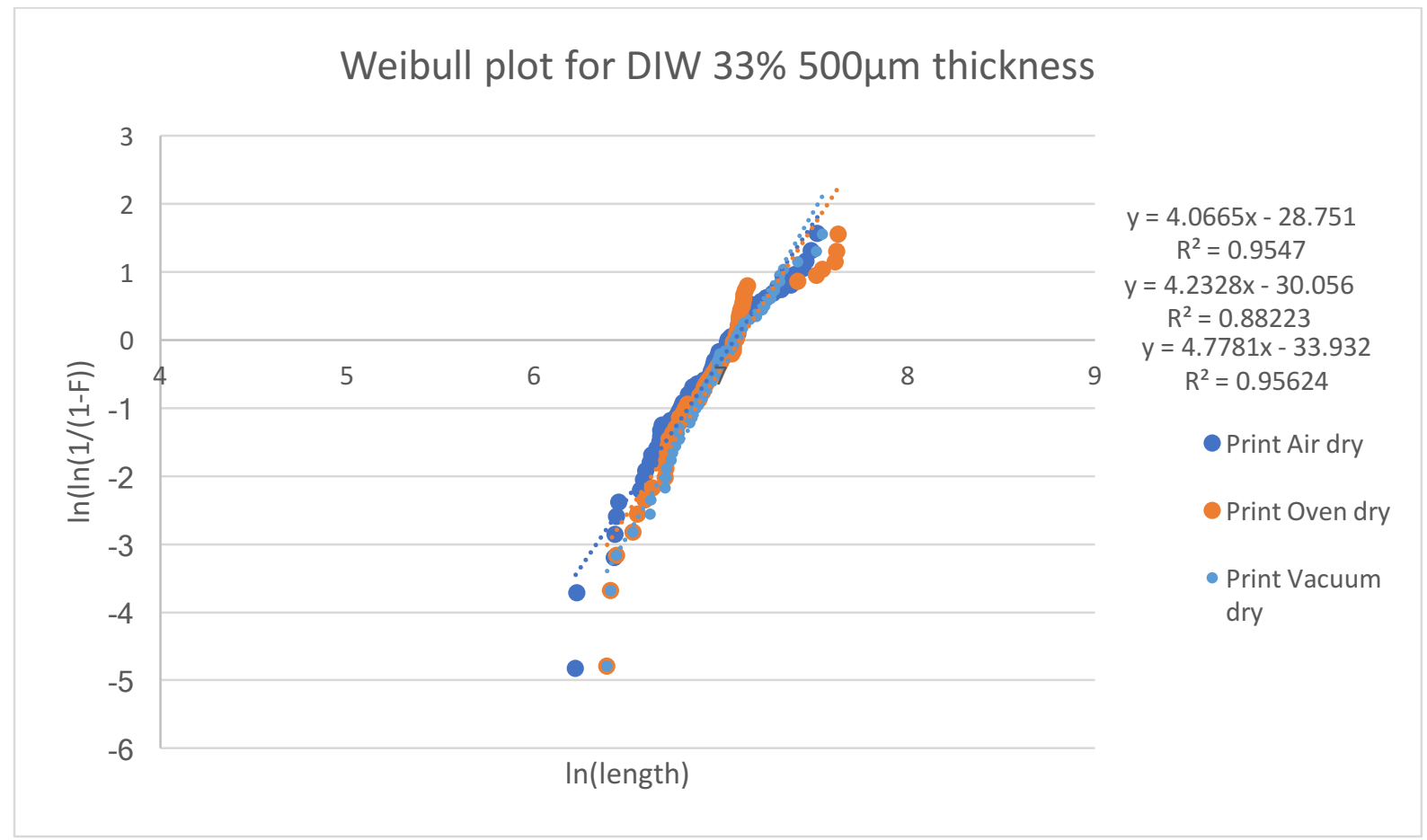

Figure 40:Weibull Plot for DIW 500 $\mu$ m thickness at 33\% $\mathrm{TiO}_{2}$ particle concentration

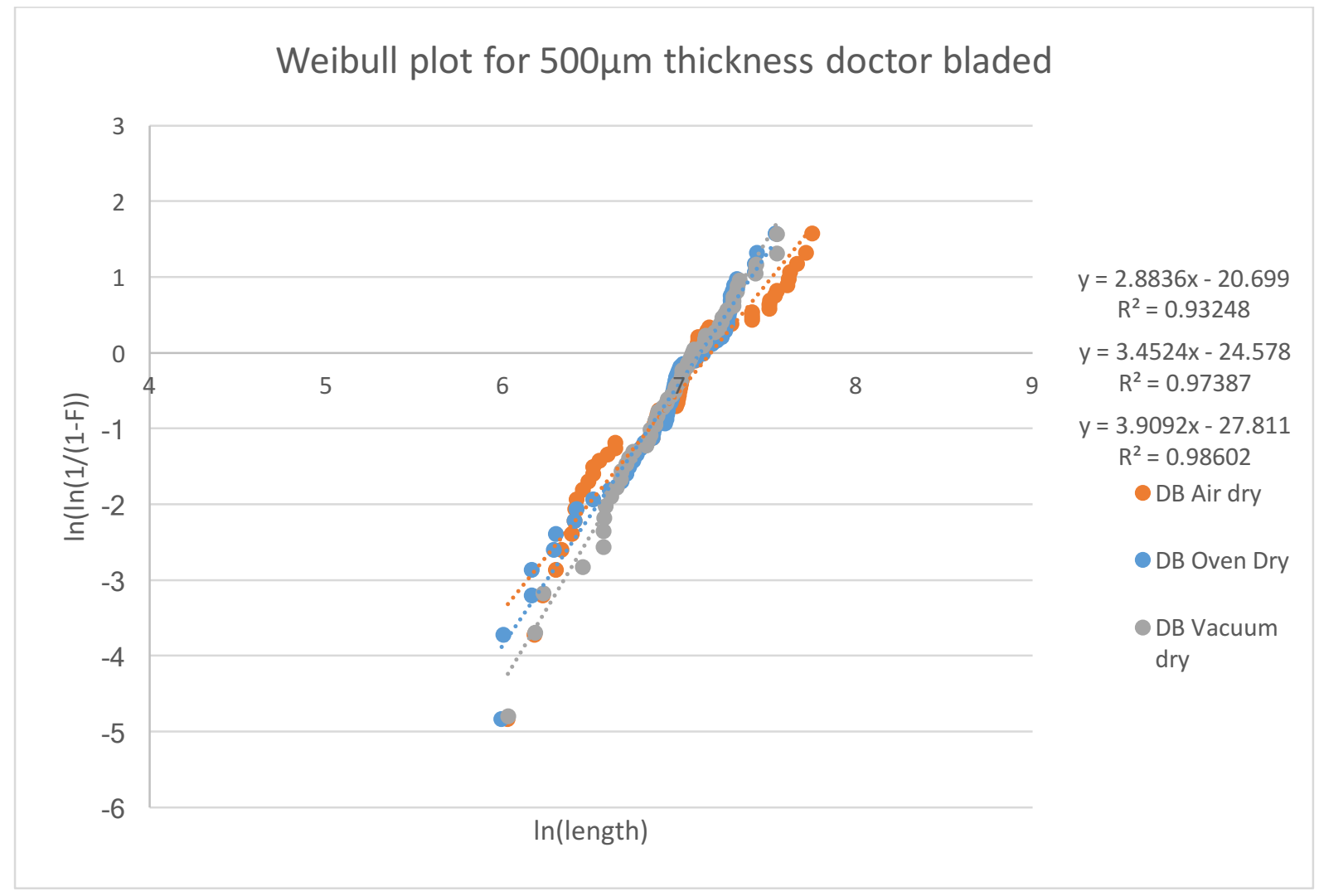

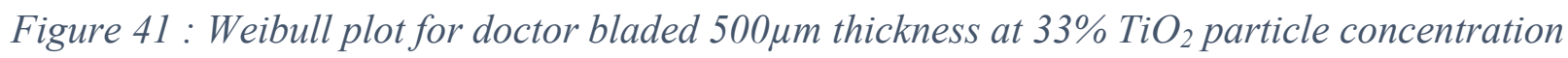




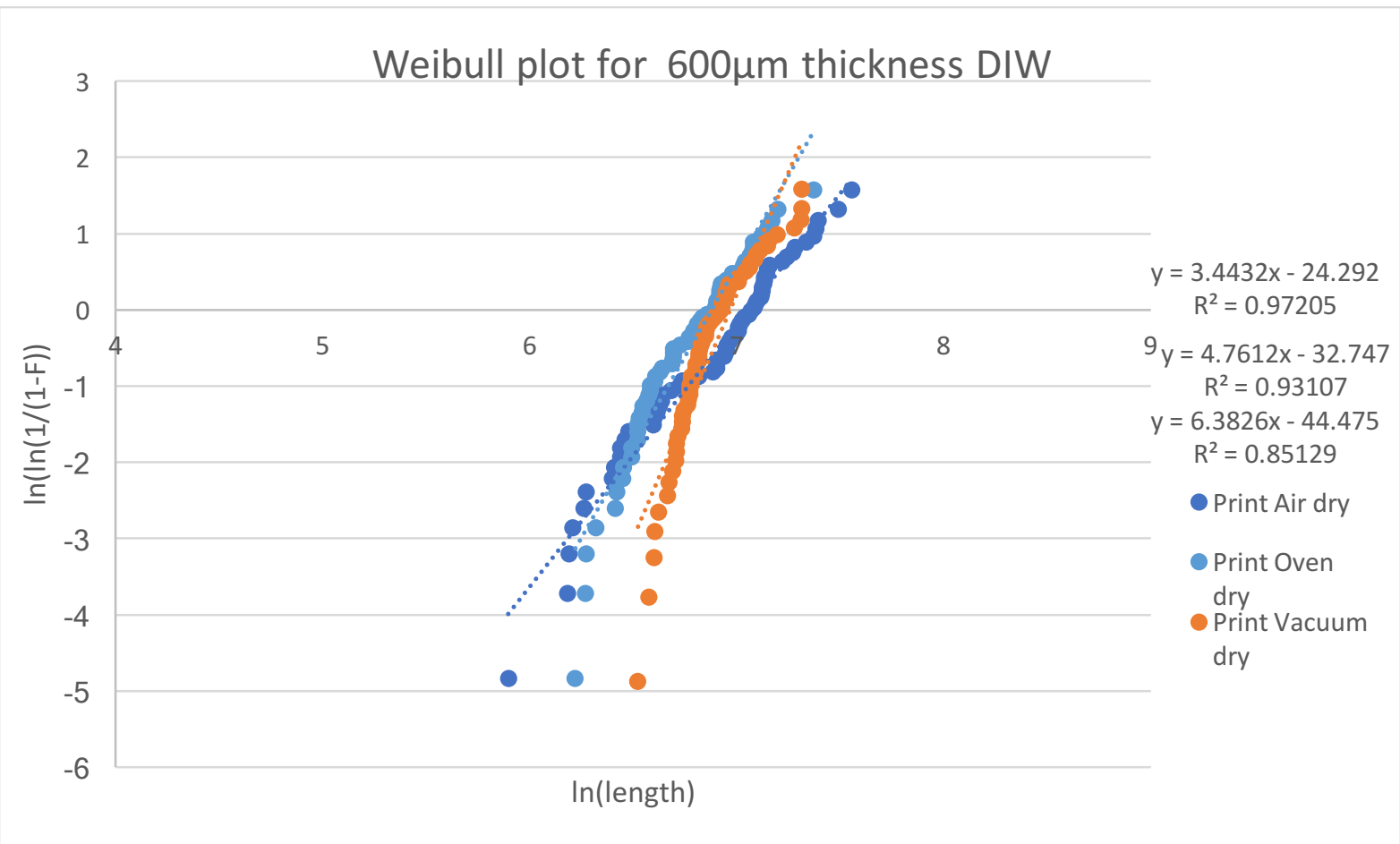

Figure 42: Weibull Plot for DIW 600 $\mu$ m film thickness at 33\% $\mathrm{TiO}_{2}$ particle concentration

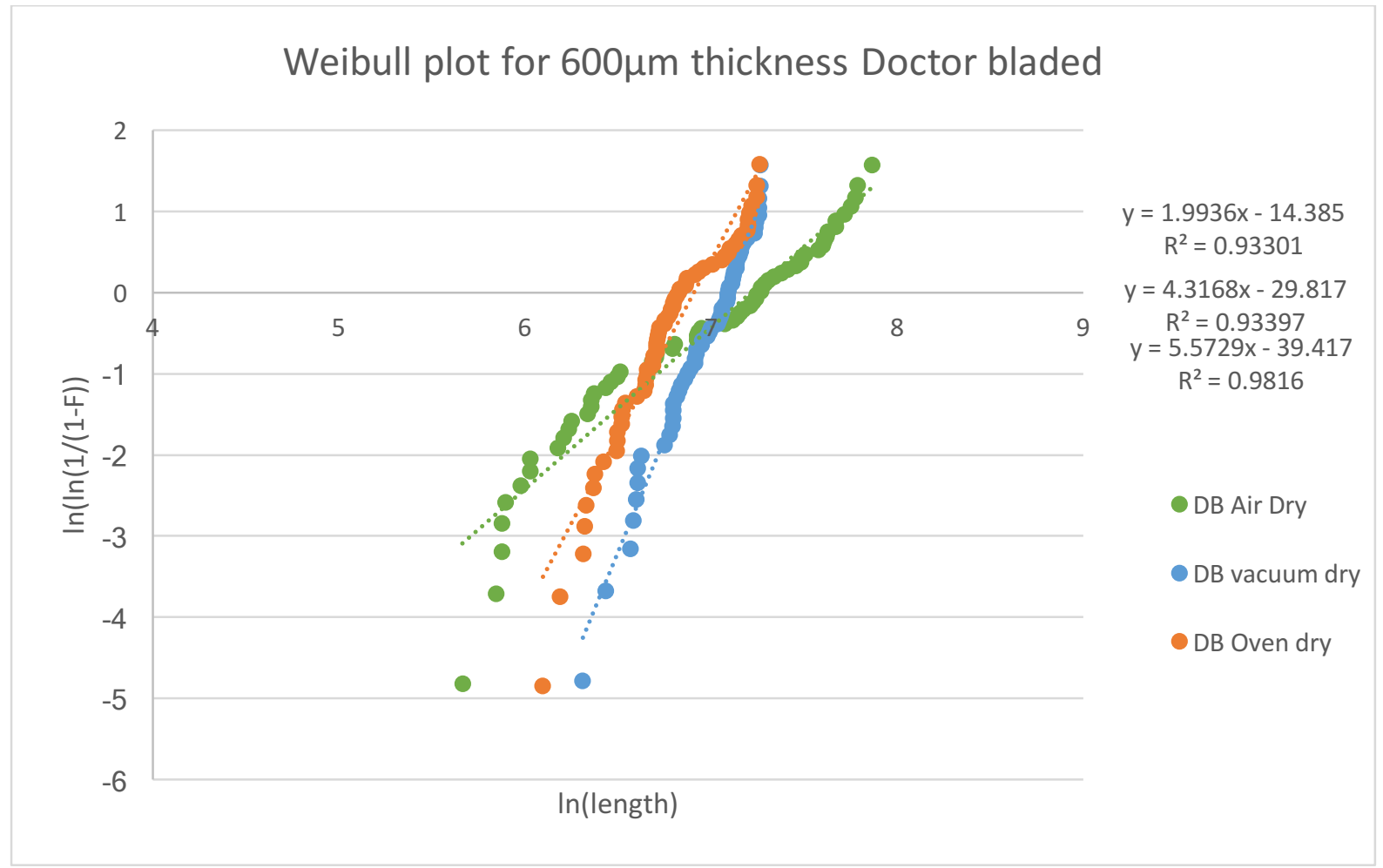

Figure 43 : Weibull Plot for doctor bladed $600 \mu \mathrm{m}$ thickness at 33\% $\mathrm{TiO}_{2}$ particle concentration 
Table 3 summarizes the calculated Weibull Moduli for deposited films with $25 \%$ and $33 \%$ ink concentrations. Weibull calculations were not made for the $18 \%$ and $12 \%$ particle concentrations as full crack fragments were not formed.

\section{Table 3: Summary of Weibull Modulus}

\begin{tabular}{|c|c|c|c|c|c|c|}
\hline \multicolumn{2}{|c|}{ Concentration } & \multicolumn{3}{c|}{$\mathbf{2 5 \%}$} & \multicolumn{2}{c|}{$\mathbf{3 3 \%}$} \\
\hline \multicolumn{2}{|c|}{ Thickness } & $\mathbf{2 5 0} \boldsymbol{\mu m}$ & $\mathbf{5 0 0} \boldsymbol{\mu m}$ & $\mathbf{6 0 0} \boldsymbol{\mu m}$ & $\mathbf{5 0 0} \boldsymbol{\mu m}$ & $\mathbf{6 0 0} \boldsymbol{\mu m}$ \\
\hline \multirow{2}{*}{ Air dry } & Printed & 4.50 & 3.18 & 2.86 & 4.06 & 3.44 \\
\cline { 2 - 7 } & Doctor bladed & 2.12 & 2.20 & 2.76 & 2.88 & 1.99 \\
\hline \multirow{2}{*}{ Oven dry } & Printed & 5.73 & 4.74 & 3.96 & 4.28 & 4.76 \\
\cline { 2 - 7 } & Doctor bladed & 2.64 & 2.29 & 2.84 & 3.45 & 4.36 \\
\hline \multirow{2}{*}{$\begin{array}{c}\text { Vacuum } \\
\text { dry }\end{array}$} & Printed & 5.89 & 5.01 & 4.41 & 4.76 & 3.44 \\
\cline { 2 - 7 } & Doctor bladed & 3.34 & 2.61 & 3.16 & 3.9 & 6.38 \\
\hline
\end{tabular}

Figure 44 compares the Weibull moduli for the three drying processes for direct ink writing process, it is observed that the vacuum drying corresponds to the highest modulus indicative of the least variability.

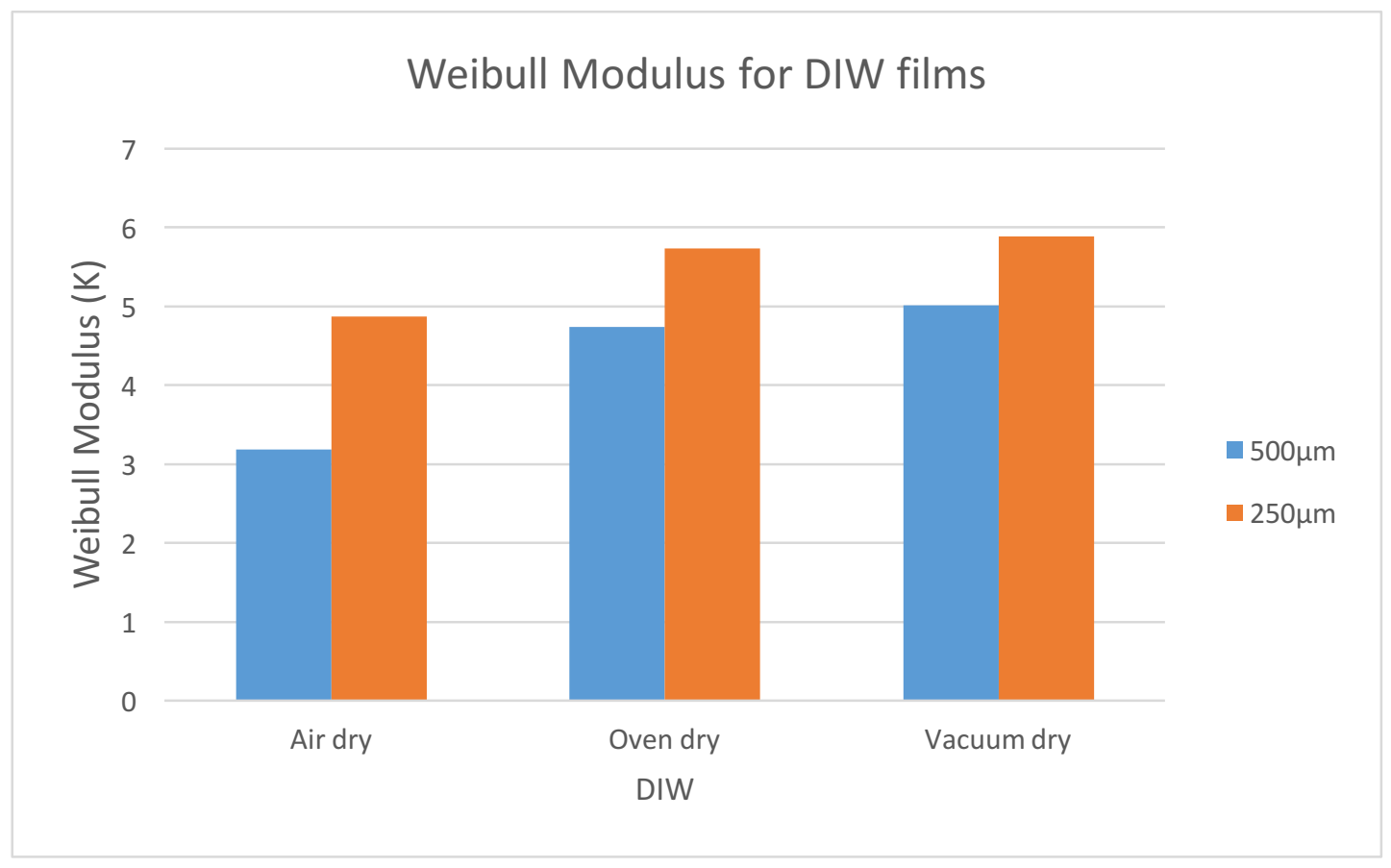

Figure 44 : Calculated Weibull Modulus for printed films 
Figure 45 compares the Weibull moduli for the three drying processes for direct ink writing process, it is observed that the vacuum drying corresponds to the highest modulus indicative of the least variability. This is due to the fact that vacuum drying was done in an enclosed container and therefore offered the most controlled drying process. Oven drying was found to have intermediate variability in fragment length distribution. Air drying was observed to have the lowest modulus thus representing the highest variability in fragment length distribution as this process was done in an uncontrolled environment.

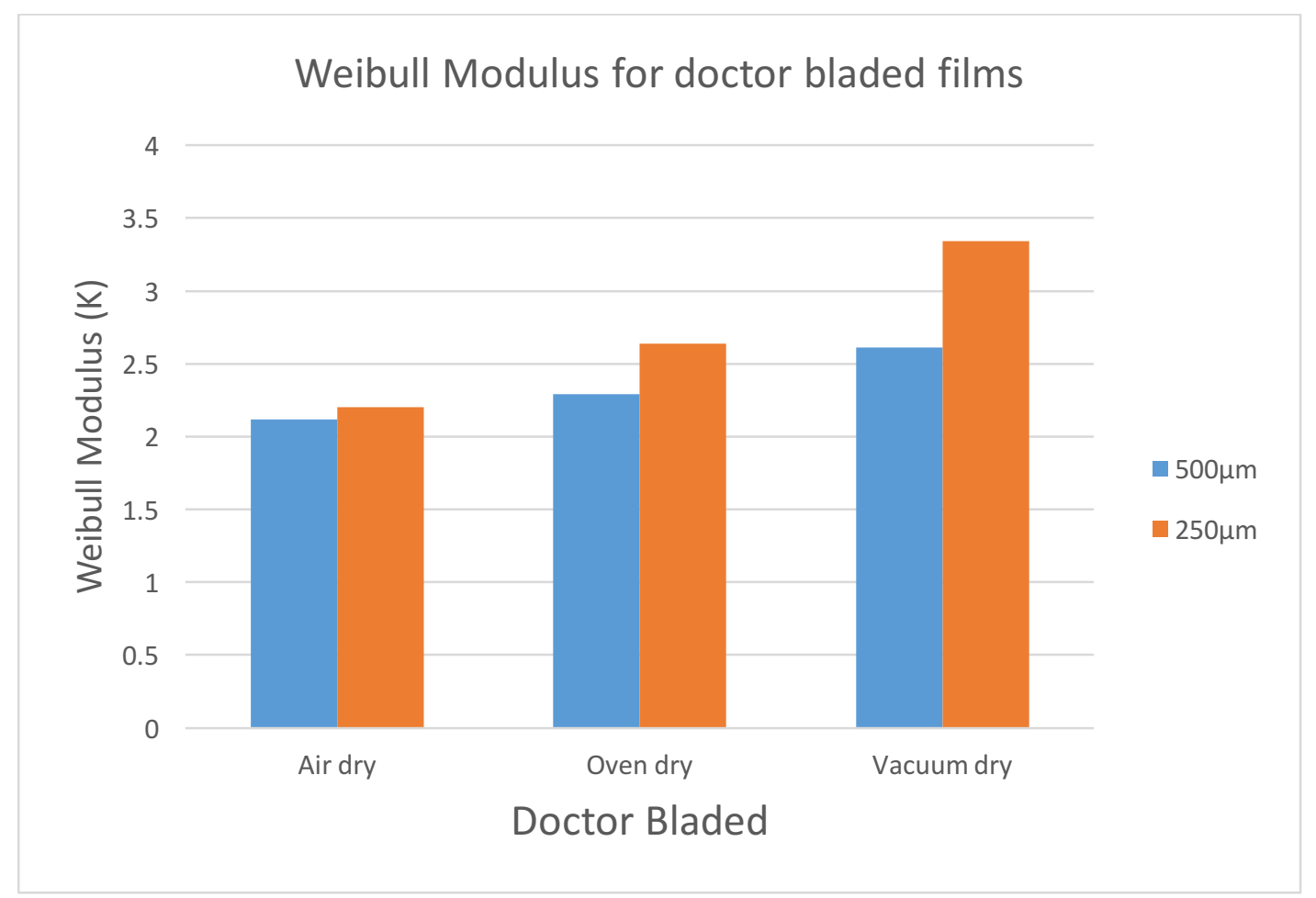

Figure 45: Calculated Weibull Modulus for doctor bladed films

Weibull plots shows a general trend that the doctor bladed samples generally have a higher variation in fragment length distribution. This is signified by the relatively lower Weibull modulus compared to the printed counterparts. If the value of the Weibull modulus $(k)$ is greater that 1 , it points to some kind of ageing process or the weakening of the material with 
the passage of time. In using this Weibull model, it is observed that all of the inks have a modulus greater than 1 , thus suggesting that the failure of the cracks occur with increasing time.

In summary, we have studied the effect of varying film thickness, effect of different drying process, the effect of concentration and effects of the two methods of deposition. It is observed that fragment size increases with increasing thickness. It is also observed that the different drying techniques do not eliminate memory effects and vacuum drying is found to be the most controlled drying process as it generally has the highest Weibull Modulus. It is observed that the two deposition methods leave two distinct crack pattern and it can be said that the Nakahara effect is seen only when the fluid is water poor or for relatively higher $\mathrm{TiO}_{2}$ concentrations. 


\section{Chapter 5: Conclusions}

For this project, the drying mechanical behavior of four different weight concentration of $\mathrm{TiO}_{2}$ ink systems were studied to demonstrate the influence of Nakahara effect in Direct-Ink Writing. This research depicted a comprehensive physical picture of drying of colloidal dispersions and drying-induced cracking and also reviewed various investigations on properties and mechanisms of cracking. Capitalizing on already established printing maps from similar systems, films were printed with varying speeds and pressures using the Nordson Robot. After deriving desired thicknesses for printed films through trial and error, equivalent film thicknesses were made by the doctor blading process. After exposing the specimens to different drying methods, the results from the two deposition methods were compared and a distinctive difference in crack pattern was observed. The printed films develop a uniaxial crack pattern whereas the doctor bladed films develop a biaxial crack pattern during drying. The printed samples display a uniform crack pattern perpendicular to the direction of the shear from the extrusion of the material caused by a longitudinal density fluctuation. The results suggest a distinction between the printed and doctor-bladed samples hence demonstrating the existence of the Nakahara Effect.

Three different drying processes were employed in drying the samples in order to observe the pattern of fragmentation. The three processes are air drying, vacuum drying and oven drying. The measured crack fragment length, modeled by the Weibull distribution suggest that there is a lasting memory in the films that is responsible for the pattern fragmentation during drying. Memory effects were still found to exist even with a change in drying method of drying as thermal fluctuation does not destroy network structure of the colloidal suspension. It 
is also observed that vacuum drying offers the most controlled drying method as it resulted in the least variability in fragment length distribution. Oven drying was observed as the intermediate while air drying was observed as the least controlled drying process.

It was also observed the transition in the crack pattern based on the concentration of $\mathrm{TiO}_{2}$ particles present in the ink. It is found that the films' ability to crack based on the initial external shear depends on the concentration of primary particles such that the memory effect decreases with decreasing $\mathrm{TiO}_{2}$ particle concentration. These experiments revealed a transition in the direction of lamellar cracks from perpendicular to random. The memory effect was found to be eliminated due to waves and global forces as the concentration of water is increased.

Lastly, it was observed that as film thickness is increased, the crack density decreases and fragment length increases. This is attributed to larger stress build up in thicker films which results in larger fragment sizes as cracking occurs to relieve this stress at the surface.

To summarize, we experimentally found that we can imprint the direction of an external shear into a paste, and the memory in the paste is visualized in the morphology of the crack patterns, which appear in the drying process. It is demonstrated that colloidal inks retain the directions of the external force that was applied during the extrusion process. These memories in the inks is visualized as the crack patterns develop when the films dry. Thus, by using the memory effect of paste, morphology of desiccation crack patterns can be controlled.

It is considered that findings of this research can be applied to industrial applications where engineers can control the direction in which cracks will form in the future, and therefore, make plans to avoid accidental serious damage. The knowledge on what influences the formation of cracks can also help in the design and control of other crack patterns for different 
applications. Moreover, as no one knows how cracks will form except the people who imprinted the order, this knowledge can be used to physically hide information from customers. Ideally, the overall goal would be to eliminate cracking but with current research the best that can be done is to minimize or control it as it is very difficult to avoid crack formation in aqueous inks. However, if the formation of crack patterns is controllable, it becomes possible to avoid serious damages. This method to control crack pattern in 3-D printing by using memory effect will become a strong tool in the field of additive manufacturing technology.

\section{Contributions}

Regarding this work, a contribution was made towards studying and understanding the mechanical behavior or crack development during drying of films. The main purpose was to demonstrate the Nakahara effect which in this case is mainly dependent on the shear force distributed applied by the Performus V pneumatic pressure system.

Other film deposition methods were performed and observed, specifically doctor blading to demonstrate how the crack development differs compared to directly written samples under different drying conditions, such as air drying, oven drying and vacuum oven drying. The solid fraction of the ink was alternated to study the transition in crack pattern as $\mathrm{TiO}_{2}$ particle percentage increases or decreases. Finally, thickness of films was varied to explore the effect of thickness on crack fragment length. 


\section{Chapter 6: Further Work}

The study of the drying mechanical behavior in printed ink systems, though has received attention in recent years, has been limited mainly due to the inherent difficulties in quantifying stresses and energies in brittle thin films and as such deserves further research efforts. The complex relationship between the development of tensile stress as shrinkage occurs simultaneously to the increase in strength of material as it compacts will definitely be a task that will be worth pursuing. In current investigations, the effect of heat transfer has received minimal research efforts so that will be something to look at in the future. Other studies that could be carried out also include observing the presence of the Nakahara effect in printing multiple layers as compared to single layers. The effect of pore size of fragmentation length is an area that could also be studied. To diminish or avoid cracking in films for future applications, there should be an advanced understanding of the mechanisms responsible for toughness in wet ceramic thin films.

Knowledge of the properties and mechanism of drying induced cracks is of high significance for both academic research and industrial research and development. This basic knowledge is the first step in controlling, reducing and eliminating cracks in thin films. In recent research there is only partial fundamental understanding of drying and cracking experiments and there are still many controversies for the most basic mechanisms of cracking.

After understanding the mechanisms of drying and cracking, the ultimate goal of this research is to produce crack-free thin films. After this has been understood, the task will be to bridge the research between academic and industrial research and development. Even though large investments have been made in developing various models for explaining characteristics 
of drying-induced cracks and understanding cracking mechanisms, most are not close to being practically applicable on a large scale, thus further understanding of drying and cracking processes will benefit the quality of thin films and their cost of production. 


\section{References}

(1) Tofail, S. A. M.; Koumoulos, E. P.; Bandyopadhyay, A.; Bose, S.; O’Donoghue, L.; Charitidis, C. Additive Manufacturing: Scientific and Technological Challenges, Market Uptake and Opportunities. Mater. Today 2018, 21 (1), 22-37.

(2) Rueschhoff, L.; Costakis, W.; Michie, M.; Youngblood, J.; Trice, R. Additive Manufacturing of Dense Ceramic Parts via Direct Ink Writing of Aqueous Alumina Suspensions. Int. J. Appl. Ceram. Technol. 2016, 13 (5), 821-830.

(3) Torres Arango, M. A.; Kwakye-Ackah, D.; Agarwal, S.; Gupta, R. K.; Sierros, K. A. Environmentally Friendly Engineering and Three-Dimensional Printing of TiO2 Hierarchical Mesoporous Cellular Architectures. ACS Sustain. Chem. Eng. 2017, 5 (11).

(4) Lakshmanan, V. I.; Bhowmick, A.; Halim, M. A. Titanium Dioxide: Production, Properties, and Applications. Chem. Phys. Res. J. 2014, 7 (1), 1935-2492.

(5) Torres Arango, M. A.; Valenç A De Andrade, A. S.; Cipollone, D. T.; Grant, L. O.; Korakakis, D.; Sierros, K. A. Robotic Deposition of TiO2 Films on Flexible Substrates from Hybrid Inks: Investigation of Synthesis Processing Microstructure Photocatalytic Relationships. 2016, 8, 24659-24670.

(6) Nakahara, A.; Matsuo, Y. Imprinting Memory into Paste and Its Visualization as Crack Patterns in Drying Process. 2005, 74 (5), 1362-1365.

(7) Fujishima, A.; Rao, T. N.; Tryk, D. A. Titanium Dioxide Photocatalysis. J. Photochem. Photobiol. C Photochem. Rev. 2000, 1 (1), 1-21.

(8) Hanaor, D. A. H.; Sorrell, C. C. Review of the Anatase to Rutile Phase Transformation. J. Mater. Sci. 2011, 46 (4), 855-874.

(9) Saravanan, R.; Gracia, F.; Stephen, A. Basic Principles, Mechanism, and Challenges of Photocatalysis; 2017; pp 19-40.

(10) Schneider, J.; Matsuoka, M.; Takeuchi, M.; Zhang, J.; Horiuchi, Y.; Anpo, M.; Bahnemann, D. W. Understanding TiO2 Photocatalysis: Mechanisms and Materials. Chem. Rev. 2014, 114 (19), 9919-9986.

(11) Diebold, U. The Surface Science of Titanium Dioxide. Surf. Sci. Rep. 2003, 48 (5-8), 53229.

(12) Islam, S.; Rahman, R. A.; Ottoman, Z. Formation of Rutile Titania Phase at Low Temperature. Mater. Today Proc. 2015, 2 (10), 5298-5301.

(13) Panda, S.; Satpathy, M. International Journal of Chemical and Pharmaceutical Review and Research A Review on Grafting and Applications of Xanthan Gum and Its Derivatives. Int. 
J. Chem. Pharm. Rev. Res 2015, 2 (2), 1-7.

(14) Santos, V. E.; Casas, J. A.; Go, E. Xanthan Gum : Production, Recovery, and Properties. Biotechnol. Adv. 2000, 18 (18), 549-579.

(15) Lopez, B. D. M.; Lessa, V. L.; Lacerda, L. G. Xanthan Gum: Properties, Production Conditions, Quality and Economic Perspective. J. Food Nutr. Res. 2015, 54 (3), 185-194.

(16) Song, K.-W.; Kim, Y.-S. Rheology of Concentrated Xanthan Gum Solutions:Steady Shear Flow Behavior. Fibers Polym. 2006, 7 (2), 129-138.

(17) Kumar, A.; Rao, K. M.; Han, S. S. Application of Xanthan Gum as Polysaccharide in Tissue Engineering: A Review. Carbohydr. Polym. 2018, 180 (October 2017), 128-144.

(18) Pi, G.; Li, Y.; Bao, M.; Mao, L.; Gong, H.; Wang, Z. Novel and Environmentally Friendly Oil Spill Dispersant Based on the Synergy of Biopolymer Xanthan Gum and Silica Nanoparticles. ACS Sustain. Chem. Eng. 2016, 4 (6), 3095-3102.

(19) Björn, A.; Segura De, P.; Monja, L.; Karlsson, A.; Ejlertsson, J.; Svensson, B. H. Rheological Characterization. Biogas 2012, 304-319.

(20) Goodwin, J. W. (James W.; Hughes, R. W. Rheology for Chemists : An Introduction. In Rheology for chemists; Royal Society of Chemistry, 2008; p 264.

(21) Lee, W. P.; Routh, A. F. Letters Why Do Drying Films Crack? Am. Chem. Soc. 2004, 20 (23), 9885-9888.

(22) Franks, G. V.; Tallon, C.; Studart, A. R.; Sesso, M. L.; Leo, S. Colloidal Processing: Enabling Complex Shaped Ceramics with Unique Multiscale Structures. J. Am. Ceram. Soc. 2017, $100(2), 458-490$.

(23) Tirumkudulu, M. S.; Russel, W. B. Cracking in Drying Latex Films. Langmuir 2005, 21, 4938-4948.

(24) Shenoy, V. B.; Schwartzman, A. F.; Freund, L. B. Crack Patterns in Brittle Thin Films. Int. J. Fract. 2001, 109, 29-45.

(25) Zhang, Y.; Qian, Y.; Liu, Z.; Li, Z.; Zang, D. Surface Wrinkling and Cracking Dynamics in the Drying of Colloidal Droplets. Eur. Phys. J. E 2014, 37 (84), 14084-14091.

(26) Xu, P.; Mujumdar, A. S.; Yu, B. Drying-Induced Cracks in Thin Film Fabricated from Colloidal Dispersions. Dry. Technol. 2009, 27 (5), 636-652.

(27) Young Kim, J.; Cho, K.; Ryu, S.; Youn Kim, S.; Mook Weon, B. Crack Formation and Prevention in Colloidal Drops. Sci. Rep. 2015, 5 (1), 13166. 
(28) Avcı, A.; Can, M.; Etemoğlu, A. B. A Theoretical Approach to the Drying Process of Thin Film Layers. Appl. Therm. Eng. 2001, 21 (4), 465-479.

(29) Nakahara, S. Microporosity in Thin Films. Thin Solid Films 1979, 64 (1), 149-161.

(30) Nakahara, A.; Nakayama, H.; Matsuo, Y. Control of Desiccation Crack Pattern Using Memory Effect of Clay Paste. Phys. Soc. Japan 2011, 319 (2), 104801.

(31) Nakahara, A.; Shinohara, Y.; Matsuo, Y. Control of Crack Pattern Using Memory Effect of Paste. J. Phys. Conf. Ser. 2011, 319 (1), 012014.

(32) Nakahara, A.; Matsuo, Y. Transition in the Pattern of Cracks Resulting from Memory Effects in Paste. Phys. Rev. 2006, 57, 045102.

(33) Feilden, E.; Ferraro, C.; Zhang, Q.; García-Tuñón, E.; D’Elia, E.; Giuliani, F.; Vandeperre, L.; Saiz, E. 3D Printing Bioinspired Ceramic Composites. Sci. Rep. 2017, 7 (1), 14236-14239.

(34) Feilden, E.; Blanca, E. G.-T.; Giuliani, F.; Saiz, E.; Vandeperre, L. Robocasting of Structural Ceramic Parts with Hydrogel Inks. J. Eur. Ceram. Soc. 2016, 36 (10), 2525-2533.

(35) Martínez-Vázquez, F. J.; Pajares, A.; Miranda, P. A Simple Graphite-Based Support Material for Robocasting of Ceramic Parts. J. Eur. Ceram. Soc. 2018, 38 (4), 2247-2250.

(36) M’Barki, A.; Bocquet, L.; Stevenson, A. Linking Rheology and Printability for Dense and Strong Ceramics by Direct Ink Writing. Sci. Rep. 2017, 7 (1), 6017.

(37) Lewis, J. A.; Smay, J. E.; Stuecker, J.; Cesarano lii, J. Direct Ink Writing of ThreeDimensional Ceramic Structures. Am. Soceity 2006, 89 (12), 3599-3609.

(38) Lewis, J. A.; Smay, J. E.; Stuecker, J. Direct Ink Writing of 3D Functional Materials. Adv. Funct. Mater. 2006, 16, 2193-2204.

(39) Mullineux, G. Non-Linear Least Squares Fitting of Coefficients in the Herschel-Bulkley Model. Appl. Math. Model. 2008, 32 (12), 2538-2551.

(40) Ngo, T. D.; Kashani, A.; Imbalzano, G.; Nguyen, K. T. Q.; Hui, D. Additive Manufacturing (3D Printing): A Review of Materials, Methods, Applications and Challenges. Compos. Part B Eng. 2018, 143, 172-196.

(41) Blade, D.; Berni, A.; Mennig, M.; Schmidt, H. 2.2.8 Doctor Blade. 1952, 8-11.

(42) Jabbari, M.; Bulatova, R.; Tok, A. I. Y.; Bahl, C. R. H.; Mitsoulis, E.; Hattel, J. H. Ceramic Tape Casting: A Review of Current Methods and Trends with Emphasis on Rheological Behaviour and Flow Analysis. Mater. Sci. Eng. B 2016, 212, 39-61.

(43) Deng, Y.; Peng, E.; Shao, Y.; Xiao, Z.; Dong, Q.; Huang, J. Scalable Fabrication of Efficient 
Organolead Trihalide Perovskite Solar Cells with Doctor-Bladed Active Layers. Energy Environ. Sci. Energy Environ. Sci 2015, 8 (8), 1544-1550.

(44) Quinn, J. B.; Quinn, G. D. A Practical and Systematic Review of Weibull Statistics for Reporting Strengths of Dental Materials. Dent. Mater. 2010, 26 (2), 135-147.

(45) Cho, C.; Holmes, J. W.; Barber, J. R. Distribution of Matrix Cracks in a Uniaxial Ceramic Composite. J. Am. Ceram. Soc. 1992, 1 (52), 316-324.

(46) Afferrante, L.; Ciavarella, M.; Valenza, E. Is Weibull's Modulus Really a Material Constant? Example Case with Interacting Collinear Cracks. Int. J. Solids Struct. 2006, 43 (17), 5147-5157.

(47) Cordill, M. J.; Taylor, A. A. Thickness Effect on the Fracture and Delamination of Titanium Films. Thin Solid Films 2015, 589, 209-214.

(48) Kitsunezaki, S.; Nakahara, A.; Matsuo, Y. Shaking-Induced Stress Anisotropy in the Memory Effect of Paste. EPL (Europhysics Lett. 2016, 114 (6), 64002.

(49) Matsuo, Y.; Nakahara, A. Effect of Interaction on the Formation of Memories in Paste. J. Phys. Soc. Japan 2011, 81 (024801), 1-7. 